\author{
Maestría en Economía \\ Facultad de Ciencias Económicas \\ Universidad Nacional de La Plata
}

TESIS DE MAESTRIA

\begin{abstract}
ALUMNO
Christian Volpe

TITULO

Integracion Económica y Localizacion de la Actividad Productiva: El caso del Mercosur

DIRECTOR

Leonardo Gasparini

FECHA DE DEFENSA
\end{abstract}

$12 / 16 / 1999$ 


\section{Integración económica y localización de la actividad productiva: El caso del Mercosur}

Christian Volpe Martincus

Tesis de Maestría

Maestría en Economía

Universidad Nacional de La Plata

Director de tesis: Dr. Leonardo Gasparini

La Plata, 30 de diciembre de 1999 


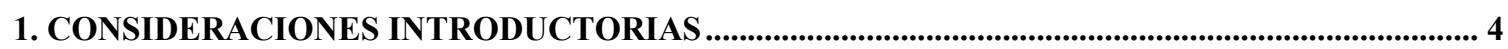

2. LA NUEVA GEOGRAFÍA ECONÓMICA Y EL REGIONALISMO............................................... 6

2.A. LAS CUESTIONES LOCALIZACIONALES EN LA TEORÍA ECONÓMICA ............................................................. 6

2.a.1. Teoría neoclásica: Las ventajas comparativas.................................................................... 7

2.a.2. Nueva teoría del comercio: El acceso al mercado ……........................................................... 8

2.a.3. Nueva geografia económica: La endogeinización del patrón de centro-periferia ...........................10

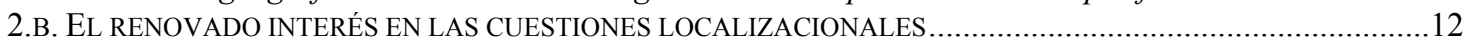

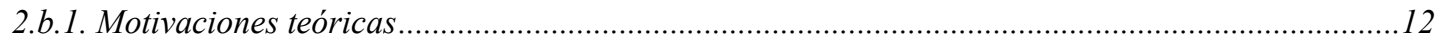

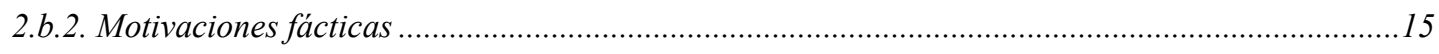

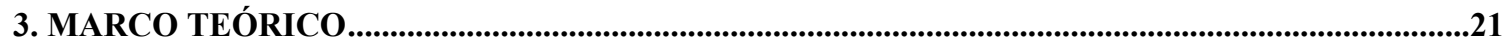

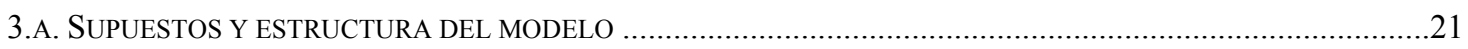

3.B. INTEGRACIÓN Y LOCALIZACIÓN: EL PUNTO DE VISTA DE LA PRODUCCIÓN …………………………….......2

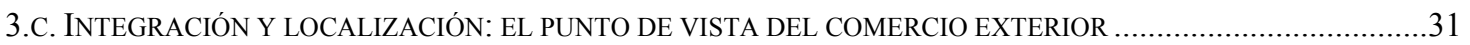

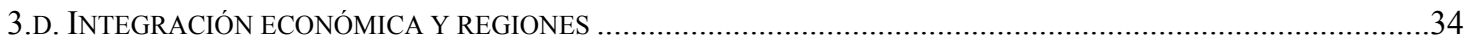

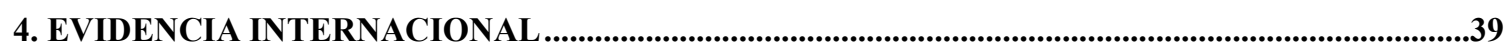

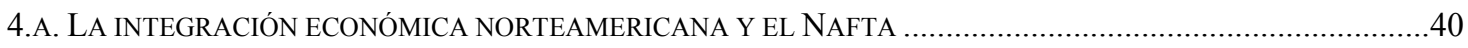

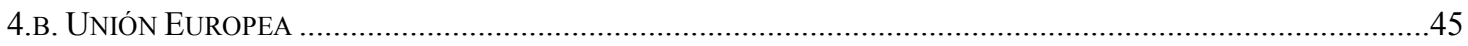

4.b.1. Localización industrial y economías de escala ………………………........................................ 45

4.b.2. Comercio intraindustrial y economías de escala .......................................................................51

4.b.3. Comercio intraindustrial e integración económica ………….....................................................53

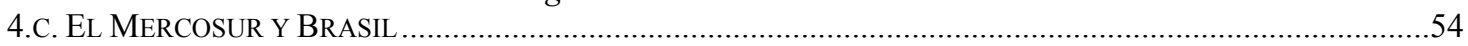

5. EL MERCOSUR Y LA DIMENSIÓN ESPACIAL DE LA INDUSTRIA EN ARGENTINA................68

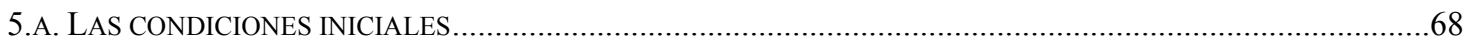

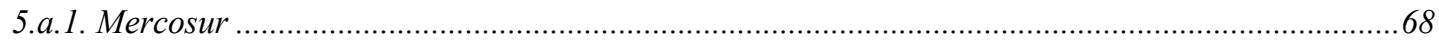

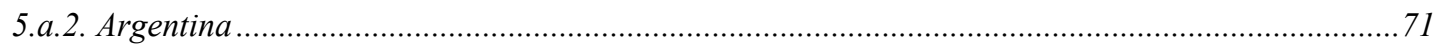

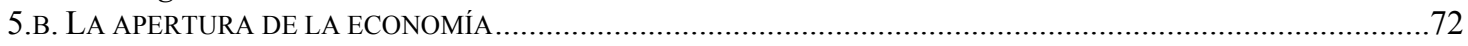

5.b.1. La apertura unilateral de la economía ...................................................................................... 72

5.b.2. El proceso de integración regional: La constitución del Mercosur .............................................. 73

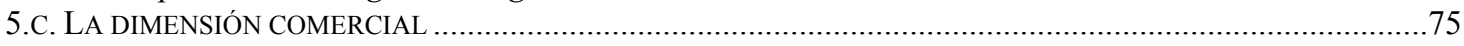

5.D. LA DIMENSIÓN ESPACIAL DE LA INDUSTRIA EN ARGENTINA..................................................................8

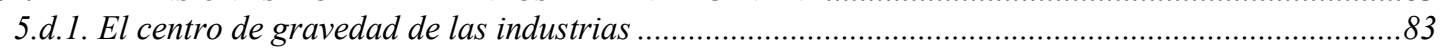

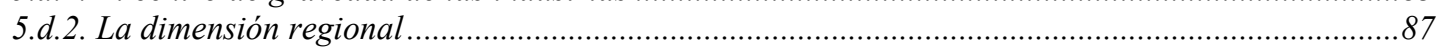

5.d.3. El sesgo localizacional hacia el centro ...................................................................................90

5.d.4. Las perspectivas: las señales derivadas de los flujos de inversión .............................................92

6. EL IMPACTO DEL MERCOSUR SOBRE EL PATRÓN DE LOCALIZACIÓN DE LA INDUSTRIA: LA EVIDENCIA ECONOMÉTRICA ……...........................................................................94

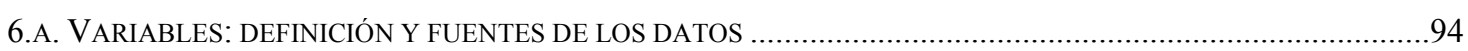

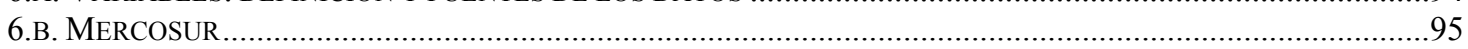

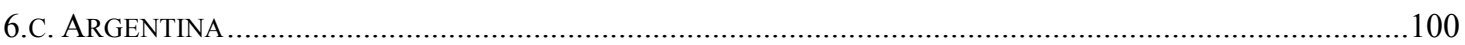

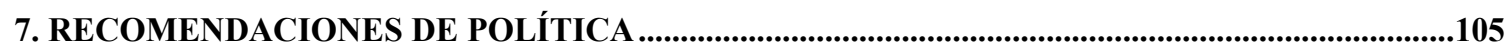

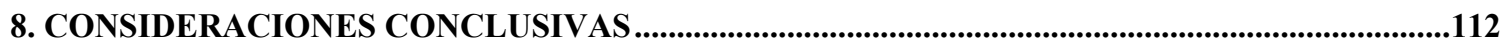

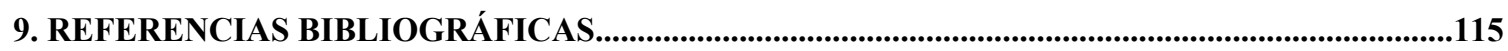

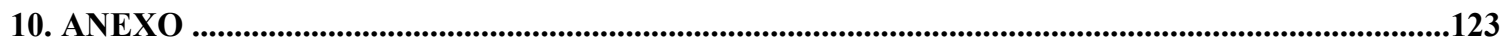




\section{Síntesis}

La década de 1990 fue el marco temporal de un vigoroso desarrollo del regionalismo así como de la emergencia de la nueva geografía económica, que se concentró en el estudio de sus consecuencias en términos de la distribución geográfica de la actividad productiva.

La teoría revela que la formación de una unión aduanera entre países de diferentes tamaños induce inicialmente un descenso del grado de concentración espacial de las industrias sujetas a rendimientos crecientes en la economía central de la misma y que dicha tendencia se revierte ulteriormente cuando la profundidad de la integración supera cierto nivel crítico. Bajo el supuesto de que las firmas pertenecientes a industrias dadas tienen propensiones a comerciar semejantes entre paises, el comercio intraindustrial intrarregional puede concebirse como una imagen de espejo de la pauta localizacional de la producción; por ende, su importancia relativa observaría una trayectoria opuesta, esto es, primero crecería y luego decrecería. Por otra parte, la reducción de los costos ligados al comercio intraunión también puede ocasionar modificaciones en la configuración espacial de la actividad industrial en el seno de los países involucrados en la integración, especificamente, puede favorecer la aglomeración industrial en las regiones con mayores mercados de los mismos.

La evidencia emanada de los principales casos de referencia internacional, la Unión Europea, el Nafta e incluso el propio Mercosur desde la perspectiva brasileña, certifica plenamente los resultados derivados de los modelos teóricos.

Argentina no constituye una excepción en este sentido. En efecto, la institución del Mercosur parece haber impelido un aumento del comercio intraindustrial bilateral entre Argentina y Brasil, en consonancia con lo que cabría esperar en las primeras instancias del proceso, y coadyuvado a eternizar la concentración regional de la actividad industrial en nuestro país.

En el contexto definido por las hipótesis que delimitan el análisis teórico, la dinámica previsible en la geografía económica del bloque podría refluir en una creciente discrepancia en los niveles de bienestar. Es evidente que la acentuación de las disparidades a este respecto puede actuar en detrimento de la viabilidad futura de la integración. En particular, si quienes tienen a su cargo la formulación de la política económica se preocupan por el bienestar relativo, podría propugnarse la implementación de una politica regional-sectorial. 


\section{Integración económica y localización de la actividad productiva:}

\section{El caso del Mercosur}

\section{Consideraciones introductorias}

El decenio de 1990 fue el escenario temporal de una intensificación sin precedentes en las negociaciones internacionales tendientes a la suscripción de acuerdos de comercio preferencial. El resultado genérico derivado de antedichos acuerdos fue la profundización de la integración económica de diversas regiones del mundo.

En concreto, un proceso de integración económica se materializa estilizadamante a través de una reducción de los costos implicados por el intercambio comercial y se manifiesta connaturalmente en una expansión del comercio intrarregional. En tal caso, es probable que se verifique una alteración en el balance de las fuerzas que determinan el equilibrio espacial en la situación previa y, en consecuencia, una redefinición del patrón localizacional prevaleciente. Asimismo, antedicho proceso puede engendrar repercusiones secundarias. En efecto, el mismo puede modificar endógenamente factores determinantes de los emplazamientos productivos como la infraestructura e incluso las condiciones macroeconómicas bajo las cuales se desenvuelve como, por ejemplo, el grado variabilidad del tipo de cambio real, $\mathrm{y}$, por ende, reforzar adicionalmente la dinámica de cambio espacial. Por último, no debería despreciarse el rol de las expectativas en esta última así como tampoco las cuestiones concatenadas con la estabilidad del proceso.

Desde el punto de vista de nuestro país, es claro que el Mercosur constituye una referencia natural para estudiar el tema.

El objetivo del presente trabajo consiste precisamente en determinar los cambios en la configuración espacial de la actividad económica industrial entre Argentina y Brasil y dentro de nuestro país derivados de la conformación del Mercosur y establecer las prescripciones de politica pertinentes.

A tal efecto, en la segunda sección, se discutirán las motivaciones del tema y las razones de su relevancia. 
En la tercera sección, se definirá un marco teórico donde se explica la lógica económica del impacto geográfico de un proceso de integración articulado en torno a los elementos resaltados por la teoría de la nueva geografía económica.

En la cuarta sección, se llevará a cabo un relevamiento de la evidencia aportada por los trabajos empíricos relativos a los principales casos referenciales, la Unión Europea y el Nafta, y al socio más importante del Mercosur, Brasil, con el propósito de establecer cuáles son las principales implicancias espaciales fácticas de los procesos de integración y en qué medida se ajustan a las predicciones de la teoría.

En la quinta sección, se realizará un análisis empírico con los objetivos de caracterizar la distribución geográfica de la actividad económica en nuestro país en diferentes momentos del tiempo, identificar los factores explicativos de la misma así como su relevancia relativa, y describir su trayectoria temporal. Resulta menester destacar que la contrastación directa de los modelos se encuentra en una etapa primitiva y que superáditamente gran parte de la literatura empírica se concentra en los casos europeo y norteamericano. Por lo tanto, el estudio que se pretende realizar puede ser una contribución interesante, debido al estadío actual de la investigación empírica del tema y específicamente al hecho de la virtual ausencia de trabajos que traten la problemática desde el punto de vista de los países en desarrollo, en general, y Argentina, en particular ${ }^{1}$.

En la sexta sección, se interpretarán los resultados de las estimaciones, a cuyo efecto se tendrán en cuenta las consideraciones realizadas en el planteo teórico.

En la séptima sección, se intentará extraer una serie de recomendaciones de política sobre la base de una discusión de la racionalidad de una política regional que apunte a atender los problemas individualizados en la sección empírica.

Finalmente, en la octava sección, se presentarán las conclusiones que surgen del análisis que las precede.

\footnotetext{
${ }^{1}$ Una excepción en este sentido son los trabajos de Sanguinetti y Garriga (1997) y Sanguinetti, Posadas y Kumar (1998).
} 


\section{La Nueva Geografía Económica y el Regionalismo}

\section{2.a. Las cuestiones localizacionales en la teoría económica}

Los modelos convencionales de comercio internacional con rendimientos constantes a escala y competencia perfecta predicen que, en ausencia de diferencias interregionales subyacentes, las actividades económicas se distribuyen uniformemente en el espacio.

No obstante, uno de los rasgos distintivos precipuos de las economías modernas es la existencia de niveles elevados de concentración espacial y las características inherentes de las regiones parecen insuficientes para determinar tales niveles. En este sentido, los desarrollos téoricos recientes encuadrados en la denominada "Nueva Geografía Económica", sugieren que los rendimientos crecientes a escala constituyen un factor esencial para explicar la distribución desigual de la actividad económica. En este contexto, la localización de las firmas es path dependence, es decir, se encuentra gobernada por el patrón de localización existente en un momento dado del tiempo. Como consecuencia, el mapa económico no es único, ya que el equilibrio espacial final, que redunda de un proceso acumulativo impelido por los beneficios de la aglomeración, depende de las radicaciones escogidas por la historia, que se entiende básicamente como los accidentes históricos o la política económica.

En concreto, las contribuciones que conforman la teoría de la localización son susceptibles de encuadrarse en tres grandes escuelas teóricas. Siguiendo a Brülhart (1998), puede realizarse una reseña breve de los principales lineamientos de cada una de las mismas, en especial en lo atinente a sus implicancias en términos de la configuración geográfica de la actividad económica. 


\section{2.a.1. Teoría neoclásica: Las ventajas comparativas}

La teoría neoclásica se caracteriza por la conjunción de competencia perfecta, homogeneidad de productos y rendimientos a escala no crecientes. En este marco, la localización se determina exógenamente; en otras palabras, se define en base a lo que Krugman (1993) denomina "primera naturaleza", específicamente, la distribución espacial de los recursos naturales, las tecnologías y los factores. Así, en ausencia de diferencias subyacentes entre las regiones del mundo, las actividades económicas se distribuirán uniformemente en el espacio. En efecto, imagínese un mundo en el cual no existen rendimientos crecientes a escala, el transporte es costoso y las discrepancias interregionales en términos de las singularidades originarias propias son pequeñas. En tal escenario, las firmas que producen en sitios donde conviven con un gran número de pares enfrentan una competencia más intensa tanto en el mercado de bienes como en el mercado de factores. Por consiguiente, la rentabilidad alcanzada por tales empresas es inferior a la obtenida por aquellas que afrontan una menor competencia. El resultado natural es la dispersión espacial de las firmas. Por el contrario, si las regiones presentan marcadas diferencias en sus características inherentes, entonces se tiene una configuración espacial desigual.

Por lo tanto, es posible aseverar que la teoría económica ha explicado tradicionalmente la localización de las actividades económicas y, en consecuencia, las diferencias espaciales en las estructuras productivas esencialmente en función de las disparidades en las propiedades subyacentes de las regiones, esto es, la geografía, las dotaciones factoriales y la tecnología tecnología, factores que en sí mismo determinan la desigualdad del espacio. De esta manera, el grado de concentración espacial de la actividad económica mantiene una relación biunívoca con el grado de concentración espacial de los atributos propios de las distintas localizaciones y el mapa económico resultante es único. Consistentemente, el patrón de comercio prevaleciente es en esencia inter-industrial, dado que los sectores se radican en aquellos sitios que cuentan con las ventajas comparativas correspondientes. Por otra parte, si se suponen costos de transporte nulos, la distribución espacial de la demanda afecta el patrón de comercio, pero no la localización de la producción. En cambio, si se asumen costos de transporte positivos y una configuración espacial de la demanda más 
desigual que la de las dotaciones factoriales, entonces la dispersión localizacional se correlaciona positivamente con el nivel de los costos de transacción. En el límite, la existencia de costos de transporte prohibitivos induce una correlación perfecta entre la distribución geográfica de las industrias y la distribución geográfica de la demanda.

Ahora bien, las ventajas comparativas se revelan evidentemente incapaces de explicar por sí mismas los niveles de concentración apreciados en la realidad. Varios estudios reafirman el aserto precedente. Por lo tanto, el interrogante que se plantea es ¿cuáles son los otros factores que inciden en la definición del patrón espacial de la actividad económica? Precisamente, es en la respuesta a la pregunta anterior donde la nueva teoría del comercio internacional desempeña un rol destacado.

\section{2.a.2. Nueva teoría del comercio: El acceso al mercado}

Los modelos encuadrados en la Nueva Teoría del Comercio pretieren virtualmente la totalidad de los elementos de "primera naturaleza" a excepción de la dimensión del mercado. Efectivamente, el mismo se halla determinado por el tamaño de la fuerza laboral en un país en particular en concurrencia con el supuesto de inmovilidad factorial internacional. En general, los modelos de la teoría en cuestión asumen que el mundo se divide en dos regiones: un país grande central y un país pequeño periférico. El primero posee una dotación factorial absoluta mayor que la correspondiente al segundo, empero ambos tienen la misma dotación relativa ${ }^{2}$. Asimismo, se supone que hay dos sectores productivos. Por un lado, un sector perfectamente competitivo que opera bajo rendimientos constantes a escala y, por otro lado, un sector monopolísticamente competitivo con firmas que producen bienes diferenciados en condiciones de rendimientos crecientes a escala. De este modo, los modelos a que se hace referencia introducen rasgos específicos a las actividades, que en la terminología de Krugman (1993) reciben la denominación de "segunda naturaleza", tales como competencia imperfecta, diferenciación de productos y rendimientos crecientes.

\footnotetext{
${ }^{2}$ De esta forma, se logra aislar el influjo de las ventajas comparativas.
} 
El resultado típico de los modelos antes aludidos reconoce dos niveles. Por una parte, existe especialización interindustrial, con sectores que se nuclean en aquellos emplazamientos que gozan del mejor acceso a los mercados de sus respectivos productos. Por otra parte, existe especialización intraindustrial entre las firmas, cada una de las cuales produce una única variedad diferenciada horizontalmente del producto de la industria. En la medida en que permanezca una cierta cantidad de empresas en el mercado más pequeño, se asegura la existencia de comercio intraindustrial. Sin embargo, si se eliminan los costos de transporte, todas las actividades de rendimientos crecientes tenderán a concentrarse en la vecindad del mercado central y, en consecuencia, cesará el comercio intraindustrial entre el centro y la periferia.

Indudablemente, los modelos de comercio con competencia imperfecta subrayan la ambigüedad fundamental de los efectos de la integración económica sobre la competitividad relativa de las regiones centrales y periféricas. No obstante, el enfoque bajo consideración presenta importantes limitaciones (Ottaviano y Puga, 1997).

En primer lugar, se puede afirmar que, en rigor de verdad, la nueva teoría del comercio internacional no deja de explicar las diferencias existentes entre las estructuras productivas de las regiones a través de disimilitudes en sus características subyacentes. En efecto, la misma parte del supuesto de que existen países que tienen grandes mercados que coexisten con países que poseen mercados de dimensiones reducidas, pero en ningún caso enuncia los motivos por los cuales se ha producido dicha distribución de tamaños de mercado.

En segundo lugar, la nueva teoría del comercio se revela incapaz de explicitar la lógica en virtud de la cual las firmas pertenecientes a ciertos sectores tienden a localizarse próximas unas de otras y definir consecuentemente un patrón nítido de especialización regional.

En tercer lugar, sobredicha teoría presenta el desarrollo industrial como un proceso gradual y simultáneo para todos los países en desarrollo. Ello no sería consistente con algunos episodios de industrialización (vgr. el fenómeno asiático), en los cuales se verifican olas de industrialización rápida que se esparcen sucesivamente de un país a otro.

Justamente, tales cuestiones son las que aborda la nueva geografía económica. 


\section{2.a.3. Nueva geografía económica: La endogeinización del patrón de centro-periferia}

Los modelos de la nueva geografía económica se caracterizan por la endogeinización de la localización. De esta forma, los factores de "segunda naturaleza" definen absolutamente todo. La movilidad de los factores y las firmas tiene como correlato el hecho de que el tamaño del mercado se determina en el modelo. El punto de partida está dado normalmente por un espacio bi o tri dimensional sin rasgos distintivos con una distribución uniforme del trabajo y el producto de una única industria. Tal distribución es intrínsecamente inestable, en virtud del papel que se asigna a las características de "segunda naturaleza" de la economía: externalidades de tamaño de mercado y eslabonamientos insumo-producto. Las mismas inducen procesos de aglomeración que se autorrefuerzan. Por lo tanto, cualquier perturbación que se produzca sobre la distribución inicial coloca a la economía en un sendero hacia el nuevo equilibrio localizacional. A este respecto, puede decirse que generalmente existen varios posibles equilibrios localmente estables. El resultado final depende de la distribución inicial, la naturaleza de la perturbación y las características de la industria. Luego, la ocurrencia de un proceso de aglomeración y la consiguiente emergencia de una estructura de centro-periferia es sólo una de las posibles configuraciones resultantes. No obstante, ello no obsta identificar un patrón general en los modelos de este tipo, a saber, la aglomeración se relaciona no monotónicamente con la integración económica, en particular, la economía exhibe una elevada concentración espacial para niveles intermedios de los costos de transacción (curva "U”).

El siguiente cuadro sintetiza los aportes fundamentales efectuados por cada teoría a la explicación de la distribución de la actividad económica en el espacio. 


\begin{tabular}{|c|c|c|c|}
\hline \multicolumn{4}{|c|}{ Teorías y localización } \\
\hline & Teoría neoclásica & $\begin{array}{l}\text { Nueva teoría del } \\
\text { comercio }\end{array}$ & $\begin{array}{c}\text { Nueva geografía } \\
\text { económica }\end{array}$ \\
\hline Trabajos seminales & $\begin{array}{l}\text { Heckscher (1919), Ohlin } \\
\text { (1933), Weber (1909), } \\
\text { Vanek(1986) }\end{array}$ & \begin{tabular}{|l|} 
Krugman \\
$(1979,1980,1981)$, Dixit y \\
Norman (1980), Helpman \\
$\begin{array}{lll}\text { y Krugman } & \text { (1985) y } \\
\text { Weder (1995) }\end{array}$
\end{tabular} & $\begin{array}{lr}\text { Marshall } & (1920), \\
\text { Krugman } & (1991), \\
\text { Venables (1993), Puga y } \\
\text { Venables (1997), Fujita, } \\
\begin{array}{l}\text { Krugman y Venables } \\
(1999)\end{array}\end{array}$ \\
\hline Estructura de mercado & Competencia perfecta & $\begin{array}{l}\begin{array}{l}\text { Competencia } \\
\text { monopolística }\end{array} \\
\end{array}$ & $\begin{array}{l}\text { Competencia } \\
\text { monopolística }\end{array}$ \\
\hline $\begin{array}{l}\text { Determinantes de la } \\
\text { localización }\end{array}$ & 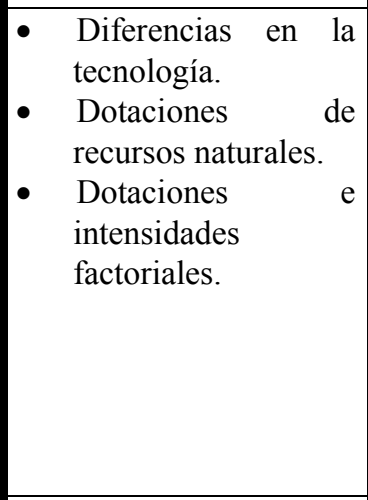 & 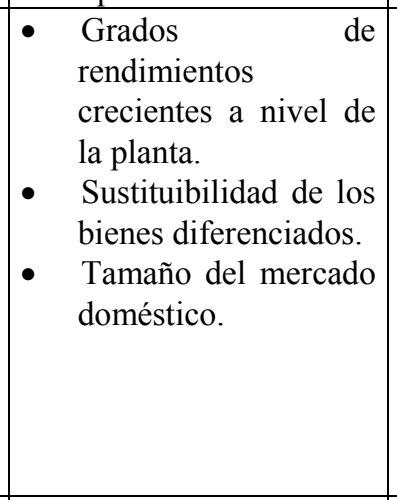 & $\begin{array}{l}\text { Externalidades } \\
\text { pecuniarias (mercado } \\
\text { de trabajo conjunto, } \\
\text { eslabonamientos } \\
\text { insumo-producto, } \\
\text { eslabonamientos de } \\
\text { demanda inducido } \\
\text { por la migración). } \\
\text { - Externalidades } \\
\text { tecnológicas. } \\
\text { Costos de } \\
\text { transacción. } \\
\end{array}$ \\
\hline $\begin{array}{l}\text { Localización de la } \\
\text { industria }\end{array}$ & \begin{tabular}{|l} 
- \\
Distribución \\
general de la \\
actividad económica \\
(trabajo) \\
determinada por \\
dotaciones. \\
- Especialización \\
interindustrial. \\
- Equilibrio único.
\end{tabular} & 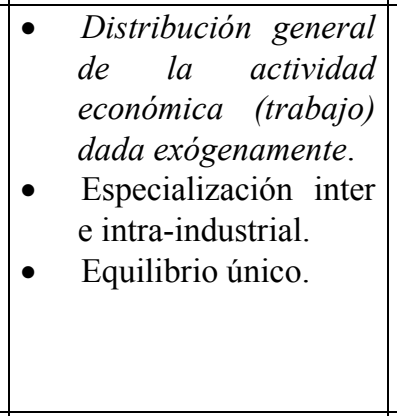 & $\begin{array}{l}\text { - } \begin{array}{l}\text { Distribución general } \\
\text { de la actividad }\end{array} \\
\text { económica (trabajo) } \\
\text { endógena. } \\
\text { - Fuerzas centrípetas } \\
\text { de aglomeración. } \\
\text { - Especialización inter } \\
\text { e intra-industrial. } \\
\text { - Equilibrios múltiples. } \\
\text { - Curva "u". }\end{array}$ \\
\hline $\begin{array}{l}\text { Estructura } \\
\text { comercio }\end{array}$ & Comercio interindustrial & $\begin{array}{l}\text { Comercio inter e intra- } \\
\text { industrial }\end{array}$ & $\begin{array}{l}\text { Comercio inter e intra- } \\
\text { industrial }\end{array}$ \\
\hline
\end{tabular}




\section{2.b. El renovado interés en las cuestiones localizacionales}

El renacimiento de la preocupación por los temas espaciales es el producto derivado de la confluencia, por un lado, de desarrollos en el ámbito de la teoría, que asumieron la forma de la denominada "Revolución de los rendimientos crecientes", y, por el otro, de fenómenos reales acaecidos en los últimos años, principalmente la generalización de los acuerdos de comercio preferencial. La presente subsección tiene por objeto justamente explicitar cada una de tales motivaciones del tema que focaliza el trabajo, sin dejar de reconocer las interrelaciones existentes entre las mismas. En efecto, el progreso de la teoría, aun cuando se funda innegablemente en una lógica evolutiva propia, es susceptible de visualizarse al menos parcialmente como la respuesta a la necesidad de redefinir la unidad geográfica de estudio relevante impuesta por los procesos de integración económica regional.

\section{2.b.1. Motivaciones teóricas}

La idea de que la decisión de los productores individuales de escoger una localización con buen acceso a los mercados y oferentes mejora efectivamente el acceso al mercado o la oferta de otros productores en dicha localización no es nueva. El proceso circular ínsito en la misma ha sido el tema central de los estudios de reconocidos geógrafos como Harris (1954) y Pred (1956).

La pregunta que uno debería plantearse entonces es la siguiente: ¿por qué tal idea no se generalizó entre los economistas hasta la década de 1990?

Según Krugman (1998), la respuesta más probable es que los trabajos antes mencionados asumen implícitamente que existen economías de escala a nivel de la firma. En ausencia de tales economías, los productores no tendrían ningún incentivo a concentrar sus actividades $\mathrm{y}$, en consecuencia, abastecerían a los consumidores desde varias plantas locales; una expansión del mercado regional no conduciría necesariamente a un aumento en el rango de 
bienes producidos dentro de la región. En otros términos, la existencia de rendimientos crecientes a escala es central en el tema.

Las consideraciones precedentes se aplican para la economía espacial en general. La mayor parte de las ideas interesantes en la teoría de la localización se basa implícita o explícitamente en el supuesto de que existen economías de escala que impelen la concentración geográfica de algunas actividades. Así, el análisis de Weber (1909) de las decisiones localizacionales de un productor individual que procura minimizar los costos combinados de producir y entregar su producto supone que sólo puede haber un sitio de producción. Por su parte, Christaller (1933), quien sugirió que las ciudades forman una jerarquía de sitios centrales, asume ínsitamente que las ciudades más grandes pueden sostener un mayor rango de actividades. Finalmente, la demostración de Lösch (1940), conforme a la cual un patrón eficiente de lugares centrales implicaría áreas de mercado hexagonales, se funda en el supuesto de existencia de actividades que sólo pueden realizarse en un número limitado de sitios ${ }^{3}$.

Ahora bien, la presencia de economías de escala no agotables a nivel de la firma socava la competencia. Precisamente, aquí yace la quintaesencia del tema.

Efectivamente, la razón por la cual la geografía se incorporó a la corriente económica en los últimos años es el hecho de que la competencia imperfecta ha perdido su condición de insusceptible de modelización. El renovado interés en la geografía puede concebirse según Krugman (1998) como la cuarta ola de la revolución rendimientos crecientes/competencia imperfecta. En primer término, emergió la Nueva Organización Industrial, que creó un conjunto de modelos convincentes de competencia imperfecta. Luego sobrevino la Nueva Teoría del Comercio, que empleó tal conjunto de herramientas para diseñar modelos de comercio internacional bajo condiciones de rendimientos crecientes. Ulteriormente, surgió la Nueva Teoría del Crecimiento, que hizo lo propio para el crecimiento económico. Finalmente, hacia comienzos del decenio en curso hizo eclosión la Nueva Geografía Económica, que puede describirse como el análisis que intenta explicar la estructura

\footnotetext{
${ }^{3}$ El principal ejemplo de modelo que no se funda en alguna forma de economías de escala, el análisis de la renta de la tierra de von Thünen (1826), oculta el rol de los rendimientos crecientes asumiendo simplemente que existe una ciudad central.
} 
espacial de la economía a través de ciertos artificios técnicos. De acuerdo a Krugman (1992,1998), tales artificios comprenden:

- El modelo de competencia monopolística desarrollado por Dixit y Stiglitz (1977). El modelo posee un rasgo distintivo trascendente para la nueva geografía económica: dado que el mismo asume un continuo de bienes, permite respetar la naturaleza entera de las decisiones localizacionales y analizar el modelo en términos del comportamiento de variables continuas como la participación industrial en una región particular. El precio de la conveniencia es que el modelo de Dixit y Stiglitz es muy restrictivo. Básicamente, el supuesto de simetría entre variedades y la ausencia consiguiente de rentas monopólicas de equilibrio y de cualquier interacción estratégica entre las firmas indudablemente implica excluir una gran parte de los factores que efectivamente intervienen en industrias imperfectamente competitivas.

- Icebergs. En la teoría de la localización los costos de transporte son esenciales. Sin embargo, cualquier intento de desarrollar un modelo de equilibrio general de geografía económica se complicaría enormemente si fuera necesario modelar tanto el sector productor de bienes como el sector de transporte. Incluso, los costos de transporte pueden subvertir el supuesto simplificativo de elasticidad constante de la demanda del modelo de Dixit y Stiglitz. Ambos inconvenientes pueden ser evitados mediante el supuesto introducido por Samuelson (1954) en la teoría del comercio internacional, según el cual una fracción del bien transportado se pierde ("se derrite") en el tránsito, de manera que los costos son incurridos efectivamente en el producto trasladado. Generalmente, en los modelos de la nueva geografía económica se supone que el "derretimiento" se verifica a una tasa constante por unidad de distancia, esto es, el costo de transporte entre dos localizaciones es siempre una fracción constante del precio f.o.b. del bien.

- Dinámica y multiplicidad de equilibrios. Los modelos de geografía económica implican usualmente equilibrios múltiples. Por ejemplo, supóngase que los productores desean localizarse donde otros productores escogen ubicarse: esto sugiere inmediatamente cierta arbitrariedad respecto de dónde terminarán estableciéndose en realidad. El interrogante es: ¿qué equilibrio elige la economía? Los modelos de la nueva geografía 
económica asumen típicamente un proceso de ajuste ad hoc, en el cual los factores de producción se mueven gradualmente hacia localizaciones que ofrecen retornos reales más elevados. En este sentido, supradichos modelos pueden visualizarse como juegos dinámicos en los cuales las localizaciones son estrategias.

- La computación. Los modelos más simples de la geografía económica son normalmente muy complejos. La solución de los mismos requiere tanto cálculos estáticos como simulaciones dinámicas, que exceden las posibilidades de los procedimientos manuales. El desarrollo de sistemas informáticos sofisticados ha representado un gran impulso al avance de la teoría.

\section{2.b.2. Motivaciones fácticas}

El interés por los temas espaciales ha sido motivado fácticamente por la integración de las economías nacionales en bloques comerciales como la Unión Europea, el Nafta o el Mercosur y su impacto consiguiente en el desarrollo de sus regiones y ciudades. A medida que el proceso de integración esfuma las fronteras económicas internacionales, las fronteras nacionales dejan de proporcionar la unidad natural de análisis. La omisión de tal hecho así como de las implicaciones del mismo es decididamente riesgosa en un contexto de nuevo impulso del regionalismo.

En efecto, hacia fines de la década de 1980 y en el marco de una tendencia secular de expansión del comercio mundial se asistió a una intensificación en la formación de bloques preferenciales de comercio ${ }^{4}$. La notificación de 30 acuerdos regionales en el período comprendido entre 1990 y 1994 (Serra y otros, 1997) y de casi 45 entre los años 1995 y 1999, el hecho de que más de la mitad del comercio mundial tenga lugar dentro de los mercados definidos por los mismos (OMC, 1995) y la pertenencia de virtualmente todos los

\footnotetext{
${ }^{4}$ A lo largo de las décadas de 1960 y 1970 también se había verificado una intensa actividad en materia de acuerdos comerciales regionales. Entre 1960 y 1979 se notificaron diversos acuerdos, la mayor parte de los cuales involucraba a países europeos $(82,8 \%)$.
} 
países integrantes de la OMC a algún tipo acuerdo (Devlin y Ffrench-Davis, 1998) constituyen un testimonio inequívoco de la magnitud del fenómeno ${ }^{5}$.

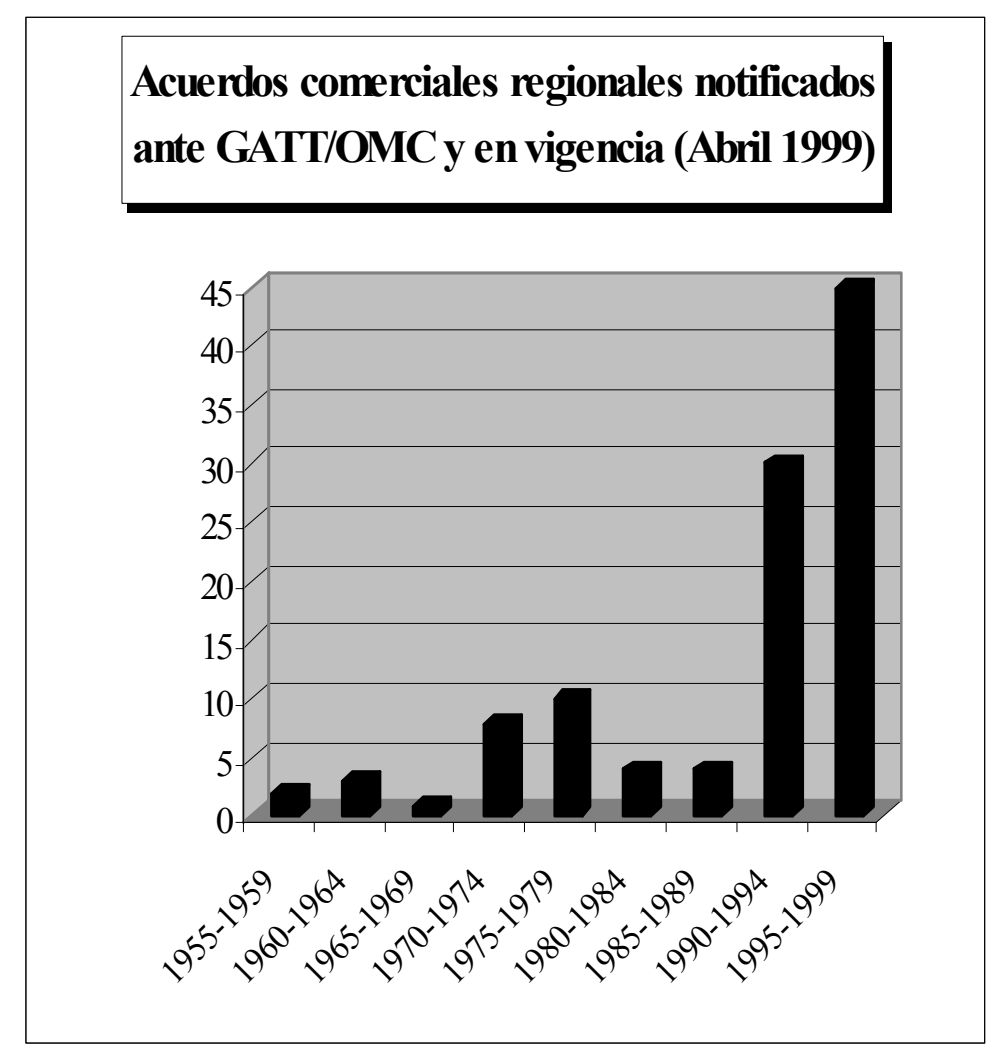

Nota: Los acuerdos se asignaron al quinquenio en que entraron en vigor.

Fuente: Elaboración propia en base a OMC.

América no constituye una excepción en este sentido. Las iniciativas de integración regional han sido singularmente prolíficas desde comienzos del decenio de 1990 (ver cuadro) y han dado lugar a un aumento significativo en la importancia del comercio intrazona (ver gráfico).

\footnotetext{
${ }^{5}$ Según un informe de la Organización Mundial del Comercio (1995), Japón y Corea del Sur son los únicos países que no han suscripto al menos un acuerdo de comercio preferencial.
} 


\begin{tabular}{|c|c|}
\hline \multicolumn{2}{|l|}{ Acuerdos comerciales regionales recientes en América Latina } \\
\hline Acuerdo & Año \\
\hline Pacto Andino (Bolivia, Ecuador, Colombia, Perú y Venezuela) & 1990 \\
\hline Mercado Común Centroamericano (Costa Rica, El Salvador, Guatemala, Honduras y Nicaragua) & 1991 \\
\hline Mercosur (Argentina, Brasil, Paraguay y Uruguay) & 1991 \\
\hline Chile-México & 1991 \\
\hline Nafta (México, Canadá y Estados Unidos) & 1993 \\
\hline Chile-Colombia & 1993 \\
\hline Chile-Venezuela & 1993 \\
\hline Chile-Ecuador & 1994 \\
\hline G-3 (Colombia, México y Venezuela) & 1994 \\
\hline México-Bolivia & 1994 \\
\hline México-Costa Rica & 1994 \\
\hline Chile-Mercosur & 1996 \\
\hline Chile-Canadá & 1997 \\
\hline Bolivia-Mercosur & 1997 \\
\hline México-Nicaragua & 1998 \\
\hline \multicolumn{2}{|l|}{ Acuerdos bajo discusión } \\
\hline \multicolumn{2}{|l|}{ Mercosur-Pacto Andino } \\
\hline \multicolumn{2}{|l|}{ Mercosur-Unión Europea } \\
\hline \multicolumn{2}{|l|}{ Chile-Mercado Común Centroamericano } \\
\hline \multicolumn{2}{|l|}{ Chile-Unión Europea } \\
\hline \multicolumn{2}{|l|}{ México-El Salvador, Guatemala y Honduras } \\
\hline \multicolumn{2}{|l|}{ México-Belize } \\
\hline \multicolumn{2}{|l|}{ México-Unión Europea } \\
\hline \multicolumn{2}{|l|}{ México-Ecuador } \\
\hline \multicolumn{2}{|l|}{ México-Perú } \\
\hline \multicolumn{2}{|l|}{ México-Panamá } \\
\hline \multicolumn{2}{|l|}{ República Dominicana-Mercado Común Centroamericano } \\
\hline \multicolumn{2}{|l|}{ República Dominicana-CARICOM } \\
\hline CARICOM-Mercado Común Centroamericano & \\
\hline
\end{tabular}




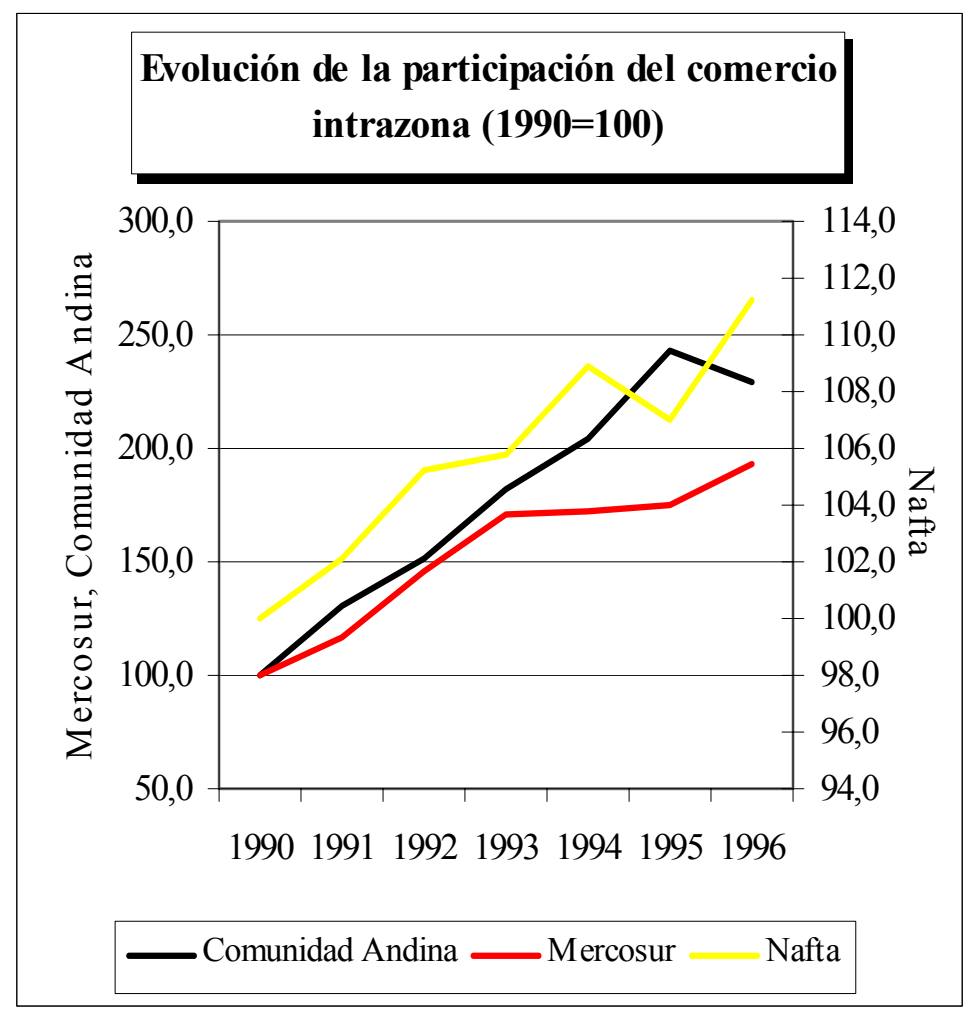

Fuente: Elaboración propia en base a Devlin y Ffrench-Davis (1998).

Ahora bien, resulta menester destacar que, en contraposición al carácter incontrovertible de la relevancia adquirida por los procesos de integración regional, se aprecia una notoria ausencia de consenso en el debate relativo a sus factores etiológicos.

Por un lado, la emergencia del regionalismo se explica en términos de la elección efectuada por los países a partir de un análisis de costo-beneficio entre las alternativas de liberalización multilateral en el marco del GATT/OMC (Principio de la Nación Más Favorecida) y el otorgamiento de preferencias arancelarias acotadas a un número reducido de países (Artículos V y XXIV y Cláusula de Concesión del GATT). Los siguientes argumentos se encuadran en esta línea de raciocinio.

- El otorgamiento de un pequeño margen de preferencias puede ser óptimo en un marco en el que los costos de transporte intercontinentales ocupan un lugar preponderante (Frankel, Stein y Wei, 1996). 
- En este contexto, los países signatarios enfrentan menores costos de ajuste (Laird, 1995) y pueden obtener beneficios potenciales como la posibilidad de impeler el desarrollo a través de la corrección de ciertas fallas de mercado (vgr: mercado incompletos e imperfectos que obstan la obtención de ganancias de eficiencia y el desarrollo de nuevos patrones productivos caracterizados por un mayor valor agregado) y la aferencia de corrientes inversoras ligada al mejoramiento en las condiciones de acceso a los mercados externos que comportan los procesos de integración regional (Devlin y Ffrench-Davis, 1998; Serra y otros, 1998).

- Los acuerdos regionales permiten mantener aranceles con respecto a los países que no forma parte del mismo, lo cual es especialmente importante en el corto-mediano plazo para aquellos países que enfrentan dificultades fiscales (Laird, 1995).

- El alcance de acuerdos en un grupo de países de menores dimensiones es más sencilllo que en el marco del sistema complexo de intercambio de concesiones comerciales multilaterales, debido a que aumentan el costo de los comportamientos no cooperativos $\mathrm{y}$ tornan factibles las discusiones acerca de las sofisticadas barreras comerciales del mundo moderno (Krugman, 1993). En la terminología de Devlin y Ffrench-Davis (1998), las iniciativas regionales constituyen "el arte de lo posible en liberalización comercial" y pueden visualizarse como un complemento de las negociaciones generales (Serra y otros, 1997). En este sentido, bajo el supuesto de que los mecanismos multilaterales son débiles y ello impide a los gobiernos implementar políticas comerciales eficientes a través de un acuerdo pluripartito que exija la vigencia de una estructura arancelaria compatible con el principio de Nación Más Favorecida, los procesos de integración regional pueden aumentar la eficiencia de la estructura arancelaria multilateral cuando el grado de cooperación internacional es reducido (Bagwell y Staiger, 1997).

Bajo el amparo de la noción de factibilidad antes delineada, se puede argüir adicionalmente que:

- La expansión del comercio entre países ejerce un influjo civilizador (Hirschman, 1982). En particular, los procesos de integración regional, que conllevan tal efecto, inducen un 
incremento de la confianza entre los naciones socias y una reducción consiguiente de la probabilidad de conflictos (Schiff y Winters, 1998) ${ }^{6}$.

- Un país en desarrollo que decide encarar un proceso de reforma de su política comercial e incluso de otro tipo de políticas puede obtener ventajas de la firma de un acuerdo de comercio preferencial con una nación grande y desarrollada, ya que el mismo contribuiría a asegurar la continuidad de las reformas en curso por medio del reaseguro que supone el tratado internacional que entra en vigor y, de esta manera, entesaría la credibilidad de las mismas (Whalley, 1996; Fernández, 1998).

- Los acuerdos preferenciales de comercio permiten a los países pequeños contar con un mayor poder de negociación en las tratativas multilaterales, garantizar el acceso de sus productos al mercado de un país grande (Whalley, 1996) y asegurarse parcialmente contra las consecuencias de una eventual guerra comercial mundial (Perroni y Whalley, $1994)^{7}$.

Por otro lado, se aduce que el regionalismo posee una lógica intrínseca propia que se no se vincula con el ritmo de avance en las negociaciones multilaterales de liberalización comercial. La idea fue expuesta por Baldwin (1993) y recibe la denominación de "Teoría del Dominó". El razonamiento es simple. La formación o la profundización de un área de comercio preferencial genera desvío de comercio e inversión. Ello promueve presiones políticas en favor de la inclusión en las naciones no participantes, que serían las potenciales damnificadas de los efectos de desvío. La intensidad de las presiones es una función creciente del tamaño del bloque comercial y el mismo, a su vez, se relaciona positivamente con el número de naciones participantes. Evidentemente, un incidente de regionalismo puede desencadenar múltiples solicitudes de membresía por parte de naciones que previamente se hallaban conformes en su calidad de no signatarias. En este contexto, el regionalismo se expande vertiginosamente, tanto si el bloque es abierto, en virtud de la incorporación de los países que así lo han pedido, como si el bloque es cerrado, dado que se induce endógenamente la suscripción de acuerdos entre las naciones excluidas.

\footnotetext{
${ }^{6}$ Los acuerdos regionales de comercio pueden contribuir asimismo a evitar conflictos internos como guerras civiles o disputas con terceros países (ver Schiff y Winters, 1998, para más detalles).

${ }^{7}$ En este último caso, los países grandes obtienen en carácter de contraprestación beneficios no comerciales (vgr: restricciones sobre las políticas domésticas de los países pequeños, una protección más firme de los derechos de propiedad intelectual, etc).
} 
Por consiguiente, tal como se ha tenido oportunidad de observar, el trasfondo del presente trabajo está dado por la conjunción temporal de dos factores: los desarrollos registrados en el campo de la teoría económica y el auge del regionalismo. Específicamente, se procurá utilizar las nuevas líneas de investigación para explicar ciertos patrones de comportamiento localizacional generados por el principal proceso de integración económica emprendido por los países de la región sur de América Latina.

\section{Marco teórico}

El marco teórico está definido por el modelo planteado por Torstensson (1995) y Brülhart y Torstensson (1996), que examina el efecto de la integración económica sobre el grado de concentración geográfica de la actividad productiva.

\section{3.a. Supuestos y estructura del modelo}

El modelo asume tres países: 1, 2 y 3. 1 se concibe como una nación agregada que representa al "resto del mundo", en tanto que 2 y 3 son las naciones que conforman la unión aduanera. Asimismo, se supone que uno de los países miembros del bloque comercial que se constituye, 2, tiene un tamaño mayor que el otro, 3. Si se tiene en cuenta que el PBI de Brasil medido en dólares equivalía a 2,5 veces el PBI de Argentina en 1998, el supuesto de asimetría dimensional es decididamente pertinente. Ahora bien, en el modelo sólo se considera un factor productivo, el trabajo, de modo que la diferencia en los respectivos tamaños se refleja en las dotaciones de dicho factor. Concretamente, el país 1 posee una 1 unidad de trabajo, el país 2 tiene $\beta$ unidades de trabajo y el país 3 cuenta con una dotación laboral de $\alpha$ unidades; la diferencia de tamaños se introduce suponiendo que $\beta>\alpha^{8}$.

\footnotetext{
${ }^{8}$ Cabe resaltar que, siguiendo los lineamientos del modelo original de Krugman (1991), el modelo asume implícitamente que existe perfecta movilidad internacional del trabajo. De este modo, se pretiere el rol del mercado correspondiente en la problemática bajo análisis. Ello sería apropiado en la medida en que la industria no fuera muy grande en relación al mercado en cuestión y el ingreso total. A este respecto, puede
} 
Por otra parte, se asume que existen dos tipos de industrias: (i) una industria Y que produce bienes homogéneos bajo rendimientos constantes a escala en un marco de competencia perfecta; (ii) una industria $\mathrm{X}$ que elabora bienes manufacturados diferenciados horizontalmente bajo rendimientos crecientes a escala en un entorno de competencia monopolística ${ }^{9}$.

Otro elemento relevante en el modelo son los costos asociados al comercio. A este respecto, se supone que la industria que produce bienes homogéneos enfrenta costos de transporte nulos y condiciones de libre comercio. Por el contrario, en el caso de la industria manufacturera, los costos de transacción son positivos. En concreto, los óbices al comercio internacional adoptan una forma "tipo iceberg", de manera que por cada unidad exportada, el importador sólo recibe una proporción de la misma. Cabe resaltar que las trabas en cuestión surgen de una combinación de barreras naturales (vgr. costos de transporte propiamente dichos, costos incurridos en el traspaso de una frontera, costos ligados a la adaptación de un producto a los estándares de demanda prevalecientes en el país

mencionarse que en Argentina la industria manufacturera representaba el 28,5\% del empleo total del país en 1994 y que sobredicha participación ha decrecido desde entonces, según se desprende de las estadísticas industriales difundidas por el Indec (1997). Efectivamente, en 1997 el sector industrial sólo representaba el $18 \%$ del total de los puestos de trabajo de la economía.

Naturalmente, el supuesto de perfecta movilidad laboral no parece plausible en el contexto del Mercosur, conforme surge de la evidencia causal reportada por la prevalencia de barreras culturales, idiomáticas e incluso en el libre ejercicio de las actividades profesionales.

No obstante, el modelo de eslabonamiento de demanda puede ser compatibilizado con la experiencia de la región, a partir del ejercicio de adaptación realizado por Ludema y Wooton (1997) para la Unión Europea, donde, a diferencia de Estados Unidos, la movilidad espacial del factor trabajo es relativamente reducida. En efecto, tales autores demuestran que la emergencia de aglomeraciones es factible aún bajo condiciones de movilidad laboral imperfecta. La misma se modeliza asumiendo que los trabajadores prefieren vivir en un determinado país, de modo que sólo son inducidos a migrar si se les ofrece un salario real suficientemente mayor que el que perciben en su país de residencia. En este marco, la intensidad de la concentración geográfica es indudablemente menor que en el modelo aquí planteado y el patrón de especialización industrial observa una secuencia trietápica: diversificación internacional, aglomeración de la actividad manufacturera y reindustrialización de la periferia. Antedicho resultado es alcanzado asimismo por Venables (1993) y Krugman y Venables (1995) en un escenario de total ausencia de movilidad internacional del trabajo. Los autores antes referidos encuentran que la dinámica espacial descripta anteriormente surge cuando existen industrias relacionadas verticalmente y que operan bajo rendimientos crecientes a escala.

Ahora bien, es necesario considerar que, en todos los casos, se supone la preeminencia de pleno empleo. La efectiva vigencia del mismo es indispensable para que el mercado laboral actúe como fuerza centrífuga, ya que, en caso contrario, una expansión de la demanda de trabajo no se traduciría en una presión ascendente sobre el salario. En este sentido, los datos de empleo de Argentina y Brasil indican claramente que ambos países han estado lejos de supradicha situación.

9 Aquí se adopta el planteo de Torstensson (1995). Alternativamente, podría asumirse, tal como hacen Brülhart y Torstensson (1996), que existe un conjunto de industrias $X_{i}$, cada una de las cuales produce una cierta cantidad de variedades de bienes diferenciados. Dado que los supuestos establecidos conducen a 
importador, etc) y barreras artificiales (vgr. aranceles). Asimismo, debe aclararse que los impedimentos al comercio intrarregional difieren de los impedimentos al comercio extrarregional. Por último, resulta menester tener en cuenta que, en el marco del modelo, luego de la institución de la unión aduanera aún persisten costos ligados al intercambio comercial entre los países miembros, ya que si bien se suprimen los óbices artificiales, aún subsisten los obstáculos naturales. En este contexto, la formación de una unión aduanera implica el establecimiento de un arancel externo común, pero no la ausencia completa de trabas al intercambio intrarregional.

En términos específicos, se asume que $1 / \tau(\tau>1)$ es la fracción de los productos diferenciados que arriba al país importador cuando la transacción se verifica entre cada país que forma parte de la unión aduanera y el resto del mundo, en tanto que $1 / \varsigma(\varsigma\rangle 1)$ es la porción de antedichos bienes que llega al país de destino cuando el flujo comercial tiene lugar entre los países componentes del acuerdo comercial regional.

Finalmente, se adopta el supuesto de preferencia por la variedad, que se modeliza à la Dixit-Stiglitz, siguiendo la estrategia de la mayor parte de los trabajos que se encuadran en la "Nueva Geografía Económica". En particular, se supone que todos los individuos tienen funciones de utilidad idénticas, dadas por:

(1) $U=\left(\sum_{i=1}^{n} x_{i}^{\varepsilon}\right)^{\gamma / \varepsilon} \cdot y^{1-\gamma} \quad, 0<\varepsilon\left\langle 1 \quad y \quad \varepsilon=1-\frac{1}{\sigma}\right.$

donde $x_{i}$ es el consumo de la variedad $i$ del bien elaborado por la industria $X$, mientras que $y$ es el consumo del bien homogéneo producido por la industria $Y, n$ es el número total de variedades disponibles y -considerando que cada una de las mismas es producida por una única empresa- la cantidad total de firmas y $\sigma$ es la elasticidad de la demanda ${ }^{10}$.

Siguiendo a Krugman y Helpman (1985), es posible establecer que la demanda agregada por productos originarios de cada una de las tres regiones viene dada por:

resultados idénticos en ambos casos se ha optado por la primera especificación, de modo de evitar una excesiva complejización de la presentación.

${ }^{10}$ Los individuos derivan la misma utilidad del consumo de bienes diferenciados producidos en distintas regiones. 
(2) $D_{1}=n_{1} \cdot x=\frac{n_{1} \cdot p_{1}^{-\sigma} \cdot \gamma}{n_{1} \cdot p_{1}^{1-\sigma}+n_{2} \cdot\left(p_{2} \cdot \tau\right)^{1-\sigma}+n_{3} \cdot\left(p_{3} \cdot \tau\right)^{1-\sigma}}+\frac{n_{1}\left(p_{1} \cdot \tau\right)^{-\sigma} \cdot \gamma \cdot \beta \cdot \tau}{n_{1} \cdot\left(p_{1} \cdot \tau\right)^{1-\sigma}+n_{2} \cdot p_{2}^{1-\sigma}+n_{3} \cdot\left(p_{3} \cdot \zeta\right)^{1-\sigma}}+\frac{n_{1 \cdot}\left(p_{1} \cdot \tau\right)^{-\sigma} \cdot \gamma \cdot \alpha \cdot \tau}{n_{1} \cdot\left(p_{1} \cdot \tau\right)^{1-\sigma}+n_{2} \cdot\left(p_{2} \cdot \zeta\right)^{1-\sigma}+n_{3} \cdot p_{3}{ }^{1-\sigma}}$

(3) $D_{2}=n_{2} \cdot x=\frac{n_{2} \cdot\left(p_{2} \cdot \tau\right)^{-\sigma} \cdot \gamma \cdot \tau}{n_{1} \cdot p_{1}^{1-\sigma}+n_{2} \cdot\left(p_{2} \cdot \tau\right)^{1-\sigma}+n_{3} \cdot\left(p_{3} \cdot \tau\right)^{1-\sigma}}+\frac{n_{2} \cdot p_{2}^{-\sigma} \cdot \gamma \cdot \beta}{n_{1} \cdot\left(p_{1} \cdot \tau\right)^{1-\sigma}+n_{2} \cdot p_{2}^{1-\sigma}+n_{3} \cdot\left(p_{3} \cdot \mathcal{S}\right)^{1-\sigma}}+\frac{n_{2} \cdot\left(p_{2} \cdot \mathcal{l}\right)^{-\sigma} \cdot \gamma \cdot \alpha \cdot \mathcal{\zeta}}{n_{1} \cdot\left(p_{1} \cdot \tau\right)^{1-\sigma}+n_{2} \cdot\left(p_{2} \cdot \mathcal{\zeta}\right)^{1-\sigma}+n_{3} \cdot p_{3}{ }^{1-\sigma}}$

(4) $D_{3}=n_{3} \cdot x=\frac{n_{3} \cdot\left(p_{3} \cdot \tau\right)^{-\sigma} \cdot \gamma \cdot \tau}{n_{1} \cdot p_{1}^{1-\sigma}+n_{2} \cdot\left(p_{2} \cdot \tau\right)^{1-\sigma}+n_{3} \cdot\left(p_{3} \cdot \tau\right)^{1-\sigma}}+\frac{n_{3 \cdot} \cdot\left(p_{3} \cdot \varsigma\right)^{-\sigma} \cdot \gamma \cdot \beta \cdot \varsigma}{n_{1} \cdot\left(p_{1} \cdot \tau\right)^{1-\sigma}+n_{2} \cdot p_{2}^{1-\sigma}+n_{3} \cdot\left(p_{3} \cdot \varsigma\right)^{1-\sigma}}+\frac{n_{3 \cdot} p^{-\sigma} \cdot \gamma \cdot \alpha}{n_{1} \cdot\left(p_{1} \cdot \tau\right)^{1-\sigma}+n_{2} \cdot\left(p_{2} \cdot \varsigma\right)^{1-\sigma}+n_{3} \cdot p_{3}{ }^{1-\sigma}}$

donde $p_{j}$ es el precio de las variedades producidas en el país $j^{11}$.

La función de costos es análoga para todas las firmas pertenecientes a la industria que opera bajo rendimientos crecientes a escala. En particular, la producción de cada variedad exige incurrir en un costo fijo y en un costo marginal constante.

(5) $C M e_{x_{j}}=\eta \cdot w+\frac{\mu \cdot w}{x_{j}}$

donde el primer término del miembro derecho es el costo marginal y el numerador del segundo término corresponde al costo fijo. A partir de la maximización de los beneficios de una firma representativa y la consideración de la condición de beneficio nulo asociada a la vigencia de una situación de libre entrada en la industria, se obtiene que el producto por firma está dado por:

(6) $x_{j}=\frac{\varepsilon . \eta}{\mu .(1-\varepsilon)}$

El equilibrio del mercado laboral requiere que:

(7) $L_{j}=a_{L y} \cdot y_{j}+\left(\eta+\frac{\mu}{x}\right) \cdot n_{j} \cdot x$

${ }^{11}$ Corresponde subrayar que existe una demanda indirecta de productos que obedece a los costos de transporte. Concretamente, las demandas foráneas deben multiplicarse por $\tau$ y $\varsigma$. 
donde $L_{j}$ es la dotación de trabajo del país $j ; a_{L y}$ y $a_{L x}=(\eta+\mu / x)$ son los insumos de trabajo necesarios para producir una unidad del bien en las industrias $y$ y $x$, respectivamente; $y_{j}$ es la producción en la industria $Y$, mientras que $n_{j} . x$ representa la producción agregada en la industria $X$. En ambas industrias se verifica que el precio es igual al costo medio. Luego,

(8) $p_{y_{j}}=a_{L y} \cdot w_{j}=1$

(9) $p_{x_{j}}=\eta \cdot w_{j}+\frac{\mu \cdot w_{j}}{x}$

En este marco, si las unidades se escogen convenientemente, es factible lograr que el precio del bien $y$ sea igual a la unidad.

El equilibrio descripto con anterioridad se encuentra sujeto a una restricción: todos los países producen el bien homogéneo. A partir de la ecuación (8) y del supuesto de libre comercio e igualdad de tecnologías en la industria $Y$ se desprende que los salarios se igualarán entre los países. A su vez, los precios de los productos diferenciados también deben ser iguales, en virtud de que, bajo tecnologías idénticas, $\eta$ y $\mu$ son análogos y del hecho de que las variables ingresan simétricamente en la función de utilidad. Finalmente, la ecuación (6) permite inferir que se igualan los productos por firmas ${ }^{12}$.

\section{3.b. Integración y localización: el punto de vista de la producción}

Considérese ahora las ecuaciones de demanda (2)-(4). Dividiendo ambos miembros de las mismas por $n_{1}, n_{2}$ y $n_{3}$, respectivamente, y escogiendo unidades de manera de que $w=p=1 \mathrm{y}$ definiendo $\rho=\tau^{1-\sigma}\left\langle 1 \quad y \quad \delta=\varsigma^{1-\sigma}\left\langle 1\right.\right.$, resulta que ${ }^{13}$ :

\footnotetext{
${ }^{12}$ La restricción impuesta sobre el equilibrio, que se basa en la igualación del precio de los factores, contribuye a facilitar sustancialmente el análisis.

${ }^{13}$ Cabe resaltar que $\rho$ y $\delta$ decrecen en los costos de transporte (recordar que $\sigma>1$ ) y crecen con las economías de escala y, en consecuencia, con el grado de diferenciación de los productos.
} 
(10) $\frac{x}{\gamma}=\frac{1}{n_{1}+n_{2} \cdot \rho+n_{3} \cdot \rho}+\frac{\beta \rho}{n_{1} \cdot \rho+n_{2}+n_{3} \cdot \delta}+\frac{\alpha \rho}{n_{1} \cdot \rho+n_{2} \cdot \delta+n_{3}}$.

(11) $\frac{x}{\gamma}=\frac{\rho}{n_{1}+n_{2} \cdot \rho+n_{3} \cdot \rho}+\frac{\beta}{n_{1} \cdot \rho+n_{2}+n_{3} \cdot \delta}+\frac{\alpha \cdot \delta}{n_{1} \cdot \rho+n_{2} \cdot \delta+n_{3}}$.

(12) $\frac{x}{\gamma}=\frac{\rho}{n_{1}+n_{2} \cdot \rho+n_{3} \cdot \rho}+\frac{\beta \cdot \delta}{n_{1} \cdot \rho+n_{2}+n_{3} \cdot \delta}+\frac{\alpha}{n_{1} \cdot \rho+n_{2} \cdot \delta+n_{3}}$

Las ecuaciones (10)-(12) constituyen un sistema. La solución del mismo posibilita la determinación del número de variedades producidas y, por tanto, de firmas radicadas en cada país:

(13) $\quad n_{1}=\gamma \frac{[(2 \cdot \rho-\delta-1) \cdot \rho \cdot(\alpha+\beta)]-(\rho-1) \cdot(\delta+1)}{x \cdot(\rho-1) \cdot(2 \cdot \rho-\delta-1)}$

(14) $n_{2}=\gamma \frac{\alpha \cdot\left(\rho^{2}-\delta\right) \cdot(2 \cdot \rho-\delta-1)+(1-\rho) \cdot\left(\beta\left(2 . \rho^{2}+\rho \cdot(1-\delta)-\delta-1\right)+\rho \cdot(1-\delta)\right)}{x \cdot(\rho-1) \cdot(\delta-1) \cdot(2 \cdot \rho-\delta-1)}$

(15) $\quad n_{3}=\gamma \frac{\alpha \cdot\left(2 . \rho^{3}-\rho^{2} \cdot(\delta+1)-2 . \rho+1+\delta\right)+\beta \cdot\left(\delta-\rho^{2}\right) \cdot(2 . \rho-\delta-1)+\rho \cdot(1-\delta) \cdot(\rho-1)}{x \cdot(\rho-1) \cdot(1-\delta) \cdot(2 . \rho-\delta-1)}$

Ahora bien, un proceso de integración regional entre los países 2 y 3 , que asume la forma de una reducción de los costos de transacción incurridos en el intercambio de bienes entre los mismos (en este caso, un aumento de $\delta$ ), conlleva los siguientes efectos:

(16) $\frac{\partial n_{1}}{\partial \delta}=\frac{-2 . \rho \cdot \gamma}{x \cdot(2 . \rho-\delta-1)^{2}}$

(17) $\frac{\partial n_{2}}{\partial \delta}=\frac{\left.\left.-\gamma \cdot\left(\alpha \cdot\left(4 \cdot \rho^{3}-4 \cdot \rho^{2} \cdot \delta+\rho \cdot(\delta-3) \cdot(\delta+1)\right)+(\delta+1)^{2}\right)-\beta \cdot\left(4 \cdot \rho^{3}-4 \cdot \rho^{2} \cdot \delta+\rho \cdot(\delta-3) \cdot(\delta+1)\right)+(\delta+1)^{2}\right)-\rho \cdot\left(\delta^{2}-2 \cdot \delta+1\right)\right)}{x \cdot(2 \cdot \rho-\delta-1)^{2} \cdot(\delta-1)^{2}}$

(18) $\frac{\partial n_{3}}{\partial \delta}=\frac{\left.\left.\gamma \cdot\left(\alpha \cdot\left(4 \cdot \rho^{3}-4 \cdot \rho^{2} \cdot \delta+\rho \cdot(\delta-3) \cdot(\delta+1)\right)+(\delta+1)^{2}\right)-\beta \cdot\left(4 \cdot \rho^{3}-4 \cdot \rho^{2} \cdot \delta+\rho \cdot(\delta-3) \cdot(\delta+1)\right)+(\delta+1)^{2}\right)-\rho \cdot\left(\delta^{2}-2 \cdot \delta+1\right)\right)}{x \cdot(2 \cdot \rho-\delta-1)^{2} \cdot(\delta-1)^{2}}$

El ejercicio de estática comparativa realizado indica que la liberalización del comercio en el seno de la unión aduanera expande efectivamente el mercado doméstico de los países integrantes de la misma y, en consecuencia, promueve una relocalización de la industria que opera bajo condiciones de rendimientos crecientes a escala desde el resto del mundo a la región que se integra. Con respecto a la distribución de la misma dentro de la unión aduanera, puede afirmarse que su constitución conduce inicialmente a un incremento en el 
tamaño absoluto de la producción manufacturera correspondiente en el país de mayores dimensiones y genera un efecto ambiguo sobre la producción en cuestión en el país pequeño. Efectivamente, evaluando las derivadas parciales con respecto a $\delta$ en el punto primigenio de ausencia de discriminación $(\delta=\rho)$, se tiene que:

$$
\begin{aligned}
& \text { (19) } \frac{\partial n_{1}}{\partial \delta}=\frac{-2 \cdot \rho \cdot \gamma}{x \cdot(\rho-1)^{2}} \\
& \text { (20) } \frac{\partial n_{2}}{\partial \delta}=\frac{\gamma \cdot(\rho+(\rho+1) \cdot(\beta-\alpha))}{x \cdot(\rho-1)^{2}} \\
& \text { (21) } \frac{\partial n_{3}}{\partial \delta}=\frac{\gamma \cdot(\rho+(\rho+1) \cdot(\alpha-\beta))}{x \cdot(\rho-1)^{2}}
\end{aligned}
$$

Evidentemente, los países miembros de la unión aduanera aumentan su competitividad respecto del resto del mundo en la industria con rendimientos crecientes a escala $\left(\partial n_{1} / \partial \delta<\right.$ $0)$. Por su parte, el país grande de la unión incrementa su competitividad tanto dentro de la misma como con referencia al país que no la integra y, en consecuencia, deviene más especializado en antedicha industria $\left(\partial n_{2} / \partial \delta>0\right.$, $\left.\operatorname{con} \alpha<\beta\right)$. En el caso del país pequeño, la ganancia de competitividad relativa al resto del mundo derivada del acceso preferencial obtenido al mercado ampliado debe ser contrabalanceada con la pérdida de competitividad vis a vis el socio comercial más grande.

El carácter no monotónico de las relaciones consignadas en las ecuaciones (16)-(18) obsta la derivación de resultados algebraicos genéricos. Sin embargo, es posible extraer información valiosa de las mismas si se sigue la estrategia a que recurre por la mayor parte de los modelos de la literatura, consistente en la realización de ejercicios de simulación numérica.

Con respecto a esta última cuestión, si se toma el espectro completo de los costos potenciales de comercio intraunión, es dable apreciar que tales costos se relacionan de una manera no monotónica con la atracción localizacional del país pequeño de la unión aduanera. En concreto, existe un intervalo de costos de intercambio comercial intrabloque para los cuales la dispersión aumenta conforme descienden tales costos $\mathrm{y}$, a partir de un cierto valor crítico de los mismos, un intervalo para el cual la relación es inversa. 
Gráficamente, se tiene que si se representa la participación del país central en la producción manufacturera agregada de la unión en el eje de las ordenadas y el nivel de los costos comerciales intraunión en el eje de las abscisas para valores dados de los restantes parámetros del modelo, se obtiene una curva en forma de "U", esto es, en las primeras fases del proceso de integración la concentración en el centro disminuye, pero una vez que los costos de intercambio caen por debajo de cierto nivel, se revierte la tendencia a la dispersión de la producción, de modo que la industria propende a relocalizarse nuevamente hacia el centro de la unión.

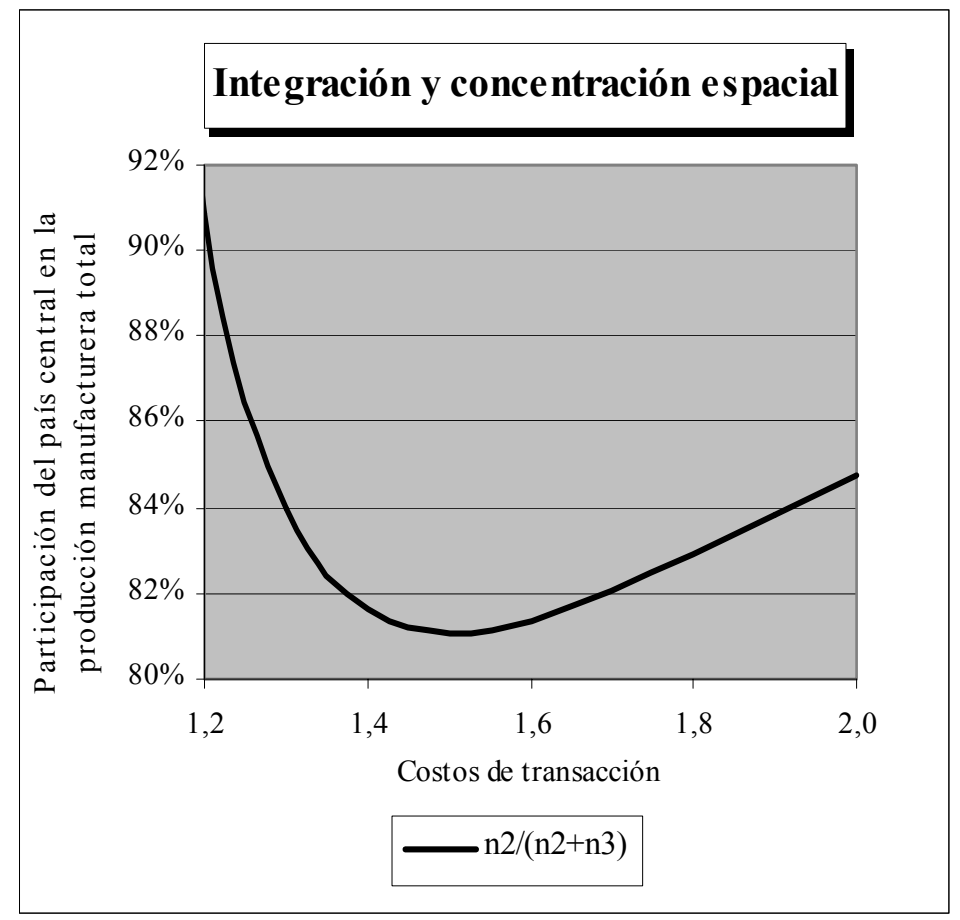

$$
\alpha=0,15 ; \beta=0,20 ; \rho=0,125 ; \sigma=5 ; \gamma=0,6
$$

La intuición económica subyacente a la curva " $U$ " puede explicarse en los siguientes términos:

La integración regional ejerce dos efectos relevantes sobre el país periférico:

- En primer lugar, el país periférico aumenta su atractivo localizacional respecto del resto del mundo, en virtud de que mejora el acceso que posee al mercado combinado de la unión aduanera. 
- En segundo lugar, supradicho país pierde competitividad en relación al país central de la unión aduanera, ya que la baja en los costos del intercambio comercial incrementa las ventajas localizacionales del país que tiene un mercado doméstico de mayores dimensiones.

Claramente, si el resto del mundo es grande y las barreras intraunión son relativamente elevadas, entonces es probable que el primer efecto domine al segundo efecto; como consecuencia, el aumento de la competitividad con referencia al resto del mundo sobrecompensa la pérdida de competitividad con respecto al socio comercial. Luego, conforme se profundiza la integración regional, la relocalización industrial desde el resto del mundo a la unión aduanera determina una caída en el tamaño relativo de la industria en el resto del mundo y un incremento simultáneo en la ventaja competitiva del país central relativa al país periférico. Por lo tanto, existe un punto crítico que define un umbral a partir del cual el segundo efecto prima sobre el primer efecto y, como resultado, el tamaño relativo de la industria periférica se contrae.

En suma, para un amplio rango de valores de los parámetros de economías de escala y costos de intercambio comercial extraunión, la localización de equilibrio de la industria se relaciona no monotónicamente con los costos vinculados al comercio. En un cierto intervalo, la reducción de los costos de comercio intraunión propulsa una mayor dispersión de la producción dentro de la misma. Sin embargo, cuando los costos caen por debajo de cierto valor crítico la disminución de sobredichos costos provoca una mayor concentración geográfica ${ }^{14}$.

Por otra parte, un análisis de estática comparativa en el que se modifique el grado de las economías de escala y se mantengan constantes todas las otras variables permite determinar que la concentración espacial se incrementa con las economías de escala (no existen no

\footnotetext{
${ }^{14}$ La aparición de una curva en forma de U es condicional a determinados valores de los parámetros. En particular, la combinación de tamaños relativos de los países y economías de escala puede ser tal que el cambio en el signo de la pendiente de la curva no tenga lugar en el intervalo relevante de los costos de comercio intraunión positivos que son menores que los costos del comercio extraunión, sino en un punto donde los costos de comerciar son negativos o donde los costos de comerciar con el resto del mundo son inferiores que los costos del intercambio con países miembros de la unión. En tales casos, se tendría que el grado de concentración espacial de la producción crecería o decrecería monotónicamente.

En este sentido, cabe destacar que cuanto mayor es el grado de economías de escala y menores los costos del comercio extraunión, menor es el valor de los costos del intercambio intraunión para el cual se registra el cambio en el signo de la pendiente de la curva.
} 
montonicidades). De esta manera, las industrias con bajo grado de economías de escala propenderán a tener, a igualdad de otras cosas, una configuración geográfica dispersa, en tanto que las industrias caracterizadas por la intensidad de las economías de escala tenderán a estar altamente concentradas en el espacio.

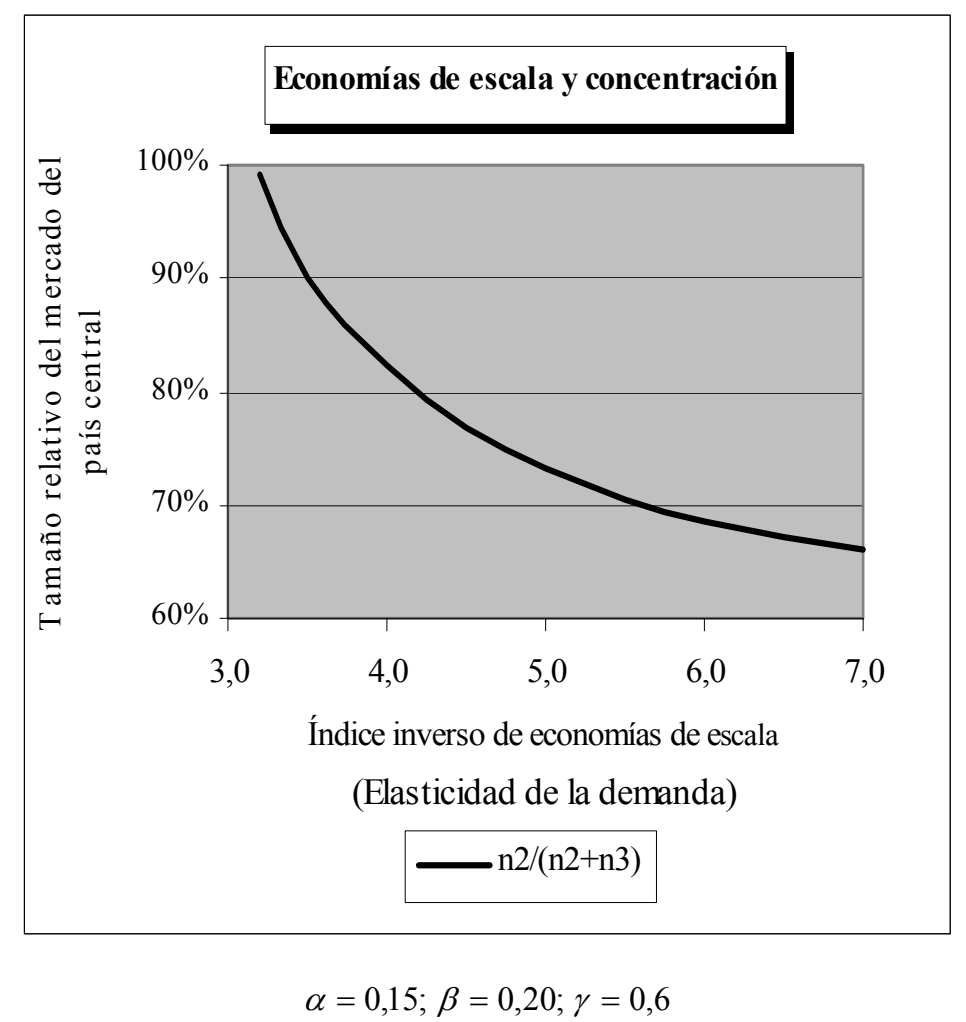

Asimismo, existe una relación monotónica entre localización y tamaño del país. La prevalencia de grandes diferencias en las dimensiones nacionales fortalece la aferencia de las industrias con rendimientos crecientes al centro de la unión.

En definitiva, las industrias con economías de escala significativas son las más localizadas territorialmente. Tal localización se verifica en el país central de las uniones aduaneras. 


\section{3.c. Integración y localización: el punto de vista del comercio exterior}

El fenómeno que los geógrafos económicos denominan "concentración” o "localización” de las industrias es designado por los economistas del comercio internacional como “especialización interindustrial”. El escenario opuesto correspondería a las expresiones de “dispersión localizacional" y "especialización intraindustrial”. Si las propensiones a comerciar de las firmas pertenecientes a industrias particulares son similares entre países, la especialización intraindustrial estará intrínsecamente concatenada con el comercio intraindustrial. En otras palabras, la naturaleza del comercio entre los países puede concebirse como la imagen especular del patrón de especialización productiva de los mismos.

Así, si se inserta el número de firmas radicadas en cada país (13)-(15) en las ecuaciones de demanda (2)-(4), se obtiene la demanda en los flujos bilaterales de comercio:

$$
\begin{aligned}
& D_{12}=\frac{\gamma \cdot \rho \cdot\left(\alpha \cdot\left(\rho^{2}-\delta\right) \cdot(2 \cdot \rho-\delta-1)-(1-\rho) \cdot\left(\beta \cdot\left(2 \cdot \rho^{2}+\rho \cdot(1-\delta)-\delta-1\right)+\rho \cdot(1-\delta)\right)\right.}{(\rho-1) \cdot(\delta-1) \cdot\left(2 \cdot \rho^{2}-\delta-1\right)} \\
& D_{13}=\frac{\gamma \cdot \rho \cdot\left(\alpha \cdot\left(\rho^{3}-\rho^{2} \cdot(\delta+1)-2 \cdot \rho+\delta+1\right)+\beta \cdot\left(\delta-\rho^{2}\right) \cdot(2 \cdot \rho-\delta-1)+\rho \cdot(1-\delta) \cdot(\rho-1)\right)}{(\rho-1) \cdot(1-\delta) \cdot\left(2 \cdot \rho^{2}-\delta-1\right)} \\
& D_{21}=\frac{\gamma \cdot \rho \cdot(\alpha \cdot \rho \cdot(2 \cdot \rho-\delta-1)-\beta \cdot \rho \cdot(2 \cdot \rho-\delta-1)-(\rho-1)(1+\delta))}{(2 \cdot \rho-\delta-1) \cdot\left(2 \cdot \rho^{2}-\delta-1\right)} \\
& D_{22}=\frac{\gamma \cdot \delta \cdot\left(\alpha \cdot\left(\rho^{3}-\rho^{2} \cdot(\delta+1)-2 \cdot \rho+\delta+1\right)+\beta \cdot\left(\delta-\rho^{2}\right) \cdot(2 \cdot \rho-\delta-1)+\rho \cdot(1-\delta) \cdot(\rho-1)\right)}{(1-\delta) \cdot(2 \cdot \rho-\delta-1) \cdot\left(2 \cdot \rho^{2}-\delta-1\right)} \\
& D_{31}=\frac{\gamma \cdot \rho \cdot(\alpha \cdot \rho \cdot(2 \cdot \rho-\delta-1)-\beta \cdot \rho \cdot(2 \cdot \rho-\delta-1)-(\rho-1)(1+\delta))}{(2 \cdot \rho-\delta-1) \cdot\left(2 \cdot \rho^{2}-\delta-1\right)} \\
& D_{32}=\frac{\gamma \cdot \delta \cdot\left(\alpha \cdot\left(\rho^{2}-\delta\right) \cdot(2 \cdot \rho-\delta-1)-(1-\rho) \cdot\left(\beta \cdot\left(2 \cdot \rho^{2}+\rho \cdot(1-\delta)-\delta-1\right)+\rho \cdot(1-\delta)\right)\right.}{(\delta-1) \cdot(2 \cdot \rho-\delta-1) \cdot\left(2 \cdot \rho^{2}-\delta-1\right)}
\end{aligned}
$$

donde $D_{j k}$ es la demanda del país $j$ de productos diferenciados producidos en el país $k$. Las exportaciones netas en la industria $i$ desde el país $j$ al país $k$ en cada bien cuya producción está sujeta a rendimientos crecientes a escala están dadas por $D_{k j}-D_{j k}$. 
El comercio intraindustrial se mide usualmente a través del índice de Grubel-Lloyd $(G L)$, que, en el caso de dos países $j$ y $k$, está dado por:

$$
G L_{j k}=\frac{2 \cdot \min \left(D_{j k}, D_{k j}\right)}{D_{j k}+D_{k j}+T_{y}}
$$

donde $T_{y}$ denota el comercio en la industria $Y$.

Las ecuaciones (22)-(27) determinan las exportaciones netas multilaterales de cada país en el bien producido bajo condiciones de rendimientos crecientes. A su vez, las exportaciones de los bienes elaborados bajo condiciones de rendimientos constantes a escala en el comercio bilateral se obtienen residualmente por la condición de equilibrio comercial multilateral.

La extracción de conclusiones generales a partir de las ecuaciones precedentes resulta sumamente difícil. No obstante, una serie de ejemplos numéricos pueden ser sumamente esclarecedores de las tendencias preponderantes en los distintos escenarios alternativos. Específicamente, se halla que la proporción de comercio intraindustrial mantiene una relación no monotónica con los costos de transacción intrazona: inicialmente aumenta y ulteriormente disminuye (ver tabla).

\begin{tabular}{|c|c|}
\hline \multicolumn{2}{|c|}{ Comercio intraindustrial entre los países integrantes de la unión aduanera } \\
\hline $\mathcal{S}$ & $C I I$ \\
\hline 2,0 & $25,2 \%$ \\
\hline 1,9 & $38,4 \%$ \\
\hline 1,7 & $51,7 \%$ \\
\hline 1,5 & $36,2 \%$ \\
\hline Fuente: Torstensson (1995). & \\
\hline
\end{tabular}

Tal resultado es perfectamente previsible. Conforme se ha mencionado anteriormente, bajo ciertas condiciones, la dispersión industrial mantiene una relación constante con el comercio intraindustrial. Por ende, cabe esperar que la curva en forma de "U" que vincula 
los costos del comercio intraunión y la localización industrial también rija para la ligazón entre tales costos y el comercio intraindustrial.

La razón es sencilla. La especialización interindustrial se encuentra determinada por el tamaño de mercado. Por lo tanto, los países miembros de la unión aduanera expanden inicialmente su producción del bien elaborado bajo condiciones de rendimientos crecientes a escala, dado que ambos ganan competitividad con relación al resto del mundo. De este modo, las estructuras productivas de los mismos devienen más semejantes y la disminución de los costos de transacción induce un aumento de la demanda de los bienes producidos en el otro país. Conforme se profundiza la integración, se verifica un proceso de creciente especialización en el seno de la unión, en virtud de que se torna posible relocalizar al menos parte de las producciones sujetas a rendimientos crecientes a escala al país más grande del bloque. Como consecuencia, las estructuras productivas tienden a divergir y la proporción del comercio intraindustrial a disminuir ${ }^{15}$.

Concretamente, para un amplio rango de valores de los parámetros de economías de escala y costos de comercio extraunión, el nivel del comercio intraindustrial entre los países componentes de la unión aduanera se relaciona no monotónicamente con los costos del intercambio comercial intraunión. Bajo tales configuraciones, el comercio intraindustrial de equilibrio aumenta en las primeras etapas del proceso de integración, pero decrece en las fases ulteriores, cuando los costos de comerciar en el seno de la unión se ubican por debajo de cierto nivel.

Adicionalmente, el hecho de que la dispersión industrial presente una relación positiva constante con el comercio intraindustrial permite colegir la existencia de una relación negativa entre el grado de economías de escala y el nivel relativo de comercio intraindustrial.

\footnotetext{
${ }^{15}$ Los efectos de la integración regional sobre la magnitud relativa del comercio intraindustrial depende del tamaño de los países que componen la unión aduanera respecto del resto del mundo. Cuando los países que conforman la mencionada unión son grandes en relación al resto del mundo, las estructuras productivas de los mismos propenden a a diferenciarse incluso desde las primeras etapas del proceso de integración. Por el contrario, cuando los países que constituyen la unión aduanera son reducidos en parangonación con el resto del mundo, podría acaecer que el país pequeño de la misma se especialice en la producción del bien que involucra rendimientos crecientes a escala en fases avanzadas del proceso de integración, ya que en este caso la competencia existente en el seno de la unión no es significativa. Por ende, se asistiría a una creciente convergencia de las estructuras productivas y a aumentos adicionales en la proporción del comercio
} 
Por lo tanto, ceteris paribus, el grado de economías de escala se relaciona negativamente con el comercio intraindustrial que tiene lugar dentro del bloque comercial.

\section{3.d. Integración económica y regiones}

El modelo desarrollado por Torstensson (1995) y Brülhart y Torstensson (1996) puede adaptarse con el designio de estudiar los efectos que el proceso de integración ejerce sobre las economías regionales de cada uno de los países que participan del mismo. En particular, resulta interesante determinar los cambios que dicho proceso ocasiona sobre el patrón localizacional de la economía de menor tamaño de la unión aduanera, que, según se apuntó precedentemente, correspondería al papel desempeñado por Argentina en el Mercosur.

Supóngase que la economía pequeña reproduce domésticamente la asimetría dimensional del bloque comercial que se constituye, de manera que se compone de dos regiones: una región central con una dotación laboral $\alpha_{c}$ y una región periférica o hinterland que cuenta con una fuerza de trabajo de $\alpha_{h}$. Las dotaciones son tales que $\alpha_{c}>\alpha_{h}$ y $\alpha_{c}+\alpha_{h}=\alpha$.

Por otro lado, tal como se había asumido originalmente, el número de trabajadores del socio comercial asciende a $\beta$. Además, se preserva la estructura bisectorial de la industria.

Ahora bien, a fin de evitar una excesiva complejización del modelo, es conveniente realizar algunos supuestos simplificativos. Por una parte, con respecto a los costos de transacción, se asume que los intercambios comerciales bilaterales de ambas regiones del país pequeño con el socio de la unión aduanera enfrentan un obstáculo común, que, como en el modelo primigenio, está dado por $\varsigma>1$. El supuesto implica enfatizar el influjo de las consideraciones de tamaño de mercado y los niveles arancelarios sobre la dinámica espacial de la actividad manufacturera y preterir la incidencia de las diferencias entre las regiones del país ligadas a la distancia geográfica respecto del otro país. Asimismo, se asume que el traslado de bienes industriales entre las regiones del país insume recursos, de manera que por cada unidad de producto remitida sólo arriba al sitio de destino una fracción $1 / v,(v>1)$.

intraindustrial. La importancia relativa de Brasil en el comercio exterior argentino tornaría exiguamente probable dicha posibilidad en el caso de nuestro país. 
Naturalmente, la pérdida de recursos provocada por el transporte de bienes dentro del mismo país, que puede interpretarse como los costos de transporte propiamente dichos, es significativamente menor que la pérdida correspondiente al intercambio entre países, es decir, $\varsigma\rangle\rangle v$.

\begin{tabular}{|c|c|c|c|}
\hline \multicolumn{4}{|c|}{ Costos de transacción } \\
\hline Pais/región & $\mathbf{2}$ & C & h \\
\hline $\mathbf{2}$ & - & $\varsigma$ & $\varsigma$ \\
\hline $\mathbf{c}$ & $\varsigma$ & - & $v$ \\
\hline $\mathbf{h}$ & $\varsigma$ & $v$ & - \\
\hline
\end{tabular}

Por otra parte, dado que el objetivo del trabajo consiste en examinar los efectos espaciales de la integración regional, se omiten las repercusiones que el intercambio con el resto del mundo podría traer aparejadas sobre la configuración geográfica interna de la actividad económica en el país pequeño de la unión aduanera.

Por último, resulta menester resaltar que se mantiene el tipo de preferencia de los consumidores.

A partir de los supuestos precedentes y procediendo análogamente a Torstensson (1995) y Brülhart y Torstensson (1996), se obtienen las expresiones que se consignan a continuación para el número de firmas radicadas en cada localización ${ }^{16}$ :

(28) $\quad n_{2}=\frac{\gamma \cdot\left[\beta \cdot(1+\theta) \cdot(1-\delta)-\left(\alpha_{c}+\alpha_{h}\right) \cdot \delta \cdot(1+\theta-2 \cdot \delta)\right]}{x \cdot(1-\delta) \cdot(1+\theta-2 \cdot \delta)}$

(29) $\quad n_{c}=\frac{\gamma \cdot\left\{\left[\alpha_{c} \cdot\left(1-\delta^{2}\right)+\alpha_{h} \cdot\left(\delta^{2}-\theta\right)\right] \cdot(1+\theta-2 \cdot \delta)-\beta \cdot \delta \cdot(1-\theta) \cdot(1-\delta)\right\}}{x \cdot(1-\delta) \cdot(1-\theta) \cdot(1+\theta-2 \cdot \delta)}$

(30) $\quad n_{h}=\frac{\gamma \cdot\left\{\left[\alpha_{h} \cdot\left(1-\delta^{2}\right)+\alpha_{c} \cdot\left(\delta^{2}-\theta\right)\right] \cdot(1+\theta-2 \cdot \delta)-\beta \cdot \delta \cdot(1-\theta) \cdot(1-\delta)\right\}}{x .(1-\delta) \cdot(1-\theta) \cdot(1+\theta-2 . \delta)}$

16 Del mismo modo que Torstensson (1995) y Brülhart y Torstensson (1996), se supone que $w=p=1$ y que $\theta=v^{1-\sigma}\left\langle 1 \quad y \quad \delta=\varsigma^{1-\sigma}\langle 1\right.$, 
Supóngase ahora que principia un proceso de integración entre los países 2 y 3 , que asume la forma de un aumento en $\delta$. Como consecuencia, se verifican los siguientes efectos sobre las economías regionales del último de los mismos:

$$
\begin{aligned}
\text { (31) } \frac{\partial n_{c}}{\partial \delta}= & \frac{\gamma \cdot\left\{\left[(-2 .) \cdot\left(\alpha_{c}-\alpha_{h}\right) \cdot(1+\theta-2 \cdot \delta)+(-2) \cdot\left(\alpha_{c} \cdot\left(1-\delta^{2}\right)+\alpha_{h} \cdot\left(\delta^{2}-\theta\right)\right)+\beta \cdot(1-\theta) \cdot(2 \cdot \delta-1)\right][x \cdot(1-\delta) \cdot(1-\theta) \cdot(1+\theta-2 \cdot \delta)]\right\}}{[x \cdot(1-\delta)(1-\theta)(1+\theta-2 \cdot \delta)]^{2}}+ \\
& +\frac{\gamma \cdot\left\{\left[\left(\alpha_{c} \cdot\left(1-\delta^{2}\right)+\alpha_{h} \cdot\left(\delta^{2}-\theta\right)\right) \cdot(1+\theta-2 \cdot \delta)-\beta \cdot \delta \cdot(1-\theta) \cdot(1-\delta)\right] \cdot[(-1) \cdot x \cdot(1-\theta) \cdot(\theta+3)]\right\}}{[x \cdot(1-\delta) \cdot(1-\theta) \cdot(1+\theta-2 \cdot \delta)]^{2}} \\
\text { (32) } \frac{\partial n_{h}}{\partial \delta} & =\frac{\gamma \cdot\left\{[(-2)) \cdot\left(\alpha_{h}-\alpha_{c}\right) \cdot(1+\theta-2 \cdot \delta)+(-2) \cdot\left(\alpha_{h} \cdot\left(1-\delta^{2}\right)+\alpha_{c} \cdot\left(\delta^{2}-\theta\right)\right)+\beta \cdot(1-\theta) \cdot(2 \cdot \delta-1)\right][[x \cdot(1-\delta) \cdot(1-\theta) \cdot(1+\theta-2 \cdot \delta)]\}^{2}}{[x \cdot(1-\delta)(1-\theta)(1+\theta-2 \cdot \delta)]^{2}}+ \\
& +\frac{\gamma \cdot\left\{\left[\left(\alpha_{h} \cdot\left(1-\delta^{2}\right)+\alpha_{c} \cdot\left(\delta^{2}-\theta\right)\right) \cdot(1+\theta-2 \cdot \delta)-\beta \cdot \delta \cdot(1-\theta) \cdot(1-\delta)\right] \cdot[(-1) \cdot x \cdot(1-\theta) \cdot(\theta+3)]\right\}}{[x \cdot(1-\delta) \cdot(1-\theta) \cdot(1+\theta-2 \cdot \delta)]^{2}}
\end{aligned}
$$

Las expresiones precedentes son sumamente complexas e impiden derivar educciones unívocas. Una forma más simple de apreciar las consecuencias de la integración regional consiste en suponer que la misma es completa, de modo que se registra una igualación en los obstáculos que enfrentan los flujos comerciales interregionales, de manera que $\delta=\theta$. En tal caso, se comprueba que:

(33) $n_{c}=\frac{\gamma \cdot\left[\alpha_{c}+\theta \cdot\left(\alpha_{c}-\alpha_{h}-\beta\right)\right]}{x \cdot(1-\theta)}$

(34) $n_{h}=\frac{\gamma \cdot\left[\alpha_{h}+\theta \cdot\left(\alpha_{h}-\alpha_{c}-\beta\right)\right]}{x \cdot(1-\theta)}$

Luego, se puede calcular la diferencia en la cantidad de firmas de cada región en la situación previa a la integración (ni) y la misma diferencia bajo condiciones de integración plena (ip).

(35) $\quad\left(n_{c}-n_{h}\right)_{n i}=\frac{\gamma \cdot\left(\alpha_{c}-\alpha_{h}\right) \cdot\left(1+\theta-2 \cdot \delta^{2}\right)}{x \cdot(1-\delta) \cdot(1-\theta)}$

(36) $\left(n_{c}-n_{h}\right)_{i p}=\frac{\gamma \cdot\left(\alpha_{c}-\alpha_{h}\right) \cdot(1+2 \cdot \theta)}{x \cdot(1-\theta)}$ 
Finalmente, la diferencia entre las expresiones precedentes permite determinar si la constitución de una unión aduanera conduce a un aumento o una disminución en el grado de concentración espacial de la actividad manufacturera en el país pequeño de la misma. Naturalmente, si la resta arroja un resultado positivo, es posible aseverar que la integración contribuye a reforzar la aglomeración en la región central del país bajo consideración.

(37) $\left[\left(n_{c}-n_{h}\right)_{i p}-\left(n_{c}-n_{h}\right)_{n i}\right]=\frac{2 \cdot \gamma \cdot\left(\alpha_{c}-\alpha_{h}\right) \cdot\left[\theta \cdot(1-\delta)-\delta \cdot\left(\frac{1}{2}-\delta\right)\right]}{x \cdot(1-\theta) \cdot(1-\delta)}>0$

Por consiguiente, la integración regional tiende a desencadenar fuerzas centripetas en el seno de la economía de menor tamaño de la unión.

Las implicancias del cambio en la política comercial pueden analizarse alternativamente a través de una simulación numérica similar a los ejercicios efectuados por Torstensson (1995) y Brülhart y Torstensson (1996). Antedicha simulación conduce a un resultado enteramente consistente con los hallazgos anteriores ${ }^{17}$.

\footnotetext{
${ }^{17}$ El grado de concentración inicial en la región central, que figura en el gráfico, $76 \%$, es aproximadamente igual a la participación conjunta de las provincias de Buenos Aires, Santa Fé, Córdoba y la Capital Federal en el empleo manufacturero total del país en 1994.
} 


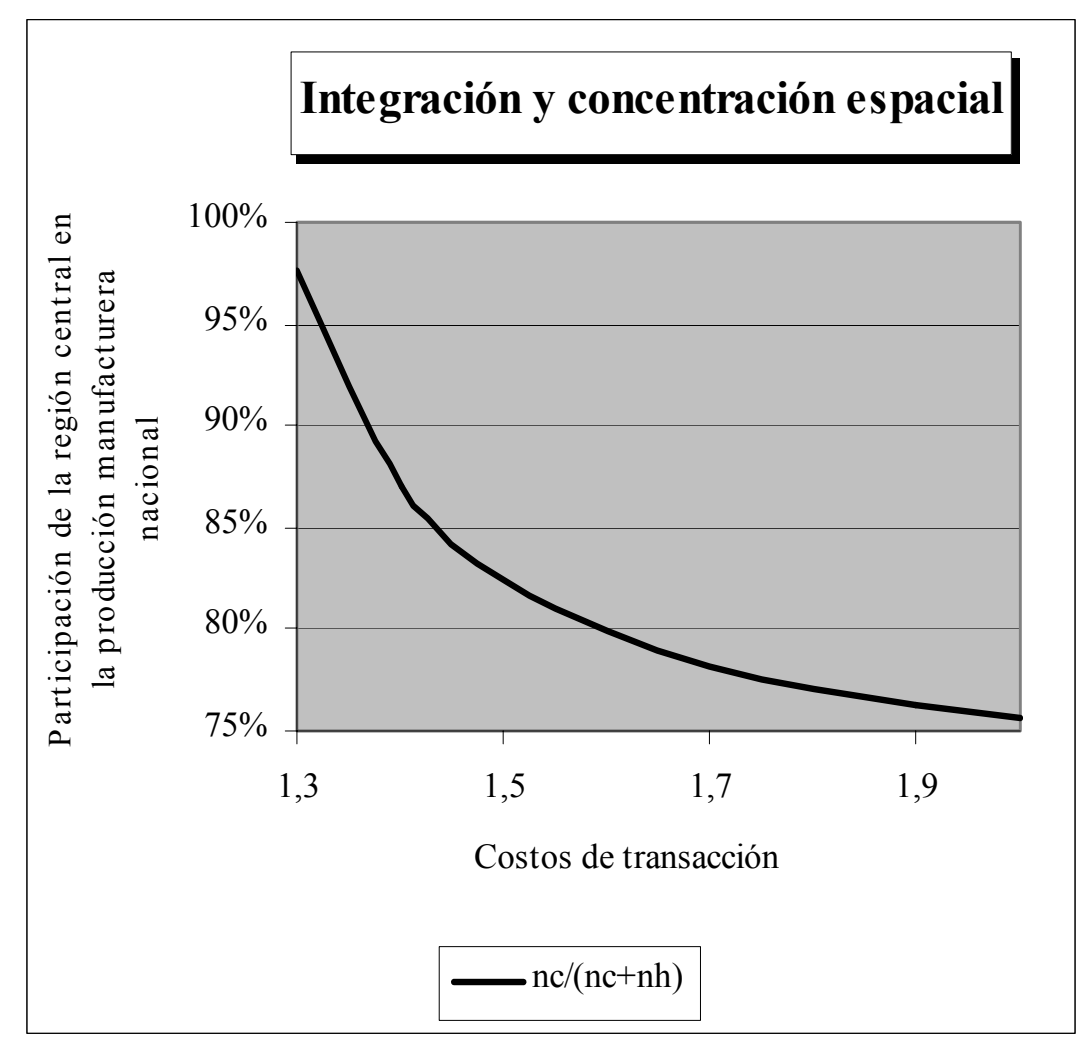

$$
\alpha_{c}=0,08 ; \alpha_{h}=0,07 ; \beta=0,20 ; \theta=0,7 ; \sigma=5 ; \gamma=0,6
$$

Resulta obvio que los desarrollo espaciales individualizados dependen de los supuestos que se formulen en relación a la relevancia de las economías de escala en la industria. Conforme se desprende de los gráficos que se incluyen seguidamente y tal como cabría esperar, la propensión a la aglomeración asociada a la integración es una función creciente de la intensidad de los rendimientos crecientes. En otras palabras, cuanto menor es la misma y, en consecuencia, mayor es la elasticidad de la demanda, menor será el efecto positivo ejercido sobre el grado de concentración espacial de la actividad manufacturera. De esta manera, es agible que la integración engendre repercusiones disímiles entre las distintas ramas industriales, dadas sus diferencias en términos de la importancia relativa de las economías de escala. 


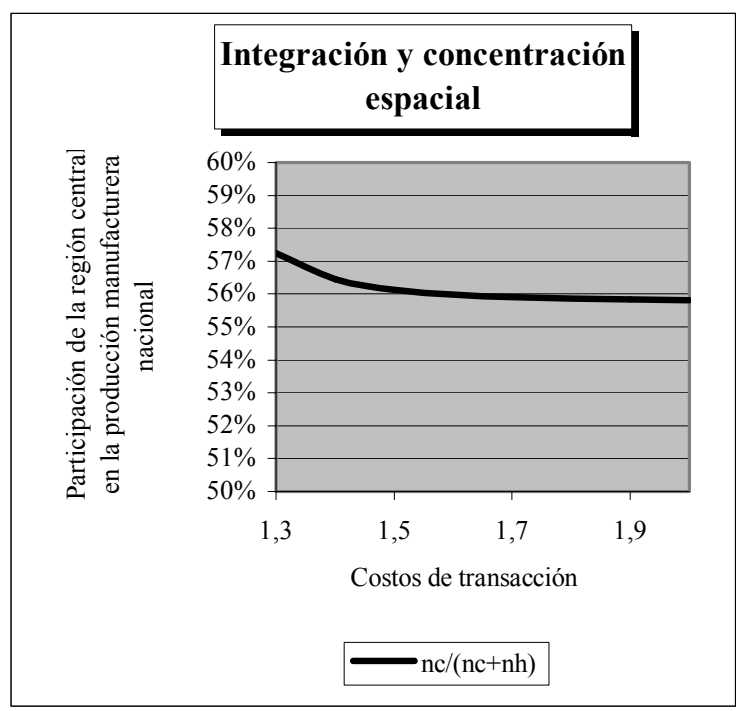

Economías de escala intermedias

$(\sigma=10)$

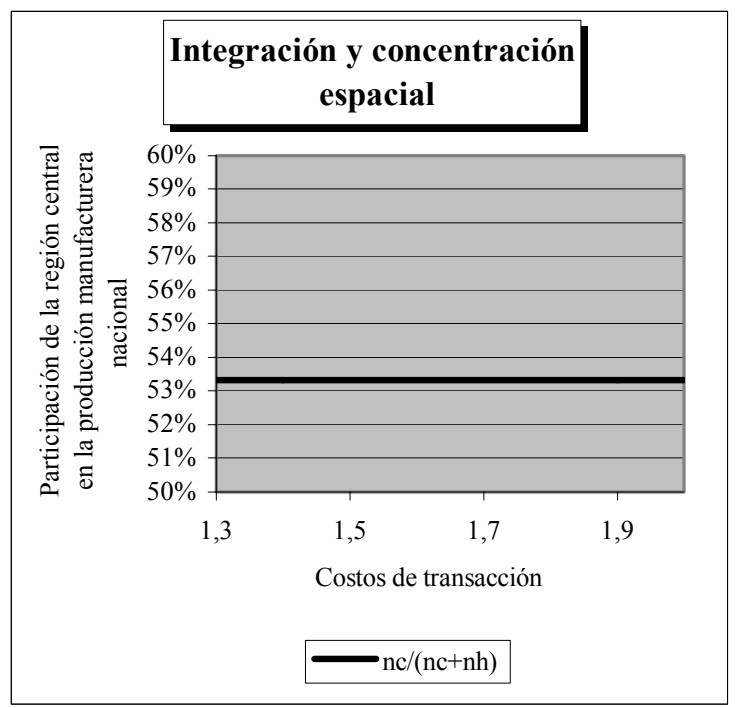

Economías de escala reducidas

$(\sigma=100)$

\section{Evidencia internacional}

Las construcciones teóricas de la nueva geografía económica explican los impactos espaciales de los acuerdos preferenciales de comercio. Sin lugar a dudas, la Unión Europea y el Nafta son los acuerdos más importantes entre los que se han notificado ante la OMC bajo el artículo XXIV. Por tal razón, no debería extrañar que la mayor parte de los trabajos empíricos versen sobre dichas regiones. La presente sección apunta entonces a repasar los principales hallazgos de tales trabajos y evaluar el grado de compatibilidad de los mismos con los resultados que surgen de la teoría.

Las consideraciones precedentes no implican en modo alguno la inexistencia total de análisis en el ámbito del Mercosur. Diversos investigadores han comenzado a examinar los efectos geográficos de su puesta en marcha sobre el principal socio del bloque. Precisamente, en la última parte de la sección, se reportan las conclusiones más relevantes de supradichos estudios. 


\section{4.a. La integración económica norteamericana y el Nafta}

La economía mexicana principió su proceso de industrialización en la década de 1930. El mismo asumió la forma de una sustitución de importaciones fáctica inducida por la elevación de las barreras comerciales y la Gran Depresión en Estados Unidos y posteriormente se convirtió en un proceso de derecho cuando el gobierno dispuso el aumento de los aranceles a la importación, adoptó un sistema de licencias de compras externas e impuso controles a la exportación con el designio de promover la industria doméstica.

Antedicha industrialización se centró en la ciudad de México, que hasta la década anterior seguía constituyendo el principal emplazamiento industrial del país. La participación de la ciudad capital en el empleo industrial total creció de 19\% en 1930 a 46\% en 1960. En otros términos, a lo largo de los tres decenios en cuestión, la ocupación manufacturera en dicha ciudad aumentó a una tasa anual promedio de 4,3 puntos porcentuales superior a la tasa del resto de la economía.

A partir de la década de 1980 la actividad industrial comenzó a desplazarse hacia los estados localizados cerca de la frontera con Estados Unidos y la importancia relativa de la ciudad capital disminuyó notablemente. En concreto, entre 1980 y 1993, la participación de la ciudad de México en el empleo manufacturero total cayó de 44,4\% a 28,7\%, en tanto que la participación correspondiente a los estados fronterizos con Estados Unidos creció de $21,0 \%$ a 29,8\%. Por lo tanto, los nuevos centros industriales de México se sitúan en las ciudades del norte como Juárez, Monterrey y Tijuana.

Tales desarrollos coincidieron temporalmente con la apertura de la economía mexicana al comercio internacional y la inversión extranjera. En efecto, en 1985 el gobierno mexicano decidió finalizar la política sustitutiva de importaciones y anunció su adhesión a la normativa del GATT. Consecuentemente, las licencias de importación, que afectaban el $92,2 \%$ de la producción nacional, redujeron su grado de cobertura al $25,4 \%$, el arancel promedio disminuyó de $23,5 \%$ a $11,8 \%$ y se anularon los controles a la exportación aplicados sobre el $85 \%$ de las ventas externas que no fueran petróleo hacia fines de 1987 . 
La profundización de las relaciones comerciales de México con Estados Unidos, iniciada con la apertura de 1985 y la ulterior firma del Nafta en 1993, constituye un caso de estudio natural para los efectos localizaciones de los procesos de integración económica. Gordon Hanson realizó un análisis de dicha experiencia e identificó un conjunto de hechos estilizados ${ }^{18}$.

- Hanson (1998) procura individualizar los distintos efectos de la apertura sobre la localización industrial en México. A tal efecto, estima el crecimiento del empleo a nivel estatal en industrias particulares para los períodos 1980-1985 y 1985-1993 como una función de los siguientes factores: (1) la distancia con referencia a la frontera norteamericana, en calidad de proxy de los costos de acceso a los mercados externos; (2) la concentración regional inicial de las industrias upstream y downstream, que captura los efectos de los eslabonamientos hacia adelante y hacia atrás; y (3) la concentración regional inicial de la actividad en la propia industria, que aprehende los efectos de aglomeración internos a la misma. Los resultados obtenidos por Hanson indican que el acceso a los mercados internacionales incide en la localización industrial; efectivamente, con anterioridad a la apertura, existía una correlación nula entre el crecimiento del empleo industrial regional y la distancia respecto de Estados Unidos, pero la misma deviene fuertemente negativa luego de la liberalización del comercio. Asimismo, halla una correlación positiva significativa entre el crecimiento del empleo industrial regional y la concentración inicial de la actividad en las industrias upstream y downstream, lo cual es consistente con la presencia de eslabonamientos hacia adelante y hacia atrás en el crecimiento económico, es decir, una industria tiende a crecer con mayor celeridad cuando se sitúa próxima a sus compradores y oferentes. Finalmente, el análisis de Hanson no encontró evidencia respaldatoria de la existencia de economías de aglomeración dentro de la industria. Los hallazgos antes consignados implican

\footnotetext{
${ }^{18}$ En Canadá la actividad industrial ha estado históricamente concentrada. La campana industrial del país parece una extensión de la campana industrial norteamericana. Ontario, que se encuentra yuxtapuesta a las mayores regiones industriales norteamericanas del noreste, explicó casi la mitad del empleo industrial de Canadá durante gran parte de la centuria. A diferencia de Estados Unidos y México, la distribución geográfica de la actividad industrial ha sido estable en el tiempo. Otrosí, el hecho de que los lazos comerciales entre Estados Unidos y Canadá hayan precedido el acuerdo de libre comercio suscripto en 1989 y que consiguientemente lo mismo sucediera con el efecto gravitatorio ejercido por el mercado norteamericano sobre la industria canadiense determina que sea particularmente complejo identificar el impacto del acuerdo
} 
adicionalmente en conjunto que la relocalización de la industria ha sido concomitada por una demudación en la composición en los centros industriales. La importancia de los eslabonamientos y la ausencia de economías de aglomeración internas a la industria se corresponde con la sustitución de las densas concentraciones industriales circundantes a la ciudad de México por centros industriales regionales ampliamente especializados.

- La nueva teoría de la localización tiene dos importantes implicancias respecto de la estructura regional de los salarios. En primer lugar, los salarios nominales son relativamente bajos en las regiones que enfrentan elevados costos de transporte respecto de los principales mercados, en este caso, la ciudad de México y Estados Unidos. En segundo lugar, el proceso de apertura comercial, que se asocia a una expansión de la demanda norteamericana de los bienes mexicanos, debilita el efecto gravitatorio ejercido por el centro industrial de economía cerrada, la ciudad de México, y entesa el influjo de los centros ligados al mercado estadounidense. Hanson $(1996,1997)$ halla que la evidencia empírica cohonesta tales resultados derivados de la teoría. Efectivamente, el autor determina, por un lado, que en el período comprendido entre 1965-1988, la ciudad de México registraba los salarios más altos, los estados fronterizos con Estados Unidos y los estados centrales se ubicaban en el segundo escalón y los estados sureños se encontraban muy por debajo en la escala salarial, y por otro lado, que el efecto de la distancia con referencia a la ciudad de México sobre el nivel de los salarios industriales de los estados se redujo ostensiblemente luego de la liberalización del comercio $^{19}$.

sobre la localización industrial, de modo que no debería extrañar la virtual inexistencia de trabajos que estudien el tema.

${ }^{19}$ Tales resultados surgen del testeo econométrico de un modelo de "redes productivas regionales" planteado por el mismo autor (Hanson, 1994), que se funda en la observación de Grunwald y Flamm (1985), conforme a la cual la expansión del comercio internacional parecería estar asociada a una desverticalización de las industrias intensivas en la utilización del factor trabajo en los países en desarrollo y la concentración de las mismas en el desarrollo de actividades de ensamblaje para firmas foráneas. El modelo de Hanson supone un país pequeño y una industria que consta de dos etapas de producción: el diseño, que tiene economías externas específicas a la localización, y el ensamblaje, que posee rendimientos constantes a escala. Las economías de localización se originan endógenamente en virtud de que el diseño, que es intensivo en el empleo de mano de obra calificada, involucra diversos servicios subsidiarios especializados, cada uno de los cuales opera bajo condiciones de rendimientos crecientes a escala. La aglomeración en el centro industrial del país posibilita a las firmas compartir las capacidades de diseño y expandir el rango de servicios disponibles. Por lo tanto, en una economía pequeña cerrada existe una propensión natural a la concentración espacial. No obstante, la aglomeración impele al alza los salarios en dicha localización y, en consecuencia, tiende a impulsar el 
- Hanson (1996) muestra asimismo que la integración mexicana norteamericana está contribuyendo a la expansión de la economía fronteriza estadounidense. Concretamente, existe una relación positiva y significativa desde el punto de vista estadístico entre las actividades manufactureras exportadoras en las ciudades fronterizas mexicanas y el empleo manufacturero en las ciudades fronterizas norteamericanas ${ }^{20}$.

\begin{tabular}{|c|c|c|c|c|c|}
\hline \multicolumn{6}{|c|}{$\begin{array}{c}\text { Crecimiento del empleo industrial promedio anual en los estados } \\
y \text { ciudades limitrofes en el período } 1970-1992\end{array}$} \\
\hline \multirow[t]{2}{*}{ Industria } & \multirow[t]{2}{*}{ Estados Unidos } & \multicolumn{2}{|r|}{ California } & \multicolumn{2}{|r|}{ Texas } \\
\hline & & Estado & Ciudades fronterizas & Estado & Ciudades fronterizas \\
\hline Privada, no agrícola & 0,02100 & 0,03010 & 0,04710 & 0,03190 & 0,03840 \\
\hline Manufacturas & $-0,00410$ & 0,00650 & 0,02670 & 0,01180 & 0,03380 \\
\hline Transporte & 0,03190 & 0,01600 & 0,03180 & 0,02710 & 0,02930 \\
\hline Comercio Mayorista & 0,02110 & 0,02970 & 0,05070 & 0,02500 & 0,03010 \\
\hline Comercio Minorista & 0,02340 & 0,02870 & 0,04180 & 0,03170 & 0,03850 \\
\hline Finanzas y Seguros & 0,02540 & 0,03060 & 0,04540 & 0,03600 & 0,03490 \\
\hline Servicios & 0,03890 & 0,04720 & 0,06240 & 0,04650 & 0,04940 \\
\hline $\begin{array}{l}\text { Nota: El crecimiento } \\
\text { dígito. Ciudades front } \\
\text { Laredo, Mc Allen y B } \\
\text { Fuente: Hanson, Gord }\end{array}$ & $\begin{array}{l}\text { del empleo es el ca } \\
\text { rizas de California: } \\
\text { ownsville. } \\
\text { on (1996). }\end{array}$ & $\begin{array}{l}\text { mbio en } \\
\text { San Die }\end{array}$ & $\begin{array}{l}\text { logaritmo del empleo } \\
\text { e Imperial County. Ciuc }\end{array}$ & $\begin{array}{l}\text { omedio an } \\
\text { des fronte }\end{array}$ & $\begin{array}{l}\text { ual de industrias de un } \\
\text { izas de Texas: El Paso, }\end{array}$ \\
\hline
\end{tabular}

desplazamiento de la actividad de ensamblaje hacia las regiones periféricas. Si el país pequeño abre su economía y, en particular, liberaliza su comercio con un país grande, el mismo induce la formación de una red productiva regional a escala internacional; en efecto, el país grande, merced a su propia dimensión, captura el centro industrial donde tiene lugar las operaciones de diseño, en tanto que el país pequeño se especializa en el ensamblaje. Los datos de México son totalmente consistentes con la descripción estilizada anterior. Así, las actividades de ensamble localizadas en el norte del país son la porción mexicana de la red que reconoce su centro en Estados Unidos.

${ }^{20}$ La relación apuntada se registra paralelamente a un proceso secular de desplazamiento del locus de la actividad económica estadounidense hacia el sur y hacia el oeste; en efecto, el crecimiento del empleo relativo al crecimiento de la nación como un todo ha sido fuertemente negativo en los estados del noreste y mediooeste, tales como Massachusetts, Michigan, Nueva York y Pennsylvania, y fuertemente positivo en los estados del sur y el oeste, como California, Florida, Georgia y Texas. De esta forma, se ha verificado una declinación de los centros industriales tradicionales como Cleveland, Detroit y Pittsburgh y la eclosión de nuevos centros como Atlanta, Los Angeles y San Jose. No obstante, debe tenerse en cuenta que, pese a tal proceso, la actividad económica permanece altamente concentrada en Estados Unidos. A este respecto, resulta suficiente notar que en 1990 los 100 condados económicamente más activos explicaban el 41,2\% del empleo industrial, pero sólo el $1,5 \%$ de la superficie territorial. 
La tabla presenta el crecimiento del empleo por industria de un dígito para los estados de California y Texas y para las ciudades fronterizas localizadas en ambos estados ${ }^{21}$. Las ciudades limítrofes estadounidenses han experimentado un crecimiento rápido del nivel de empleo en el transcurso de los dos últimos decenios. En particular, la manufactura ha sido la industria de crecimiento más rápido en dichas ciudades, si el mismo se mide en relación al crecimiento registrado en los respectivos estados y la economía nacional en su conjunto.

En el transcurso del período 1970-1992, el crecimiento del empleo manufacturero anual promedio fue de $2,7 \%$ en las ciudades limítrofes de California y de 3,4\% en las ciudades fronterizas de Texas en comparación con una tasa de $0,7 \%$ en el estado de California, una tasa de $1,2 \%$ en el estado de Texas y una tasa de $-0,4 \%$ en la nación en su conjunto.

El patrón espacial de la industria manufacturera de Estados Unidos en las ciudades lindantes a México refleja la naturaleza intraindustrial del comercio bilateral entre ambos países: las ciudades fronterizas norteamericanas se especializan en las industrias productoras de partes y componentes para las plantas ensambladoras mexicanas. El Nafta importa una reducción adicional de las barreras comerciales; por consiguiente, es probable que sobredicho acuerdo esté contribuyendo al crecimiento de los centros de producción binacionales que se están erigiendo a lo largo de la frontera mexicananorteamericana. En la medida en que las operaciones de ensamble continúen relocalizándose desde Estados Unidos a México, proseguirá el desplazamiento geográfico de actividades industriales complementarias desde el interior del primero de tales países a las ciudades fronterizas del mismo ${ }^{22}$.

\footnotetext{
${ }^{21}$ La clasificación usada corresponde a la Oficina de Análisis Económico -OAE- de Estados Unidos.

${ }^{22}$ Los hallazgos de Hanson son compatibles con un escenario donde prevalecen los elementos resaltados por los modelos de la nueva geografía económica: los rendimientos crecientes y el acceso a los mercados son relevantes para la localización y los salarios son mayores en las aglomeraciones económicas. No obstante, tales resultados no pueden visualizarse como un test riguroso de explicaciones teóricas alternativas, dado que la principal limitación es que en los procedimientos usados para su derivación no se ha controlado por las dotaciones específicas de las regiones y los requerimientos de recursos específicos de la industria (Brülhart, 1998).
} 


\section{Resumiendo}

La apertura de la economía mexicana al comercio internacional ha inducido una modificación significativa en la configuración geográfica de la actividad manufacturera. El centro de gravedad de la misma ha tendido a desplazarse hacia el norte, merced al mayor poder de determinación espacial adquirido por el mercado norteamericano. Dicho fenómeno se manifiesta claramente en la ligazón negativa entre el crecimiento del empleo industrial de cada estado mexicano y su respectiva distancia con referencia a Estados Unidos, la relación negativa entre el nivel de los salarios predominantes en cada estado y sobredicha distancia y la marcada disminución de la incidencia de la lejanía a la ciudad de México sobre el nivel salarial estadual. Asimismo, se ha verificado una transmutación en la naturaleza de los centros industriales; en particular, han emergido focos industriales regionales con un espectro de especialización amplio. Ello se desprende del efecto positivo de la aglomeración inicial de la actividad en las industrias upstream y downstream y el efecto nulo de la concentración espacial de la actividad en la propia industria sobre el crecimiento del empleo estadual. Por último, la profundización de la integración entre México y Estados Unidos parece favorecer la expansión industrial de las ciudades fronterizas del último país.

\section{4.b. Unión Europea ${ }^{23}$}

\section{4.b.1. Localización industrial y economías de escala}

A efectos de identificar el grado de concentración espacial de los sectores industriales de la Unión Europea, Brülhart y Torstensson (1996) estimaron los "índices de Gini localizacionales" $\left(G_{i}\right)$, que miden la estructura locacional del empleo industrial. La variable de referencia es entonces la participación $(L)$ de un país $(j, k, \ldots)$ en el empleo total de una cierta industria $i$ y la fórmula utilizada es la siguiente:

\footnotetext{
${ }^{23}$ La presente subsección reseña los principales resultados que obtienen Brülhart y Torstensson (1996). Resulta menester aclarar que tales resultados deben considerarse como indicativos antes que concluyentes, dadas la pluralidad de restricciones estadísticas que han debido enfrentar los autores.
} 
$G_{i}=\frac{1}{2 \cdot n^{2} \cdot \overline{L_{i}}} \cdot \sum_{j} \sum_{k}\left|L_{j}-L_{k}\right|$

donde $n$ es la cantidad total de industrias y $\bar{L}_{i}$ es la participación nacional media en el empleo de la industria.

Tales índices pueden tomar valores comprendidos entre 0 y 1 . Un índice de Gini elevado implica un alto grado de especialización interindustrial; por el contrario, un índice de Gini reducido, próximo a cero, significa que el sector no se halla localizado, sino esparcido espacialmente en consonancia con la distribución geográfica del empleo industrial total. 


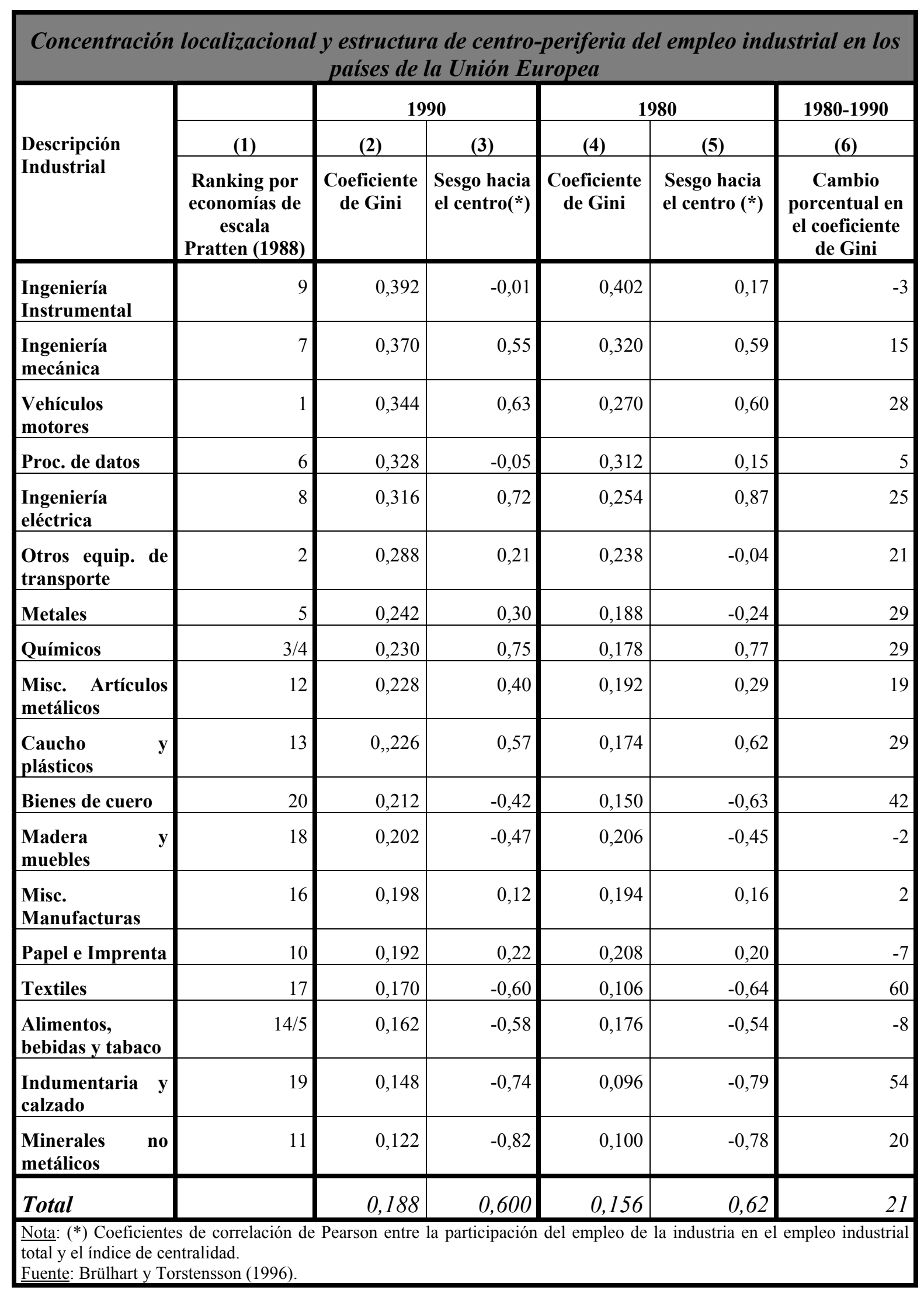


Las columnas 2 y 4 del cuadro muestran los índices de Gini para la distribución de 18 industrias entre 11 países europeos en los años 1990 y 1980, respectivamente. Las industrias se ordenan en función decreciente del nivel de su índice de Gini localizacional en 1990. Si se comparan los índices de Gini con el orden en el ranking de economías de escala resultante del trabajo realizado por Pratten (1988), que se reportan en la columna 1, se aprecia la existencia de algún grado de correlación entre la concentración localizacional de una industria y la trascendencia de los rendimientos crecientes ${ }^{24}$. Así, las primeras ocho industrias en el ranking de Pratten (1988) también se sitúan en los primeros lugares en el ranking confeccionado a partir de los índices de Gini ${ }^{25}$. El coeficiente de correlación de Spearman entre la escala de rendimientos crecientes y la escala de índice localizacionales asciende a 0,69, que es estadísticamente significativo al 1\%. El hallazgo empírico precedente cohonesta entonces la predicción teórica según la cual las industrias con rendimientos crecientes a escala se aglomerarán geográficamente.

Las columnas 3 y 5 de la tabla muestran los coeficientes de correlación de Pearson entre la centralidad de un país y la participación en el empleo manufacturero total de una industria radicada en el mismo ${ }^{26}$. Tales coeficientes se conciben como indicadores de la presencia de un sesgo localizacional hacia los países centrales, dado que cuanto mayores son los valores del índice, mayor es la participación en el empleo manufacturero de una industria establecida en países centrales respecto de la participación de las industrias emplazadas en los países periféricos. Una parangonación de las columnas 3 y 5 con el ranking derivado del

\footnotetext{
${ }^{24}$ Economías de escala de las diferentes industrias: Sin lugar a dudas, no es fácil capturar empíricamente la variable de economías de escala. Una gran parte de los estudios han empleado proxies que no guardan una relación estrecha con el concepto teórico relevante. Una excepción destacable es el trabajo de Pratten (1988). Antedicho autor compiló un ranking de las industrias manufactureras en función de la importancia de las economías de escala para la difusión de los costos de desarrollo y los costos de producción, donde el grado de economías de escala se determina por "productos y cadenas de productos" y "el tamaño de los establecimientos". En concreto, el ordenamiento se basa en estimaciones ingenieriles de escalas eficientes mínimas y las pendientes de las curvas de costo medio a nivel de la industria. Evidentemente, existe una correspondencia entre esta clasificación empírica y el concepto teórico de economías de escala internas.

${ }^{25} \mathrm{El}$ aserto se refiere a un patrón genérico, ya que, en términos individuales, no se ubican exactamente en la misma posición.

26 Tamaño del país y centralidad en la Unión Europea: Los modelos teóricos normalmente identifican regiones centrales y regiones periféricas. La contraparte empírica de los conceptos de "centro" y "periferia" es capturada por el índice de centralidad propuesto por Keeble (1986). Dicho índice evalua la accesibilidad de las regiones en función del tamaño de su mercado y la distancia que la separa de los mercados de las restantes localizaciones. Los autores estimaron la centralidad de los países europeos. A tal fin, agregaron los índices calculados por Keeble para las 166 regiones europeas para los 12 países miembros y los ponderaron por la población regional en 1983.
} 
ordenamiento en función de las economías de escala 1 hace factible individualizar una asociación notoria entre el potencial de economías de escala de una industria y su sesgo localizacional hacia los países centrales de la Unión Europea. En particular, la correlación entre las columnas 1 y 3 es igual a 0,63 , que es estadísticamente significativa al 1\%. Luego, las industrias caracterizadas por la presencia de rendimientos crecientes parecen concentrarse en los países centrales de la unión.

Por consiguiente, existe una correlación positiva entre las economías de escala y la localización, por un lado, y el sesgo centro-periferia, por el otro. Por lo tanto, no debería extrañar que las dos últimas variables también estén correlacionadas. Efectivamente, una inspección comparativa de las columnas 2 y 4 y 3 y 5 permite observar una relación positiva entre el grado de concentración localizacional medido por el índice de Gini y la localización en los países centrales de la Unión Europea. En síntesis, tal como cabría esperar a priori, las industrias que se encuentran altamente localizadas tienden a concentrarse esencialmente en los países centrales de la unión.

Ahora bien, Brülhart y Torstensson (1996) reconocen que los países enteros podrían ser unidades localizacionales inapropiadas como base referencial de análisis. Por tal razón, llevan a cabo un estudio suplementario fundado en datos regionales para 9 países de la Unión Europea y 7 de los 18 sectores industriales cubiertos en la tabla anterior. Los resultados se exponen en el siguiente cuadro. Los mismos confirman los hallazgos realizados a partir de los datos nacionales. En efecto, los autores encuentran que cuanto mayor es la relevancia de las economías de escala, mayores son los incentivos a concentrarse en las regiones centrales europeas (tanto en 1976 como en 1985). 


\begin{tabular}{|l|r|r|r|r|}
\hline \multicolumn{1}{|c|}{ Estructura de centro-periferia del empleo industrial en las regiones europeas } \\
\hline $\begin{array}{c}\text { Descripción de la } \\
\text { industria }\end{array}$ & $\begin{array}{c}\text { Ranking por } \\
\text { economías } \\
\text { de escala }\end{array}$ & $\begin{array}{c}\text { Número de } \\
\text { observaciones }\end{array}$ & $\begin{array}{c}\text { Sesgo } \\
\text { localizacional } \\
\text { hacia regiones } \\
\text { centrales, 1985 }\end{array}$ & $\begin{array}{c}\text { Sesgo } \\
\text { localizacional } \\
\text { hacia regiones } \\
\text { centrales, 1976 }\end{array}$ \\
\hline Vehículos motores & 1 & 72 & 0,39 & 0,40 \\
\hline Químicos & 3 & 80 & 0,23 & 0,31 \\
\hline Procesamiento de datos & 6 & 34 & 0,09 & 0,16 \\
\hline Ingeniería instrumental & 9 & 70 & 0,13 & 0,09 \\
\hline Textiles & 17 & 88 & $-0,09$ & 0,14 \\
\hline Indumentaria y calzado & 19 & 76 & $-0,42$ & $-0,19$ \\
\hline Bienes de cuero & 20 & 65 & $-0,28$ & $-0,32$ \\
\hline Fuente: Brülhart y Torstensson (1996). & & & \\
\hline
\end{tabular}

Por otra parte, el modelo teórico sugiere que, más allá de un cierto intervalo, la atracción de los países grandes se acrecienta como consecuencia de la desaparición de las barreras comerciales. La medición empírica de tal efecto resulta particularmente complexa, debido a la imposibilidad de aislar los cambios inducidos por la integración. Incluso un examen de la última columna de la primera tabla hace posible determinar que la concentración de la industria se ha incrementado a lo largo de la década de 1980 (los coeficientes de Gini crecieron), pero sin un sesgo a favor de los países centrales (las correlaciones con la centralidad disminuyeron $)^{27}$; en consecuencia, el grado de aglomeración en los países centrales de la Unión Europea de las industrias caracterizadas por un elevado grado de economías de escala no parece haber aumentado durante el decenio anterior.

En principio, los resultados precedentes comportarían una contradicción de las predicciones del modelo de Brülhart y Torstensson (1996). No obstante, se pueden identificar dos escenarios donde los mismos son compatibles:

\footnotetext{
${ }^{27}$ Amiti $(1997,1998)$ también detecta un incremento en la especialización interindustrial en los países de la Unión Europea en el período 1968-1990 y, especialmente, en el lapso de referencia.
} 
- Es probable que los principales pasos en dirección a la integración económica en la Unión Europea hayan tenido lugar con anterioridad al período cubierto por los datos. La formación de la unión aduanera y la ampliación de la Unión Europea podrían haber comportado una remoción de los principales óbices al comercio intraunión en los bienes industriales e inducido consecuentemente la concentración espacial de los sectores de rendimientos crecientes que se visualiza en la actualidad. En tal caso, las fuerzas contempladas por el modelo habrían operado en el transcurso del lapso 1950-1970. Como consecuencia, cabría esperar una concentración adicional relativamente reducida de las industrias caracterizadas por un elevado grado de economías de escala.

- Alternativamente, podría hipotizarse que las barreras no arancelarias remanentes en el seno de la unión continuaron segmentando los mercados en la década pasada y sólo fueron desmanteladas gradualmente en virtud del Programa Mercado Único ${ }^{28}$. Bajo tales condiciones, las fuerzas localizacionales entronizadas por el modelo podrían ser un importante factor determinativo del ajuste industrial subsiguiente a la implementación del Mercado Único.

\section{4.b.2. Comercio intraindustrial y economías de escala}

El modelo de Brülhart y Torstensson (1996) indica una marcada correspondencia entre el nivel de comercio intraindustrial y la dispersión de las industrias.

Según las hipótesis derivadas del modelo, la participación relativa del comercio intraindustrial debe decrecer con el grado de economías de escala de la industria.

A efectos de evaluar empíricamente la afimación anterior los autores consideran una serie de medidas de comercio intraindustrial altamente desagregadas para 12 países europeos.

Considérese la siguiente tabla. Los datos son incontrovertiblemente compatibles con sobredicha predicción. Efectivamente, los mismos reflejan que las industrias con economías de escala intermedias y altas de acuerdo a la clasificación de Pratten exhiben 
consistentemente niveles relativos de comercio intraindustrial menores que las industrias con economías de escala bajas. Las industrias "intensivas en escala" identificadas por la OECD (1987) también muestran un comercio intraindustrial significativamente menor que el promedio. Los resultados antes descriptos concuerdan con los hallazgos de otros trabajos empíricos ${ }^{29}$.

\begin{tabular}{|c|c|c|c|c|}
\hline \multicolumn{5}{|c|}{$\begin{array}{c}\text { Tendencias en el comercio intraindustrial entre los países europeos en diferentes } \\
\text { categorías de industrias }\end{array}$} \\
\hline & Muestra completa & $\begin{array}{c}\text { Economías de } \\
\text { escala altas } \\
\text { (Pratten) }\end{array}$ & \begin{tabular}{|c|}
$\begin{array}{c}\text { Economías de } \\
\text { escala intermedias }\end{array}$ \\
(Pratten)
\end{tabular} & $\begin{array}{c}\text { Intensivas en } \\
\text { escala } \\
\text { (OECD) }\end{array}$ \\
\hline Industrias & 98 & 20 & 33 & 26 \\
\hline CII, 1961 & 0,35 & 0,32 & 0,29 & 0,29 \\
\hline CII, 1967 & 0,41 & 0,38 & 0,36 & 0,35 \\
\hline CII, 1972 & 0,43 & 0,40 & 0,39 & 0,38 \\
\hline CII, 1977 & 0,47 & 0,44 & 0,44 & 0,42 \\
\hline CII, 1985 & 0,47 & 0,45 & 0,46 & 0,43 \\
\hline CII, 1990 & 0,46 & 0,42 & 0,44 & 0,41 \\
\hline
\end{tabular}

Los valores que figuran en la tabla también revelan que el crecimiento registrado en el período de post-guerra en el comercio intraindustrial en el marco de la Unión Europea se ha revertido en las industrias escala intensivas en la década de 1980. El aumento y la subsecuente reducción del comercio intraindustrial en aquellas industrias podrían sugerir un desarrollo simétrico en las industrias de las regiones periféricas de la Unión Europea, esto es, la expansión relativa de los sectores sujetos a rendimientos crecientes a escala en los

\footnotetext{
${ }^{28}$ Resulta menester subrayar que, conforme se desprende de varios estudios empíricos, las barreras no arancelarias entre las naciones europeas tendieron a incrementarse con posterioridad al sobrevenimiento de las dos crisis del petróleo acaecidas en la década de 1970.

${ }^{29}$ Loerstscher y Wolter (1980), Greenaway y Milner (1984), Balassa y Bauwens (1987), Ray (1991) y Somma (1994).
} 
países periféricos de la unión durante las primeras fases del proceso de integración europea parece haber sido sucedida por una contracción relativa en las etapas más recientes. Ello se ajusta exactamente a las predicciones del modelo teórico. Asimismo, el comercio intraindustrial en su conjunto presenta una tendencia al estancamiento, lo cual puede asumirse como una evidencia empírica que avala de la hipótesis de una relación en forma de $\mathrm{U}$ invertida entre el comercio intraindustrial y los costos de comerciar dentro de la unión.

\section{4.b.3. Comercio intraindustrial e integración económica}

Si las industrias con rendimientos crecientes se subdividen en función de la importancia de las barreras no arancelarias intraunión, es posible comprobar que los sectores sujetos a barreras reducidas exhiben niveles de comercio intraindustrial menores que el promedio a lo largo del período 1960-1990 y una reversión manifiesta en el crecimiento del mencionado comercio en la década de 1980. Si se considera que es probable que tales industrias hayan sido las más afectadas por la abolición de las barreras arancelarias intraunión, puede colegirse que su trayectoria temporal refleja una relación no monotónica entre integración y concentración industrial.

\section{Resumiendo}

El estudio empírico desarrollado por Brülhart y Torstensson (1996), que se basa en datos de empleo y comercio de la Unión Europea, establece una serie de resultados que en líneas generales son consistentes con las predicciones del modelo teórico.

Así, se encuentra que las industrias con rendimientos crecientes tienden a exhibir un patrón espacial altamente localizado, se concentran en los países centrales de la Unión Europea, se caracterizan por un nivel de comercio intraindustrial relativamente bajo $\mathrm{y}$ han experimentado una reversión en el crecimiento de supradicho comercio en el transcurso del decenio de 1980. Sin lugar a hesitación alguna, los resultados a que arriban los autores son de gran relevancia en el debate de los efectos regionales del Mercado Único. En efecto, 
podría inferirse que una disminución adicional de los costos de comercio intraunión puede desencadenar importantes desplazamientos centrípetos en la industria europea. Bajo tal escenario, cabría esperar un incremento del grado de concentración industrial en los países centrales de la Unión Europea. Ello implicaría un estancamiento e inclusive un decrecimiento de la participación del comercio intraindustrial en el comercio total entre los países de la unión. Naturalmente, un desarrollo de tal naturaleza plantearía una multiplicidad de problemas de ajuste estructural.

Sin embargo, las estimaciones de los autores parecerían sugerir que la mayor parte del proceso de concentración espacial en la industria europea inducido por las economías de escala ya habría tenido lugar. Como contrapartda, parecería existir un mayor espacio para la especialización interindustrial en industrias que son fundamentalmente sensibles a los costos factoriales. Krugman ha encontrado que las industrias tradicionales con un bajo grado de economías de escala son precisamente aquellas que exhiben la aglomeración localizacional más pronunciada en Estados Unidos. Los resultados de Brülhart y Torstensson muestran que tales sectores se hallan relativamente dispersos en la Unión Europea y que es probable que los desplazamientos localizacionales esperables en tales actividades beneficien a los países periféricos. Obviamente, ello sería de singular trascendencia en la hipótesis de una ampliación de la Unión Europea hacia el este.

\section{4.c. El Mercosur y Brasil}

La configuración espacial de la economía brasileña se caracteriza por un elevado grado de concentración. Así, según datos de 1994, el estado de San Pablo, que representa aproximadamente el 3\% de la superficie total del país, explica la tercera parte del PBI del mismo, mientras que la región del Norte, que equivale $42 \%$ del área total, sólo genera el $4,8 \%$ de antedicho agregado económico. La aglomeración también se expresa en términos demográficos. El índice de Gini correspondiente a la distribución jurisdiccional de la población brasileña calculado a partir de los datos emanados del censo nacional de 1991 asciende a 0,61 (IBGE, 1999). 
Desde una perspectiva dinámica, los indicadores estadísticos estaduales elaborados por los organismos oficiales de Brasil desde 1939 indican inequívocamente la prevalencia de una tendencia a la concentración geográfica en la región del Sureste hasta mediados de la década de 1970.

A partir de entonces y en un marco de elevado crecimiento del producto industrial nacional y vigencia de múltiples políticas activas regionales, se verifica una reversión en la orientación de los desplazamientos espaciales de la actividad económica.

En efecto, el período comprendido entre tal fecha y 1985 es susceptible de tipificarse sin ningún tipo de ambigüedad como una fase de desconcentración espacial. A título ilustrativo, puede mencionarse que la participación conjunta de los estados de San Pablo y Río de Janeiro en el valor agregado industrial se contrajo del 73,2\% al 61,4\%. Asimismo, resulta menester subrayar que sobredicho proceso involucró a una amplia diversidad de segmentos de la industria y fue singularmente trascendente para los sectores con una utilización intensiva de mano de obra y cuya producción se comercializaba fundamentalmente en el mercado doméstico. Las principales ramas involucradas fueron tabaco, productos textiles, indumentaria y calzados, alimentos y bebidas.

\begin{tabular}{|l|r|r|r|r|}
\hline \multicolumn{5}{|c|}{ Distribución espacial del valor agregado industrial (1970-1985) } \\
\hline \multicolumn{1}{|c|}{ Estado } & \multicolumn{1}{c|}{1 1970 } & \multicolumn{1}{c|}{$\mathbf{1 9 7 5}$} & \multicolumn{1}{c|}{$\mathbf{1 9 8 0}$} & \multicolumn{1}{c|}{$\mathbf{1 9 8 5}$} \\
\hline Bahía & 1,5 & 2,0 & 3,1 & 3,8 \\
\hline Pernambuco & 2,0 & 2,2 & 1,9 & 1,9 \\
\hline Minas Gerais & 6,4 & 6,3 & 7,7 & 8,3 \\
\hline Río de Janeiro & 15,6 & 13,5 & 10,2 & 9,5 \\
\hline San Pablo & 57,6 & 55,8 & 54,4 & 51,9 \\
\hline Paraná & 3,0 & 4,0 & 4,1 & 4,9 \\
\hline Santa Catarina & 2,6 & 3,3 & 3,9 & 3,9 \\
\hline Rio Grande del Sur & 6,3 & 7,6 & 7,7 & 7,9 \\
\hline Otros estados & 5,0 & 5,3 & 7,0 & 7,9 \\
\hline Total & 100,0 & 100,0 & 100,0 & 100,0 \\
\hline Fuente: Pacheco (1999). & \multicolumn{4}{|c}{} \\
\hline
\end{tabular}

No obstante, es necesario reconocer que las ramas industriales más dinámicas continuaron altamente concentradas en San Pablo (Pacheco, 1999) y que las regiones Sur y Sureste, que conforman el núcleo industrial tradicional del país, en modo alguno han perdido su 
condición de emplazamientos de los parques industriales más diversificados e importantes a nivel nacional (Mendes, 1997) ${ }^{30}$.

\begin{tabular}{|c|c|c|c|c|c|}
\hline \multicolumn{6}{|c|}{ Estructura espacial de la industria (1985) } \\
\hline Sector/Región & Norte & Noreste & C-Oeste & Sureste & Sur \\
\hline Agroindustria & $\mathrm{x}$ & $\mathrm{x}$ & $\mathrm{x}$ & $\mathrm{x}$ & $\mathrm{x}$ \\
\hline Textil & $\mathrm{x}$ & $\mathrm{x}$ & & $\mathrm{x}$ & $\mathrm{x}$ \\
\hline Química & & $\mathrm{x}$ & & $\mathrm{x}$ & $\mathrm{x}$ \\
\hline Metalurgia & $\mathrm{x}$ & $\mathrm{x}$ & & $\mathrm{x}$ & $\mathrm{x}$ \\
\hline Minerales no metálicos & $\mathrm{x}$ & $\mathrm{x}$ & $\mathrm{x}$ & $\mathrm{x}$ & $\mathrm{x}$ \\
\hline Madera y muebles & $\mathrm{x}$ & $\mathrm{x}$ & $\mathrm{x}$ & $\mathrm{x}$ & $\mathrm{x}$ \\
\hline Equipos & & & & $\mathrm{x}$ & $\mathrm{x}$ \\
\hline Material de Transporte & & & & $\mathrm{x}$ & \\
\hline Papel y gráfica & & & & $\mathrm{x}$ & $\mathrm{x}$ \\
\hline Electrónica & $\mathrm{x}$ & & & & \\
\hline
\end{tabular}

Es sabido que desde principios de la década de 1990 la economía brasileña emprendió un proceso de profundas transformaciones económicas consistentes en la pérdida de participación del sector público en la actividad económica inducida por el programa de privatizaciones, el lanzamiento del Plan Real, la apertura de la economía y la integración del Mercosur.

\begin{tabular}{|l|c|c|c|c|}
\hline \multicolumn{4}{|c|}{ Aranceles medios extrazona e intrazona (1990 y 1996) } \\
\hline \multirow{2}{*}{ Sector/Arancel medio } & \multicolumn{3}{|c|}{ Externo } & Países miembros del Mercosur \\
\cline { 2 - 5 } & $\mathbf{1 9 9 0}$ & $\mathbf{1 9 9 6}$ & $\mathbf{1 9 9 0}$ & $\mathbf{1 9 9 6}$ \\
\hline Alimentos & 40,0 & 14,0 & 26,3 & 0,0 \\
\hline Textiles & 52,0 & 18,0 & 34,2 & 0,0 \\
\hline Cueros y calzados & 50,0 & 40,0 & 40,0 & 0,0 \\
\hline Productos químicos & 42,0 & 12,0 & 30,0 & 0,0 \\
\hline Metalurgia & 50,0 & 16,0 & 34,7 & 0,0 \\
\hline Automóviles & 44,8 & 70,0 & 39,2 & 0,0 \\
\hline Autopartes & 20,0 & 20,0 & 20,0 & 0,0 \\
\hline Otros productos & 40,3 & 20,0 & 39,5 & 0,0 \\
\hline Fuente: Gonzaga, Terra y Cavalcante (1999) en base a DTIC y GATT. & \\
\hline
\end{tabular}

${ }^{30}$ La participación de San Pablo en el valor agregado de la industria de bienes intermedios sólo descendió $3,8 \%$ entre 1970 y 1985 , en virtud del bajo grado de desconcentración de la industria química, que fue una de las ramas industriales de mayor crecimiento en el período de referencia. 
En este sentido, resulta claro que el proceso liberalización comercial unilateral y regional acaecido en Brasil ha engendrado dos impactos contrarios sobre la producción doméstica. Por un lado, ha influido positivamente sobre el comportamiento de la misma merced al impulso a las exportaciones ejercido por la asequibilización de un mejor acceso al mercado de los países socios y la disminución en el costo de los insumos importados. Por otro lado, ha afectado negativamente antedicha producción a través del incremento en el grado de competencia que importa la reducción de los óbices a las compras externas ligada a la apertura comercial. Ambos fenómenos, tanto en su dimensión global como en su faceta regional, pueden apreciarse mediante los coeficientes de exportación e importación estaduales.

\begin{tabular}{|l|r|r|r|r|}
\hline \multicolumn{5}{|c|}{ Coeficientes de exportación e importación estaduales (1990, 1995) } \\
\cline { 2 - 5 } \multicolumn{1}{c}{ Estado } & \multicolumn{2}{c|}{ Coeficiente de exportación } & \multicolumn{1}{c|}{ Coeficiente de importación } \\
\hline Pernambuco & $\mathbf{1 9 9 0}$ & $\mathbf{1 9 9 5}$ & $\mathbf{1 9 9 0}$ & $\mathbf{1 9 9 5}$ \\
\hline Bahía & 6,6 & 7,9 & 3,8 & 9,0 \\
\hline Minas Gerais & 8,6 & 10,9 & 3,8 & 9,0 \\
\hline Río de Janeiro & 9,7 & 10,4 & 3,9 & 8,4 \\
\hline San Pablo & 4,0 & 4,9 & 3,9 & 8,4 \\
\hline Paraná & 6,3 & 7,3 & 3,9 & 8,4 \\
\hline Santa Catarina & 7,0 & 11,2 & 2,8 & 6,2 \\
\hline Río Grande del Sur & 8,7 & 11,5 & 2,8 & 6,2 \\
\hline Brasil & 11,3 & 13,2 & 2,8 & 6,2 \\
\hline Nota: Los coeficientes de importación han sido calculados por región. & & & $\mathbf{8 , 6}$ \\
\hline Fuente: Kume y Piani (1998). & 7,3 & $\mathbf{9 , 3}$ & \\
\hline \hline
\end{tabular}

Conforme surge de la tabla, el coeficiente de exportación de la industria brasileña subió de $7,3 \%$ en 1990 a 9,3\% en 1995 . Los estados que en 1995 poseían una coeficiente mayor que la media nacional fueron: Rio Grande del Sur (13,2\%), Santa Catarina (11,5\%), Paraná $(11,2 \%)$, Bahía y Minas Gerais $(10,4 \%)^{31}$. Rio de Janeiro se destaca como uno de los estados con coeficiente de ventas externas inferior a la media nacional. Por otro lado, el

\footnotetext{
${ }^{31}$ Sectorialmente, es dable observar en los estados del Sur coeficientes de exportación altos para vestuario y calzados (57\%), tabaco (34\%), cueros $(27 \%)$, material eléctrico y productos textiles $(21 \%)$.
} 
coeficiente de importación aumentó de 3,9\% en 1990 a 8,6\% en 1995; el mayor crecimiento del mismo se verificó en los estados de Pernambuco y Bahía ${ }^{32}$.

Por otro lado, la importancia relativa del Mercosur en las exportaciones creció significativamente, en especial en los estados San Pablo, Rio de Janeiro y Bahía. Los estados del Sur (Río Grande del Sur, Santa Catarina y Paraná) revelan una elevada concentración de las importaciones con los países del bloque ${ }^{33}$. Resulta menester destacar que los flujos comerciales no sólo se expandieron en términos absolutos, sino también en términos del valor bruto de producción.

\begin{tabular}{|l|r|r|r|r|}
\hline \multicolumn{3}{|c|}{$\begin{array}{c}\text { Participación de las exportaciones al y las importaciones desde el } \\
\text { Mercosur en los totales correspondientes (en porcentaje) }\end{array}$} \\
\cline { 2 - 5 } \multicolumn{1}{|c}{ Estado } & \multicolumn{2}{c|}{ Exportación } & \multicolumn{1}{c|}{ Importación } \\
\hline Pernambuco & $\mathbf{1 9 9 0}$ & $\mathbf{1 9 9 5}$ & $\mathbf{1 9 9 0}$ & $\mathbf{1 9 9 5}$ \\
\hline Bahía & 1,8 & 6,6 & 13,4 & 8,7 \\
\hline Minas Gerais & 6,1 & 16,1 & 22,5 & 20,9 \\
\hline Río de Janeiro & 2,2 & 10,0 & 12,4 & 12,7 \\
\hline San Pablo & 8,0 & 17,2 & 9,1 & 9,6 \\
\hline Paraná & 5,6 & 20,2 & 10,9 & 11,6 \\
\hline Santa Catarina & 4,7 & 9,8 & 38,9 & 32,6 \\
\hline Río Grande del Sur & 3,6 & 12,0 & 41,1 & 34,6 \\
\hline Brasil & 4,3 & 14,0 & 37,6 & 30,9 \\
\hline Fuente: Kume y Piani (1998). & 4,5 & $\mathbf{1 4 , 2}$ & $\mathbf{1 4 , 7}$ & $\mathbf{1 3 , 8}$ \\
\hline
\end{tabular}

Tales transformaciones redundaron en una demudación sustancial del patrón de localización de la actividad productiva en el principal socio del bloque regional.

Los cambios acaecidos motivaron diversos análisis, cuyas conclusiones principales distan de ser coincidentes, esencialmente en lo atinente al carácter centrípeto o centrífugo de los mismos.

\footnotetext{
32 En los estados del Noreste, sobresalen como sectores con coeficientes de importación elevados mecánica $(28,1 \%)$, material de transporte $(26,3 \%)$ y productos textiles $(18 \%)$.

${ }^{33}$ No obstante, las respectivas participaciones han mostrado una declinación.
} 
Así, Carlos Pacheco (1999) examina la evolución de la participación estadual en el valor agregado industrial, la producción física, el empleo manufacturero total y la inversión sectorial efectiva y planificada en el período 1970-1997.

A partir de dicho estudio, el autor sostiene que en el transcurso del último decenio se asiste a una continuidad del proceso de desconcentración geográfica que se venía registrando desde la década de 1970. La actualidad de supradicho proceso se evidencia en una renovada reducción de la importancia relativa del núcleo espacial tradicional de la economía brasileña constituido por el eje Río de Janeiro-San Pablo. Concretamente, la participación de dichos estados en el valor agregado manufacturero se redujo de $61,4 \%$ en 1985 a $56,9 \%$ en 1997.

La desconcentración presente obedece al hecho de que las industrias paulista y carioca crecieron a una tasa inferior a la tasa nacional durante los años de recuperación y decrecieron a una tasa superior a la misma en los años recesivos. Sobredicha dinámica se origina en la estructura de la industria de San Pablo así como en el mayor nivel de encadenamiento intersectorial de la misma, que la torna especialmente susceptible a los efectos negativos derivados de contracciones en la inversión privada.

Los datos de producción y empleo y el relevamiento de las inversiones realizadas y a efectuar presentados por Pacheco (1999) ponen de manifiesto que el proceso de reconfiguración geográfica en curso no es uniforme, de modo que existen diferencias ostensibles en términos sectoriales. Así, aun cuando sigue teniendo lugar una nítida desconcentración espacial en los sectores de calzados, textiles e indumentarias, que beneficia fundamentalmente al Noreste, y, en menor medida en los sectores de alimentos y bebidas, en los sectores de telecomunicaciones e informática, que poseen un gran potencial de crecimiento, se registra una creciente concentración regional de las inversiones canalizadas hacia los mismos en las áreas tradicionalmente centrales. 
Distribución regional del empleo industrial (Variación 1996-1986 en puntos porcentuales)

\begin{tabular}{|c|c|c|c|c|c|c|c|}
\hline \multirow{2}{*}{ Sector/Región ${ }^{34}$} & \multirow[b]{2}{*}{ Norte } & \multirow[b]{2}{*}{ Noreste } & \multicolumn{3}{|c|}{ Sureste } & \multirow[b]{2}{*}{ Sur } & \multirow[b]{2}{*}{$\begin{array}{l}\text { Centro- } \\
\text { Oeste }\end{array}$} \\
\hline & & & $\mathbf{R J} / \mathbf{S P}$ & $\overline{M G}$ & $\begin{array}{c}\text { Total } \\
\text { estado }\end{array}$ & & \\
\hline Calzados & 0,2 & 5,4 & $-8,3$ & 1,5 & $-6,8$ & 1,7 & $-0,2$ \\
\hline Textil & $-0,3$ & 1,3 & $-8,7$ & 1,2 & $-6,6$ & 4,6 & 1,2 \\
\hline Alimentos y bebidas & 0,0 & $-3,4$ & $-1,6$ & 1,5 & $-0,1$ & 0,9 & 2,9 \\
\hline Material de transporte & 0,2 & $-0,6$ & $-10,5$ & 5,4 & $-4,5$ & 4,6 & 0,2 \\
\hline Mecánica & 0,4 & 0,2 & $-8,2$ & 1,6 & $-6,6$ & 5,5 & 0,5 \\
\hline Minerales no metálicos & $-0,4$ & 0,9 & $-7,1$ & 2,2 & $-3,5$ & 2,5 & 0,7 \\
\hline Metalurgia & 0,5 & $-1,3$ & $-1,9$ & $-0,6$ & $-2,7$ & 2,8 & 0,7 \\
\hline $\begin{array}{l}\text { Material eléctrico y de } \\
\text { comunicaciones }\end{array}$ & $-0,9$ & 1,7 & $-6,9$ & 3,4 & $-3,5$ & 1,7 & 0,5 \\
\hline Industria química & 0,2 & $-0,9$ & $-4,6$ & 2,3 & $-2,3$ & 1,8 & 1,1 \\
\hline Papel, edición y gráfica & 0,1 & 0,0 & $-4,1$ & 2,2 & $-1,5$ & 0,7 & 0,5 \\
\hline $\begin{array}{l}\text { Total industria de } \\
\text { transformación }\end{array}$ & 0,0 & 0,5 & $-6,5$ & 1,5 & $-4,9$ & 2,9 & 1,2 \\
\hline
\end{tabular}

Nota: Las variaciones no suman cero por problemas de redondeo.

Fuente: Elaboración propia en base a Pacheco (1999).

Por otra parte, el patrón de desconcentración se circunfiere esencialmente a los estados del Sureste y del Sur, es decir, se observa una redistribución espacial de la actividad industrial dentro del territorio de los mismos; en particular, en el primer caso, cabe subrayar el incremento de la importancia relativa de Minas Gerais (MG) en detrimento de Río de Janeiro (RJ) y San Pablo (SP).

A este respecto, los sectores más destacados son material de transporte, mecánica, minerales no metálicos y, en menor grado, metalurgia y material eléctrico y de comunicaciones. Por último, existen sectores para los cuales las variaciones regionales son de magnitud reducida, como, verbigracia, la industria química y las industrias del papel y extractiva mineral, que ya mostraban una conformación geográfica relativamente dispersa.

\footnotetext{
${ }^{34}$ Las regiones comprenden los siguientes estados:

Norte: Rondónia, Acre, Amazonas, Roraima, Pará, Amapá.

Noreste: Maranhao, Piaui, Ceará, Río Grande del Norte, Paraíba, Pernambuco, Alagoas, Fernando de Noronha, Sergipe, Bahía.

Sureste: Minas Gerais, Espíritu Santo, Río de Janeiro y San Pablo.

Sur: Paraná, Santa Catarina, Río Grande del Sur.

Centro-Oeste: Goiás, Mato Grosso, Mato Grosso del Sur, Distrito Federal (Brasilia).
} 
Las razones que explican los matices sectoriales y regionales antes individualizados se vinculan con las diferencias interindustriales en los pesos relativos de los determinantes localizacionales (los costos salariales, las externalidades y las economías de aglomeración, la proximidad a los mercados y los proveedores) y el hecho de que en varios casos el aumento de la capacidad instalada se produce en los sitios ya existentes (vgr: petroquímica y siderurgia), de manera que las nuevas inversiones sólo afectan marginalmente la conformación espacial del sector.

Ahora bien, Pacheco (1999) nota que la intensidad del proceso de desconcentración en los últimos años fue claramente menor que en el período 1970-1985. A juicio del autor, ello responde a una modificación sustancial en el escenario micro y macroeconómico que se enmarca el mismo. Efectivamente, las reformas estructurales implementadas en la economía generaron profundas demudaciones de naturaleza microeconómica, habida cuenta del ajuste que se promovió en los niveles de eficiencia con que operaban las firmas, así como cambios macroeconómicos sustantivos, dadas las fases de inestabilidad y estabilización que se sucedieron desde inicios del decenio de 1990.

Además, la desconcentración ha sido concomitada por un creciente grado de heterogeneidad en el desarrollo interno de las regiones brasileñas, conforme lo testimonia la eclosión de "islas de productividad" en virtualmente cada una de tales regiones, el mayor crecimiento relativo de las antiguas periferias nacionales y el incremento de la relevancia del subconjunto urbano de dimensión intermedia.

Azzoni y Ferreira (1997) y Lavinas, García y do Amaral (1997) arriban a conclusiones notablemente disímiles.

En efecto, Azzoni y Ferreira (1997) estiman una medida de competitividad regional inspirada en el modelo de salario de eficiencia de Kaldor a partir de indicadores de productividad laboral, salarios y rentabilidad industrial ${ }^{35}$. Los resultados que obtienen

\footnotetext{
${ }^{35}$ Según Kaldor, la varianza regional de los niveles de productividad es mucho mayor que la varianza regional de los niveles salariales. Ello responde a la interacción de las economías de aglomeración que fundan las disparidades interregionales en los niveles de productividad y la actuación sindical que propende a homogeneizar las remuneraciones entre las localizaciones alternativas.

Las desigualdades regionales crecen debido a la denominada ley de Verdoorn, conforma a la cual el aumento de la productividad se relaciona con el volumen de producción regional. Así, (a) la existencia de economías de aglomeración implica que el nivel de productividad del centro industrial es mayor que el nivel de productividad correspondiente a la periferia; (b) dado que la varianza de los niveles salariales es menor que la
} 
señalan una reversión en la tendencia a la desconcentración que primaba desde la década de 1970. En concreto, el centro industrial del país ha mejorado su posición relativa desde 1985, mientras que las regiones periféricas han experimentado un deterioro en su situación relativa; específicamente, según se desprende de la tabla consignada a continuación, se ha registrado un notorio aumento de la competitividad en San Pablo y Minas Gerais en los últimos diez años y una caída pronunciada en la competitividad de las restantes zonas ${ }^{36}$. La solidez aparente de tal tendencia, sustentada en el gran potencial para atraer nuevas inversiones industriales que exhibe el núcleo manufacturero tradicional del país, permitiría hipotizar una ampliación de las desigualdades regionales en el futuro próximo.

\begin{tabular}{|c|c|c|c|c|c|}
\hline \multicolumn{7}{|c|}{ Indicador de excedente regional (1970-1995) } \\
\hline Año/Región-Estado & Noreste & Sur & Rio de Janeiro & Minas Gerais & San Pablo \\
\hline $\mathbf{1 9 7 0}$ & 0,71 & 0,91 & 1,09 & 1,11 & 1,12 \\
\hline $\mathbf{1 9 7 5}$ & 0,79 & 0,95 & 1,03 & 0,97 & 1,07 \\
\hline $\mathbf{1 9 8 0}$ & 1,05 & 0,97 & 1,02 & 1,03 & 1,05 \\
\hline $\mathbf{1 9 8 5}$ & 0,81 & 1,00 & 0,86 & 1,03 & 1,00 \\
\hline $\mathbf{1 9 8 6}$ & 0,79 & 1,00 & 0,92 & 1,06 & 0,98 \\
\hline $\mathbf{1 9 8 7}$ & 0,77 & 1,04 & 0,80 & 1,02 & 1,01 \\
\hline $\mathbf{1 9 8 8}$ & 0,67 & 0,99 & 0,76 & 1,10 & 1,03 \\
\hline $\mathbf{1 9 8 9}$ & 0,70 & 1,00 & 0,58 & 1,31 & 1,05 \\
\hline $\mathbf{1 9 9 0}$ & 0,71 & 1,00 & 0,62 & 1,23 & 1,04 \\
\hline $\mathbf{1 9 9 1}$ & 0,75 & 1,01 & 0,65 & 1,25 & 1,02 \\
\hline $\mathbf{1 9 9 2}$ & 0,70 & 0,94 & 0,59 & 1,44 & 1,03 \\
\hline $\mathbf{1 9 9 3}$ & 0,63 & 0,93 & 0,61 & 1,38 & 1,03 \\
\hline $\mathbf{1 9 9 4}$ & 0,74 & 0,99 & 0,59 & 1,42 & 1,01 \\
\hline $\mathbf{1 9 9 5}$ & 0,76 & 0,88 & 0,54 & 1,36 & 1,05 \\
\hline Fuente: Azzoni y Ferreira $(1997)$. & & & & \\
\hline
\end{tabular}

Nota: El indicador regional de excedente empleado por Azzoni y Ferreira (1997) es el siguiente:

$$
I E_{r, t}=\frac{\sum_{i}\left(P_{i, r, t}-W_{i, r, t}\right)}{\sum_{i}\left(\left(N_{i, r, t} \cdot p_{i, r, t}\right)-\left(N_{i, r, t} \cdot w_{i, r, t}\right)\right)}
$$

donde $P_{i, r, t}, W_{i, r, t}$ y $N_{i, r, t}$ denotan la producción, la masa salarial y el número de empleados, respectivamente, del sector industrial $i$ en la región $r$ en el momento $t ; p_{i, r, t}=P_{i, r, t} / N_{i, r, t}$ representa la

varianza de la productividad, el salario de eficiencia es menor en el centro industrial; (c) luego, la rentabilidad es mayor en el mismo, motivo por el cual atraerá más inversiones expansivas de la capacidad productiva regional, que, merced a la ley de Verdoorn, (d) magnificará el diferencial en las tasas de crecimiento de la productividad. De este modo, existe un círculo virtuoso para el centro industrial y un círculo vicioso para la periferia industrial del país.

${ }^{36}$ El resultado de Minas Gerais concuerda con los hallazgos de Pacheco (1999). 
productividad de la mano de obra, en tanto que $w_{i, r, t}=W_{i, r, t} / N_{i, r, t}$ simboliza el salario medio. Por lo tanto, el indicador de excedente se define como la diferencia proporcional entre el valor agregado y la masa salarial. Una región con un indicador superior a la unidad posee un nivel de rentabilidad mayor a la media nacional, de manera que se posiciona competitivamente para suscitar la aferencia de nuevas inversiones industriales.

Por su parte, Lavinas, García y do Amaral (1997) analizaron la forma en que el proceso de integración regional ha repercutido en la evolución de las desigualdades regionales a través del comportamiento de varios indicadores económicos como el producto bruto estadual y las exportaciones y las importaciones estaduales tanto en términos agregados como en términos de su composición sectorial. La evidencia empírica revela un aumento en la dispersión de las rentas estaduales a partir de 1992. Los autores sostienen que el Mercosur parece haber desempeñado un rol significativo en dicha dinámica económica regional, ya que, según surge de las estadísticas de comercio exterior, favorece fundamentalmente a los estados de las regiones del Sur y el Sureste, que concentran aproximadamente el $90 \%$ de las exportaciones, y, en especial, a San Pablo. En efecto, el hecho de que la participación de las exportaciones brasileñas al Mercosur en las exportaciones totales sigan una trayectoria creciente y que la mayor parte de las mismas provenga de los estados tradicionalmente industriales importa ventajas que, al menos en el corto plazo, se circunscriben a los mismos. Magüer con ciertos matices, una conclusión semejante es alcanzada por Mendes (1997).

\begin{tabular}{|c|c|c|c|c|c|c|c|c|}
\hline \multicolumn{9}{|c|}{ Participación de los estados en las exportaciones al Mercosur (1989-1995) } \\
\hline Región/Año & 1989 & 1990 & 1991 & 1992 & 1993 & 1994 & 1995 & Var. 1995-1989 \\
\hline Región Sureste (1) & 69,5 & 69,8 & 70,1 & 72,8 & 69,7 & 68,3 & 65,6 & $-3,9$ \\
\hline San Pablo & 54,5 & $\overline{54,2}$ & 52,4 & 53,9 & 52,5 & 52,6 & 52,2 & $-2,3$ \\
\hline Río de Janeiro & 5,4 & 7,5 & 7,4 & 6,9 & 7,0 & 6,8 & 5,8 & 0,4 \\
\hline Minas Gerais & 9,6 & 8,1 & 10,3 & 12,0 & 10,3 & 8,8 & 7,6 & $-2,1$ \\
\hline Región Sur & 18,6 & 18,5 & 19,6 & 19,1 & 22,8 & 22,4 & 22,2 & $\overline{3,6}$ \\
\hline Río Grande del Sur & 10,3 & 9,7 & 9,4 & 9,2 & 11,2 & 11,7 & 11,5 & 1,3 \\
\hline Santa Catarina & 3,7 & 4,1 & 4,9 & 4,8 & 5,5 & 5,0 & 5,4 & 1,7 \\
\hline Paraná & 4,7 & 4,8 & 5,3 & 5,1 & 6,1 & 5,8 & 5,3 & 0,6 \\
\hline Resto & 11,9 & 11,7 & 10,3 & 8,1 & 7,5 & 9,3 & 12,2 & 0,3 \\
\hline
\end{tabular}


Las restantes regiones muestran diferentes grados de integración de acuerdo a su localización geográfica. El extremo opuesto al centro dinámico es el Noreste, que se halla inmerso en una estadío de estancamiento y posee un nivel de integración relativamente bajo con el bloque regional.

La contraparte sectorial de tal asimetría es el hecho de que los estados del Sureste poseen una participación superior al $53 \%$ en la exportación de todos los productos, con la excepción del rubro madera y derivados, en el cual la región Sur detenta el 76,6\% del total nacional. En particular, San Pablo se destaca en la mayor parte de los grupos de productos, con índices que oscilan entre 35,9\% y $81,4 \%$. Antedicha prevalencia se replica en las importaciones. En efecto, los estados de la región Sureste tienen una participación superior al 53\% en seis de los ocho grupos en cuestión (Mendes, 1997).

\begin{tabular}{|c|c|c|c|c|c|c|}
\hline \multicolumn{2}{|c|}{ Producto/Región } & Norte & Noreste & Sureste & Sur & Cto-Oeste \\
\hline \multirow{2}{*}{ Alimentos, bebidas, tabaco y derivados } & Exportación & 1,9 & 8,5 & 64,3 & 21,3 & 4,1 \\
\hline & Importación & 1,5 & 18,0 & 42,6 & 36,0 & 2,0 \\
\hline \multirow{2}{*}{ Productos minerales } & Exportación & 4,1 & 1,2 & 66,4 & 17,0 & 11,3 \\
\hline & Importación & 0,3 & 6,0 & 54,8 & 30,1 & 8,8 \\
\hline \multirow{2}{*}{ Industria quimica y conexas } & Exportación & 0,3 & 22,8 & 60,9 & 16,0 & 0,1 \\
\hline & Importación & 2,1 & 6,8 & 37,0 & 54,1 & 0,0 \\
\hline \multirow{2}{*}{ Madera y sus derivados } & Exportación & 9,2 & 0,0 & 11,4 & 76,6 & 2,9 \\
\hline & Importación & 0,0 & 2,8 & 78,2 & 19,0 & 0,0 \\
\hline \multirow{2}{*}{ Productos textiles y sus derivados } & Exportación & 0,0 & 14,8 & 53,9 & 31,3 & 0,1 \\
\hline & Importación & 0,0 & 7,8 & 53,7 & 38,4 & 0,2 \\
\hline \multirow{2}{*}{ Metales comunes y sus derivados } & Exportación & 1,9 & 7,8 & 75,6 & 14,4 & $\overline{0,4}$ \\
\hline & Importación & 0,0 & 2,5 & 81,7 & 15,7 & 0,1 \\
\hline \multirow{2}{*}{ Máquinas y aparatos electrónicos } & Exportación & 0,6 & 2,8 & 68,1 & 28,5 & 0,0 \\
\hline & Importación & 0,6 & 1,2 & 83,8 & 14,0 & 0,4 \\
\hline \multirow{2}{*}{ Material de transporte } & Exportación & 0,6 & 0,0 & 89,5 & 10,0 & $\overline{0,0}$ \\
\hline & Importación & 0,0 & 0,2 & 97,8 & 1,8 & 0,2 \\
\hline
\end{tabular}

Un efecto localizacional favorable al centro también es hallado por Azzoni y Haddad (1999). A diferencia de los trabajos precedentes, los autores derivan sus educciones a partir de simulaciones producidas por un modelo interregional de equilibrio general computado con enfoque bottom-up y calibrado para 1985, que es un año previo a la reforma comercial $^{37}$. En particular, Azzoni y Haddad evalúan los desplazamientos geográficos en el

\footnotetext{
${ }^{37}$ En un modelo de equilibrio general computado con enfoque bottom-up los resultados nacionales se obtienen a partir de la agregación de los resultados regionales.
} 
centro de gravedad económica y especialización regional en la economía brasileña derivados de una reducción uniforme en los aranceles del 25\% y encuentran que la apertura económica unilateral y regional se asocia a traslaciones geográficas de la actividad productiva hacia el núcleo Centro-Sur del país y, en consecuencia, a una acrecentamiento de las disparidades regionales. La explicación sostenida por los autores es que a partir de la liberalización comercial los efectos de oferta, ligados a la alta participación de los insumos importados en la producción regional, podrían contrapesar los efectos de demanda, vinculados con el deterioro en los términos de intercambio con las regiones periféricas del país promovido por la desaparición de las barreras comerciales respecto del resto del mundo.

Finalmente, Kume y Piani (1998) realizan un análisis diferencial estructural de los efectos de los flujos de comercio entre Brasil y el resto de los países miembros del Mercosur sobre la producción regional en el período 1990-1995.

El trabajo tiene por objeto precisamente cuantificar las repercusiones de los desarrollos comerciales sobre las economías regionales del principal socio del Mercosur. A tal fin, los autores recurren al método de análisis diferencial estructural, que consiste en descomponer algebraicamente la variación experimentada por una determinada variable en un cierto lapso temporal en una serie de términos. Específicamente, Kume y Piani intentan explicar la variación en el valor de la producción en la industria de un estado entre 1990 y 1995 en términos de un componente nacional, que refleja la incidencia del crecimiento económico del país en su conjunto, un componente estructural, que aprehende el efecto de la estructura industrial estadual, y un factor regional, que captura el influjo de las especificidades estaduales, esto es, representa la fracción de la variación del producto imputable a las características peculiares de cada estado; en todos los casos, los mismos fueron expandidos de manera de contemplar individualmente la gravitación de las importaciones y las exportaciones agregadas y con el Mercosur sobre los cambios registrados en la variable de referencia.

El componente regional constituye sin lugar a dudas el elemento más relevante en el examen de los efectos derivados de la integración desde una perspectiva regional. 
El mismo indica que los estados que evidencian una dinámica exportadora superior a lo esperado en función del resto de los factores explicativos son aquellos que pertenecen a la región Sur y Bahía, en tanto que los datos de importación permiten colegir que los estados con mayor grado de exposición son Bahía y, en menor grado, Paraná, Santa Catarina, Minas Gerais y Río Grande del Sur. Luego, la región Sur y Bahía muestran el mayor nivel de integración al mercado internacional.

Con respecto al comercio en el marco del Mercosur, el valor asumido por el componente regional revela que los estados de la región Sur y Bahía presentan una ventaja competitiva en sus exportaciones dirigidas al Mercosur y, en mayor medida, al resto del mundo. Los estados de Pernambuco, Minas Gerais, Río de Janeiro se encuentran en una situación diametralmente opuesta. Por último, cabe resaltar que el estado de San Pablo constituye el único caso en el cual en que se verifica una compensación de una ventaja en el caso del Mercosur y una desventaja con el mundo. Con relación a las importaciones, se advera una mayor vulnerabilidad del Sur y Pernambuco con referencia a las compras externas originarias del Mercosur.

Por otra parte, si se agrupan los componentes de demanda según su contribución a la variación total de la producción de manera de evaluar la importancia del comercio internacional, se aprecia que las exportaciones fueron significativas en el crecimiento registrado por el producto en Bahía y Paraná, mientras que San Pablo y Minas Gerais exhiben una demanda con menor nivel de dependencia de los mercados externos; por su parte, las importaciones han afectado sustancialmente las producciones de Bahía y Rio de Janeiro, en tanto que el Sur muestra un menor grado de exposición a la competencia externa. Una reproducción del análisis precedente que se concentre exclusivamente en los países del Mercosur indica que los estados más favorecidos en sus exportaciones fueron Bahía, Rio de Janeiro, San Pablo y Rio Grande del Sur; asimismo, señala que los estados más afectados fueron Pernambuco, Paraná, Rio de Janeiro, Santa Catarina y Rio Grande del Sur. En síntesis, los estados que obtuvieron ganancias netas en el comercio con el Mercosur fueron Bahía, San Pablo, Rio de Janeiro y Rio Grande del Sur.

Por lo tanto, el trabajo no permite extraer conclusiones unívocas con respecto al efecto del proceso de integración comercial sobre las disparidades regionales, ya que el mismo parece 
haber beneficiado tanto a regiones no desarrolladas (Bahía) como a regiones pertenecientes al núcleo industrial tradicional del país (estados de las regiones Sur y Sureste). Ahora bien, si se tiene en cuenta las pronunciadas asimetrías preexistentes en Brasil, las consideraciones precedentes permiten hirmar al menos que la integración no está contribuyendo significativamente a desleir las mismas.

\section{Resumiendo}

Brasil ha mostrado en el transcurso de la centuria un patrón geográfico altamente concentrado. Sin embargo, a partir del decenio de 1970 y hasta mediados de la década de 1980 el país fue testigo de una cierta tendencia a la dispersión de la industria, que afectó fundamentalmente a las ramas trabajo-intensivas y orientadas al mercado interno. Ahora bien, hacia fines de supradicho período, Brasil emprendió un conjunto de reformas económicas sustantivas, entre las que sobresalen indudablemente la apertura económica general y regional. Las mismas engendraron efectos derivados sobre la dinámica espacial de la actividad productiva hasta entonces prevaleciente. Aun cuando no existe consenso pleno acerca del carácter centrífugo o centrípeto de los movimientos localizacionales de la producción, es irrefutable que la mayor parte de los trabajos concluyen que la constitución del Mercosur ha propendido a acentuar las disparidades interregionales, dado que, al menos hasta el presente, el comercio exterior inducido con los países integrantes del bloque parece haber mejorado el posicionamiento de las regiones con mayor presencia industrial preexistente así como su potencial de atracción de nuevas inversiones. 
$\underline{\text { 5.a. Las condiciones iniciales }}$

5.a.1. Mercosur

Usualmente se sostiene que Argentina y Brasil son las economías más importantes del Mercosur. De hecho, el PBI combinado de las mismas equivale a más del 90\% del PBI regional. Ahora bien, el hecho anterior no debería conducir a omitir la asimetría dimensional de ambos países, que subyace al modelo esbozado en el marco teórico. La razón entre las poblaciones y los niveles de producto son esclarecedoras a este respecto (ver gráficos).

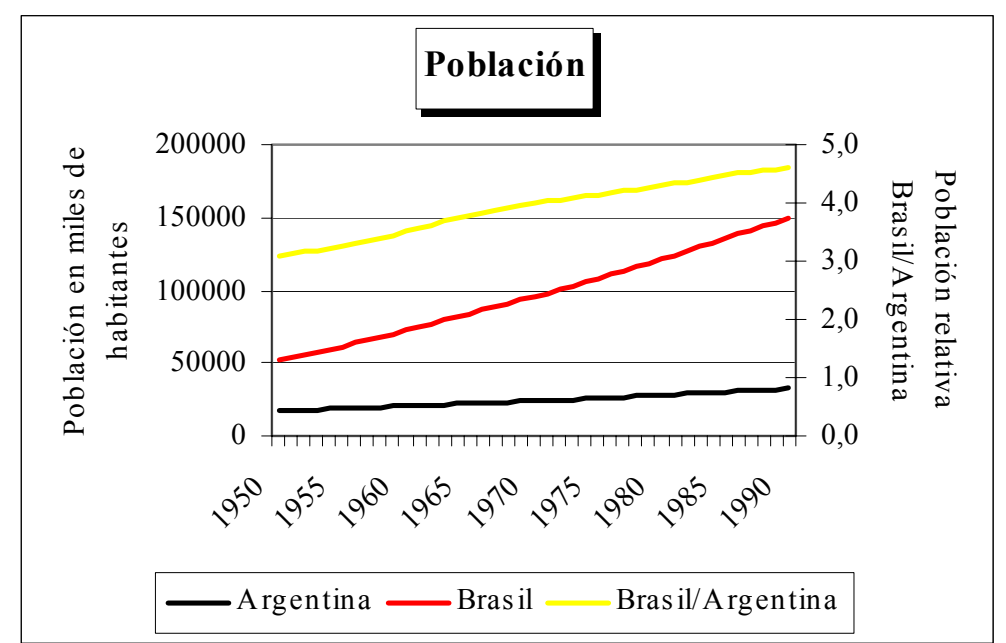




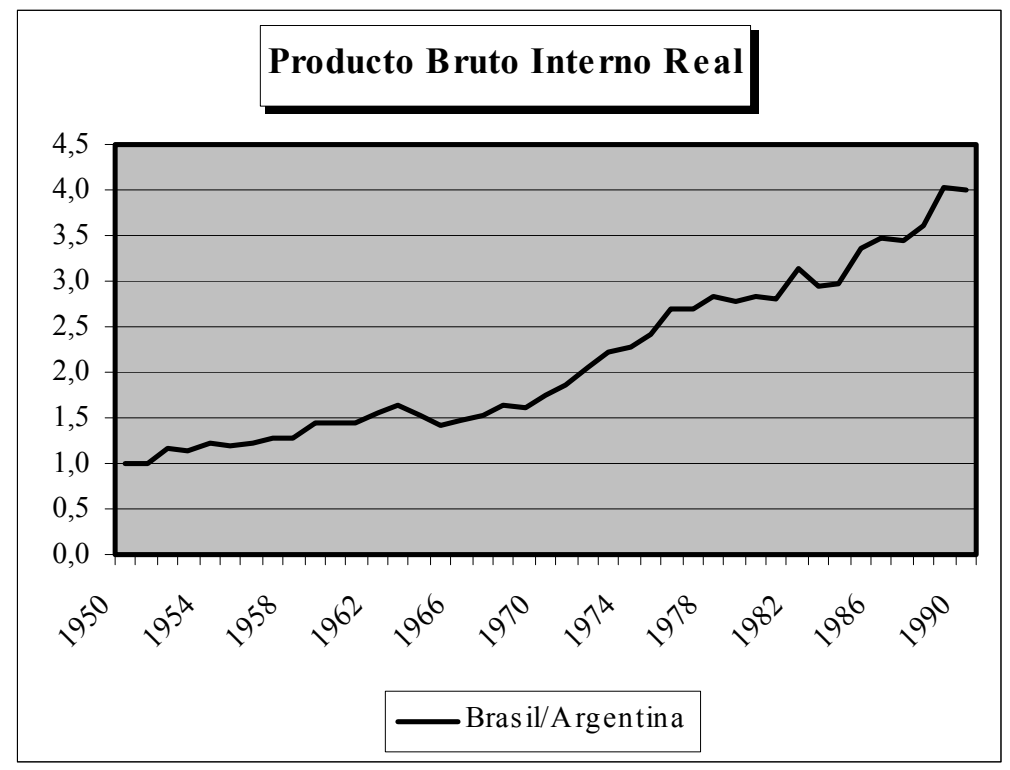

Fuente: Penn World Tables 5.6

El comercio bilateral de ambos países en la fase previa a la conformación del Mercosur se caracterizaba por una intensidad relativa sustancialmente menor a los niveles actuales. Así, en el período comprendido entre los años 1976 y 1985, la participación promedio de Brasil sólo ascendía al 7,1\% de las exportaciones y al 12,1\% de las importaciones argentinas. 


\begin{tabular}{|c|c|c|c|c|c|c|c|c|c|c|}
\hline Grupo de productos & 1976 & 1977 & 1978 & 1979 & 1980 & 1981 & 1982 & 1983 & 1984 & 1985 \\
\hline Total exportaciones & 9,1 & 6,6 & 7,4 & 10,2 & 8,6 & 6,5 & 7,3 & 4,9 & 6,5 & 6,4 \\
\hline Productos agropecuarios & 6,8 & 4,3 & 4,7 & $\overline{9,4}$ & 6,4 & 3,1 & 5,0 & 4,0 & 5,9 & 5,9 \\
\hline Productos pecuarios & 0,5 & 0,9 & 5,9 & 6,8 & 1,5 & 1,9 & 3,5 & 4,8 & 8,4 & 7,4 \\
\hline Carne & 0,4 & $\overline{0,4}$ & 6,6 & 7,9 & 1,4 & 0,3 & 0,1 & 0,0 & 0,1 & 0,7 \\
\hline Cueros & 0,5 & 2,3 & 3,6 & 3,7 & 2,0 & 5,6 & 12,7 & 15,7 & 19,5 & 16,5 \\
\hline Productos agrícolas & 8,6 & 4,9 & 4,1 & 10,4 & $\overline{7,8}$ & 3,4 & 5,3 & 3,8 & 5,6 & 5,8 \\
\hline Cereales & 8,1 & $\overline{5,5}$ & 3,3 & 13,9 & 10,5 & $\overline{0,8}$ & 3,0 & 1,7 & 5,7 & 5,3 \\
\hline Oleaginosas & 5,7 & 1,9 & 3,1 & 6,3 & 3,7 & 2,5 & 2,0 & 3,0 & 2,9 & 3,5 \\
\hline Legumbres y hortalizas & & & & & & & & & & \\
\hline Frutos comestibles & 11,6 & 7,9 & 7,4 & 9,0 & 8,1 & 14,9 & 19,5 & 17,9 & 15,8 & 14,4 \\
\hline Pesca & 25,8 & 14,7 & 10,6 & 15,0 & 14,4 & 5,8 & 6,1 & 3,6 & 3,0 & 1,8 \\
\hline Productos industriales no tradicionales & 15,9 & 13,5 & 13,9 & 15,1 & 16,2 & 16,6 & 10,6 & 10,4 & 8,4 & 10,1 \\
\hline Alimentos & 28,5 & 23,8 & 16,8 & 12,4 & $\overline{9,4}$ & 10,8 & 14,1 & 10,1 & 7,3 & 12,8 \\
\hline Químicos & 18,8 & 11,9 & 13,6 & 18,8 & 16,5 & 10,0 & 7,8 & 7,5 & 11,5 & 10,2 \\
\hline Combustibles & 2,4 & 20,0 & 6,9 & 6,5 & 24,7 & 25,1 & 14,5 & 14,2 & 5,9 & 10,0 \\
\hline Maquinaria & 13,4 & 11,3 & 13,8 & 15,1 & 14,2 & 12,7 & 7,9 & 9,5 & 8,3 & 9,8 \\
\hline Resto & 12,8 & $\overline{13,7}$ & 17,4 & $\overline{9,2}$ & 9,4 & 10,6 & 13,3 & 3,5 & 8,2 & 3,5 \\
\hline ente: CEPAL & & & & & & & & & & \\
\hline
\end{tabular}

\begin{tabular}{|l|r|r|r|r|r|r|r|r|r|r|}
\hline Importaciones de Argentina desde Brasil como porcentaje de las importaciones totales por grupo de productos (en porcentaje) \\
\hline \multicolumn{1}{|c|}{ Grupo de productos } & $\mathbf{1 9 7 6}$ & $\mathbf{1 9 7 7}$ & $\mathbf{1 9 7 8}$ & $\mathbf{1 9 7 9}$ & $\mathbf{1 9 8 0}$ & $\mathbf{1 9 8 1}$ & $\mathbf{1 9 8 2}$ & $\mathbf{1 9 8 3}$ & $\mathbf{1 9 8 4}$ & $\mathbf{1 9 8 5}$ \\
\hline Total importaciones & $\mathbf{1 2 , 2}$ & $\mathbf{9 , 0}$ & $\mathbf{8 , 9}$ & $\mathbf{9 , 8}$ & $\mathbf{1 0 , 2}$ & $\mathbf{9 , 5}$ & $\mathbf{1 2 , 9}$ & $\mathbf{1 4 , 8}$ & $\mathbf{1 8 , 1}$ & $\mathbf{1 6 , 0}$ \\
\hline Bienes intermedios & 10,3 & 10,9 & 11,2 & 14,4 & 13,9 & 12,7 & 18,1 & 17,7 & 22,5 & 19,8 \\
\hline Alimentos & 47,3 & 43,7 & 37,3 & 40,0 & 30,1 & 22,3 & 37,9 & 31,1 & 42,7 & 31,0 \\
Químicos & 2,5 & 2,2 & 4,3 & 5,7 & 7,0 & 8,7 & 15,4 & 15,0 & 18,0 & 16,2 \\
Caucho & 1,5 & 4,5 & 2,6 & 4,4 & 10,7 & 10,7 & 20,2 & 25,7 & 19,8 & 21,1 \\
Madera & 20,5 & 24,3 & 31,7 & 31,8 & 23,3 & 19,0 & 26,5 & 19,9 & 12,0 & 17,2 \\
Papel & 2,1 & 2,2 & 5,6 & 13,2 & 16,2 & 15,1 & 21,3 & 23,0 & 31,1 & 30,7 \\
Hierro y acero & 15,4 & 17,9 & 19,9 & 25,6 & 23,8 & 26,0 & 39,4 & 34,3 & 47,8 & 45,1 \\
Repuestos & 5,5 & 4,9 & 5,3 & 8,0 & 10,7 & 8,6 & 6,6 & 8,1 & 11,4 & 10,3 \\
\hline Combustibles & 23,4 & 6,2 & 3,4 & 1,1 & 7,4 & 8,2 & 3,3 & 4,6 & 2,3 & 3,9 \\
\hline Bienes de capital & 4,7 & 5,2 & 5,8 & 6,0 & 7,6 & 7,0 & 6,2 & 11,4 & 12,5 & 12,0 \\
\hline Bienes de consumo no duraderos & 41,0 & 26,6 & 21,8 & 10,6 & 3,5 & 2,6 & 5,2 & 10,2 & 14,5 & 16,2 \\
\hline Resto & 10,6 & 11,2 & 9,5 & 12,7 & 9,4 & 8,3 & 12,3 & 15,4 & 17,5 & 15,5 \\
\hline Fuente: CEPAL. & & & & & & & & & \\
\hline
\end{tabular}

En el caso de las exportaciones, sobresalían en términos relativos los rubros alimentos, combustibles, frutos comestibles, químicos, maquinarias. En el caso de las importaciones, se destacaban los complejos alimentario, maderero y metalúrgico.

En suma, el punto de partida del proceso de integración regional es pasible de tipificarse a través de dos condiciones básicas: por una parte, la diferencia significativa de tamaños entre los principales países miembros y, por otra parte, un comercio bilateral relativamente reducido. 


\section{5.a.2. Argentina}

Argentina, al igual que Brasil, se caracteriza por un patrón espacial marcadamente concentrado. La evidente asimetría entre la participación de los grupos de provincias en el área total del país y la respectiva participación en la población total es el testimonio más simple de dicha situación (ver cuadro).

\begin{tabular}{|l|c|c|}
\hline \multicolumn{3}{|c|}{ Población y superficie (1991) } \\
\hline \multicolumn{1}{|c|}{ Región/Año } & Población (en porcentaje) & Superficie (en porcentaje) \\
\hline Región central & 64,7 & 21,8 \\
Región hinterland & 35,3 & 78,2 \\
\hline Nota: La región central comprende a Capital Federal, Buenos Aires, Santa Fé y Córdoba. \\
La región hinterland comprende al resto de las provincias. \\
Fuente: Indec.
\end{tabular}

En particular, la actividad industrial ha exhibido tradicionalmente un alto grado de aglomeración geográfica en nuestro país. La estabilidad de dicha concentración es asimismo manifiesta. Tal fenómeno puede visualizarse nítidamente a través del seguimiento de la evolución de una pluralidad de variables económicas. Una variante interesante consiste en observar la trayectoria temporal de un indicador sintético definido como un promedio simple de la participación de la jurisdicción provincial en el número de establecimientos, el personal ocupado, las remuneraciones abonadas, el valor de la producción y el valor agregado (Brambilla, Porto y Posadas, 1998). Como en el caso anterior, el cuadro presenta los datos en forma consistente con la distinción entre regiones realizada en el modelo teórico. A este respecto, se ha identificado como "región central" al conjunto de las provincias cuya importancia relativa en la industria medida por el indicador sintético excede el $4,5 \%$ en el promedio de la muestra. 


\begin{tabular}{|c|c|c|c|c|c|c|}
\hline Región/Año & 1935 & 1946 & 1953 & 1963 & 1974 & 1985 \\
\hline Región central & 83,6 & 84,3 & 81,9 & 82,5 & 84,2 & 81,2 \\
\hline Región hinterland & 16,4 & 15,7 & 18,1 & 17,6 & 15,8 & 18,8 \\
\hline
\end{tabular}

\section{5.b. La apertura de la economía}

\section{5.b.1. La apertura unilateral de la economía}

Argentina inició un proceso de liberalización comercial unilateral a partir de 1988 con la denominada "Reforma Canitrot". Antedicha reforma consistió en la eliminación del sistema de importación bajo licencia previa y la reducción moderada y progresiva de los aranceles para los insumos básicos. Como consecuencia, el arancel promedio descendió desde un promedio de 47\% en 1987 a una media de 26\% en 1989 (Berlinsky, 1994, 1997). La política de apertura comercial externa fue profundizada hacia comienzos de la década de 1990 a través de la supresión de las sobretasas, los aranceles mínimos y los aranceles específicos, la implementación de nuevas disminuciones en los aranceles nominales y el establecimientos de 3 niveles arancelarios $(0 \%$ para las materias primas, $11 \%$ para insumos intermedios y $22 \%$ para bienes manufacturados). El resultado fue una caída del promedio aritmético de aranceles a 12\% hacia fines de 1991 y una marcada reducción en la dispersión de los mismos.

A partir de octubre 1992, se asiste a una reversión en la tendencia declinante de los aranceles (Lifschitz y Crespo Armengol, 1995).

En el mes de noviembre de 1992 se dispuso la aplicación de reintegros a la exportación con el designio de compensar los impuestos que inciden en cascada a través de la cadena insumo-producto. La instrumentación de los mismos exigió espejar los aranceles nominales 
de modo de evitar la creación de desigualdades en los incentivos a vender en los mercados interno y externo.

Concomitantemente, se elevó en forma temporaria la tasa estadística del 3\% vigente a la sazón a un $10 \%$ (excepto en el caso de los bienes de capital y productos encuadrados bajo el régimen de admisión temporaria) y se incrementó el número de niveles arancelarios de acuerdo al valor agregado: $0 \%$ para bienes de capital no competitivos con la producción nacional; 2,5\% para bienes primarios; 5\%, 7,5\% y 10\% para la cadena de bienes alimenticios; 7,5\%, 10\% y 12,5\% para la cadena de industrias básicas (celulosa, papel y sus piezas, plástico, hierro y acero, otros metales, telas de la cadena textil) y $20 \%$ para consumo final (vestuario, electrodomésticos, automóviles, etc) (CEP, 1998). La estructura arancelaria antes descripta se mantuvo esencialmente sin modificaciones hasta diciembre de 1994, que constituye el límite superior del lapso bajo estudio. Cabe subrayar que la misma experimenta modificaciones sustanciales a partir de 1995, año en que comienza a regir el Arancel Externo Común del Mercosur.

\begin{tabular}{|c|c|c|c|c|c|c|c|c|}
\hline \multicolumn{9}{|c|}{ La apertura comercial unilateral de Argentina } \\
\hline & 1987 & 1988 & 1989 & 1990 & 1991 & 1992 & $1993(*)$ & $1994(*)$ \\
\hline $\begin{array}{l}\text { Arancel } \\
\text { promedio }\end{array}$ & 47,0 & 28,8 & 26,4 & 17,2 & 9,3 & 10,2 & 9,8 & 9,1 \\
\hline Dispersión & 22,5 & 13,9 & 12,8 & 5,3 & 8,9 & 5,1 & 9,5 & 5,7 \\
\hline Modo & & 40,0 & 37 & 24 & - & - & - & - \\
\hline Máximo & 85,0 & 40,0 & 40 & 24 & 35 & 20 & 20 & 20 \\
\hline Mínimo & 0,0 & 0,0 & 5,0 & 0,0 & 0,0 & 0,0 & 0,0 & 0,0 \\
\hline $\begin{array}{l}\text { Nota: }(*) \text { Lo } \\
\text { Los datos de } \\
\text { los valores d } \\
\text { Fuente: San }\end{array}$ & & & & & & & & $\begin{array}{l}\text { viembre, } \\
\text { abril. }\end{array}$ \\
\hline
\end{tabular}

\section{5.b.2. El proceso de integración regional: La constitución del Mercosur}

La apertura comercial argentina también asumió una modalidad regional mediante el Mercosur. En este caso, las medidas de liberalización de las operaciones de comercio 
exterior sólo se aplicaron sobre las importaciones procedentes de los países con quienes se había constituído el bloque comercial: Brasil, Paraguay y Uruguay.

El Mercosur fue establecido por el Tratado de Asunción de 1991, que representó la manifestación formal de un proceso tendiente a la integración regional asentado en el afianzamiento de una concepción cooperativa en las relaciones entre los países de la región.

El Tratado de Asunción tuvo como objetivo la conformación gradual de un mercado común, definido en base a la concurrencia de las siguientes condiciones:

- la libre circulación de bienes, servicios y factores productivos, a través de la supresión de los derechos aduaneros, las restricciones no arancelarias y otras medidas equivalentes;

- el establecimiento de un arancel externo común y la adopción de una política comercial común;

- la coordinación de políticas macroeconómicas y sectoriales entre los Estados Parte;

- el compromiso de los países miembros de armonizar sus legislaciones en áreas pertinentes.

Asimismo, se determinó un conjunto de instrumentos para el período de transición hasta la puesta en práctica de la unión aduanera en 1995. Desde el prima perspéctico del tema bajo consideración y el período sujeto a análisis, el elemento más relevante es el programa de liberalización comercial, que consistió en rebajas arancelarias progresivas, lineales y automáticas y la eliminación de medidas no arancelarias o de efectos equivalentes ${ }^{38}$.

El cronograma de reducciones arancelarias contemplado en el Tratado de Asunción prevía un aumento semestral de las mismas hasta alcanzar la preferencia total en el mercado común a principios de 1995. Cada país signatario del acuerdo presentó oportunamente una lista de excepciones. En el caso de nuestro país, la misma caducó el 31 de diciembre de 1994; sin embargo, gran parte de los productos incluidos en ella se incorporaron al denominado Régimen de Adecuación Final a la Unión Aduanera, que supuso una reprogramación de las desgravaciones hasta llegar al arancel nulo a comienzos de 1999.

\footnotetext{
${ }^{38}$ Aun cuando el cronograma arancelario se cumplió en líneas generales, la supresión de las barreras no arancelarias ha sufrido importantes dilaciones.
} 
El criterio instrumental definido consistía en aplicar las preferencias arancelarias a cada tipo de bien sobre las preferencias previamente concedidas para los mismos a la fecha de la firma del tratado constitutivo por las naciones miembro en el marco de la ALADI o en virtud de acuerdos bilaterales o multilaterales preexistentes.

La siguiente tabla muestra el cronograma estipulado originariamente.

\begin{tabular}{|c|c|c|c|c|c|c|c|c|c|}
\hline \multicolumn{10}{|c|}{ Mercosur } \\
\hline $12 / 90$ & $1 / 91$ & $6 / 91$ & $12 / 91$ & $6 / 92$ & $12 / 92$ & $6 / 93$ & $12 / 93$ & $6 / 94$ & $12 / 94$ \\
\hline 00 a 40 & 40 & 47 & 54 & 61 & 68 & 75 & 82 & 89 & 100 \\
\hline 41 a 45 & 50 & 52 & 59 & 66 & 73 & 80 & 87 & 94 & 100 \\
\hline 46 a 50 & 50 & 57 & 64 & 71 & 78 & 85 & 92 & 100 & \\
\hline 51 a 55 & 55 & 61 & 67 & 73 & 79 & 86 & 93 & 100 & \\
\hline 56 a 60 & 60 & 67 & 74 & 81 & 88 & 95 & 100 & & \\
\hline 61 a 65 & 65 & 71 & 77 & 83 & 89 & 96 & 100 & & \\
\hline 66 a 70 & 70 & 75 & 80 & 85 & 90 & 95 & 100 & & \\
\hline 71 a 75 & 75 & 80 & 85 & 90 & 95 & 100 & & & \\
\hline 76 a 80 & 80 & 85 & 90 & 95 & 100 & & & & \\
\hline 81 a 85 & 85 & 89 & 93 & 97 & 100 & & & & \\
\hline 86 a 90 & 90 & 95 & 100 & & & & & & \\
\hline 91 a 95 & 95 & 100 & & & & & & & \\
\hline 96 a 100 & 100 & & & & & & & & \\
\hline
\end{tabular}

\section{5.c. La dimensión comercial}

El Mercosur trajo aparejado una expansión notable en el comercio intrabloque. En términos absolutos, el mismo se incrementó un 506,3\%, lo cual significa una tasa anual promedio del $22,2 \%$. En términos relativos, esto es, en relación al intercambio que los países miembros realizan con el resto de los países del mundo, dicho comercio ascendió de 6,7\% del total exportado en 1988 al 24\% de idéntico agregado en 1997 (CEP, 1998). El crecimiento del comercio intrazona también puede apreciarse mediante la evolución del índice de intensidad de dicho comercio, que es un método más preciso para evaluar su 
significación $^{39}$. Sobredicho índice pone de manifiesto un marcado aumento en la intensidad del comercio intrabloque para nuestro país hasta 1995.

\begin{tabular}{|c|c|c|c|}
\hline Año & $\begin{array}{c}\text { Intensidad del comercio intrarregional } \\
\text { Mensidad Comercio }\end{array}$ & $\begin{array}{c}\text { Intensidad } \\
\text { Exportaciones } \\
\text { Argentinas-Mercosur }\end{array}$ & $\begin{array}{c}\text { Intensidad } \\
\text { Exportaciones Brasil - } \\
\text { Mercosur }\end{array}$ \\
\hline 1986 & 7,8 & 11,5 & 5,0 \\
\hline 1987 & 8,3 & 15,8 & 5,3 \\
\hline 1988 & 8,8 & 15,4 & 5,8 \\
\hline 1989 & 9,1 & 17,2 & 4,5 \\
\hline 1990 & 10,5 & 17,1 & 5,0 \\
\hline 1991 & 11,6 & 17,4 & 7,7 \\
\hline 1992 & 14,2 & 19,0 & 11,4 \\
\hline 1993 & 14,2 & 21,6 & 10,7 \\
\hline 1994 & 12,9 & 19,6 & 9,5 \\
\hline 1996 & 13,7 & 22,0 & 8,9 \\
\hline Fuente: CEP (1998). & 13,5 & 20,0 & 9,1 \\
\hline
\end{tabular}

En particular, la puesta en funcionamiento del Mercosur estuvo asociada a un aumento de del comercio intraindustrial entre Argentina y Brasil medido por el índice de Grubel-Lloyd, tal como cabría esperar de acuerdo a la teoría (ver gráfico).

\footnotetext{
39 Dicho índice considera, además de la participación de las exportaciones intrazona y las totales, las
} exportaciones mundiales, razón por la cual es un indicador más exacto. 


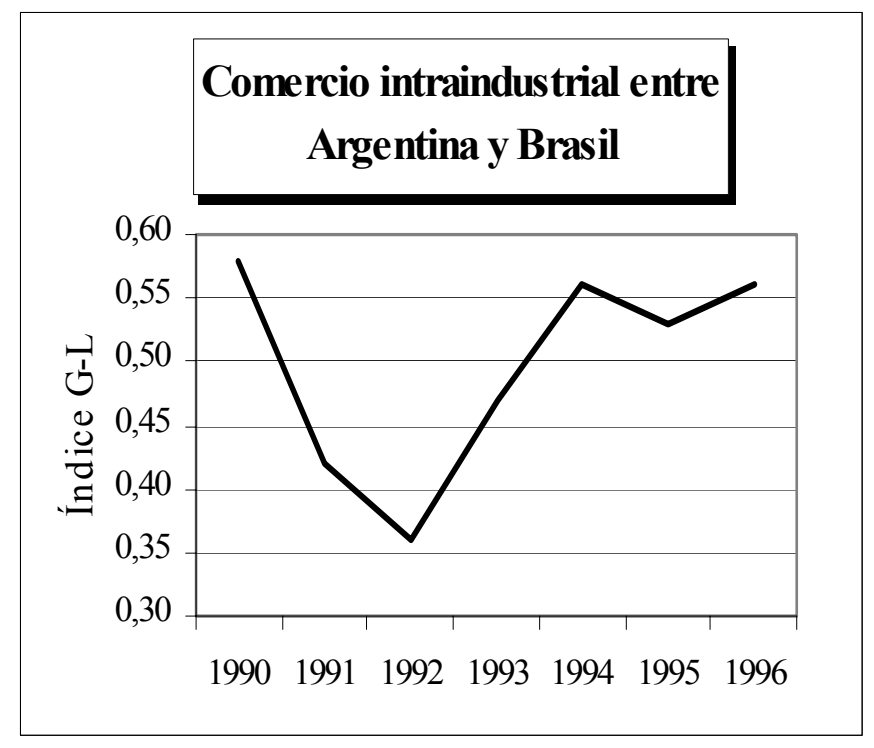

Fuente: Baumann (1998).

El fenómeno antes destacado posee naturalmente una dimensión sectorial. Los siguientes gráficos ilustran la evolución de la importancia relativa de Brasil en el comercio exterior de nuestro país para cada una de las categorías de dos dígitos de la clasificación CIIU (revisión 3). En consonancia natural con el patrón agregado, en la mayor parte de los casos, se nota una suba de la misma que es singularmente pronunciada en los sectores de productos textiles, prendas de vestir, madera, maquinaria y aparatos eléctricos, equipos y aparatos de radio, televisión y comunicación y vehículos automotores, remolques y semirremolques. 

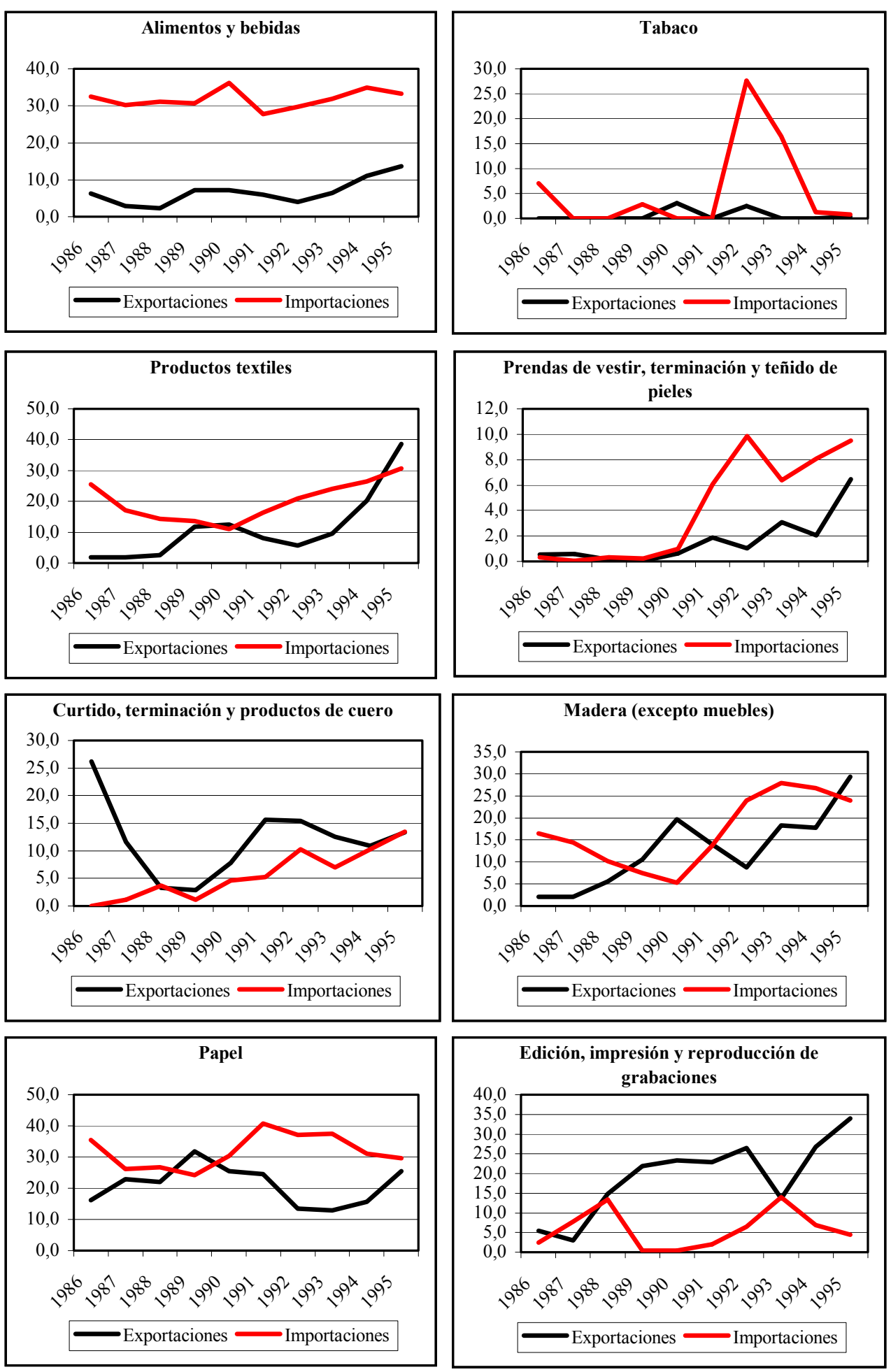

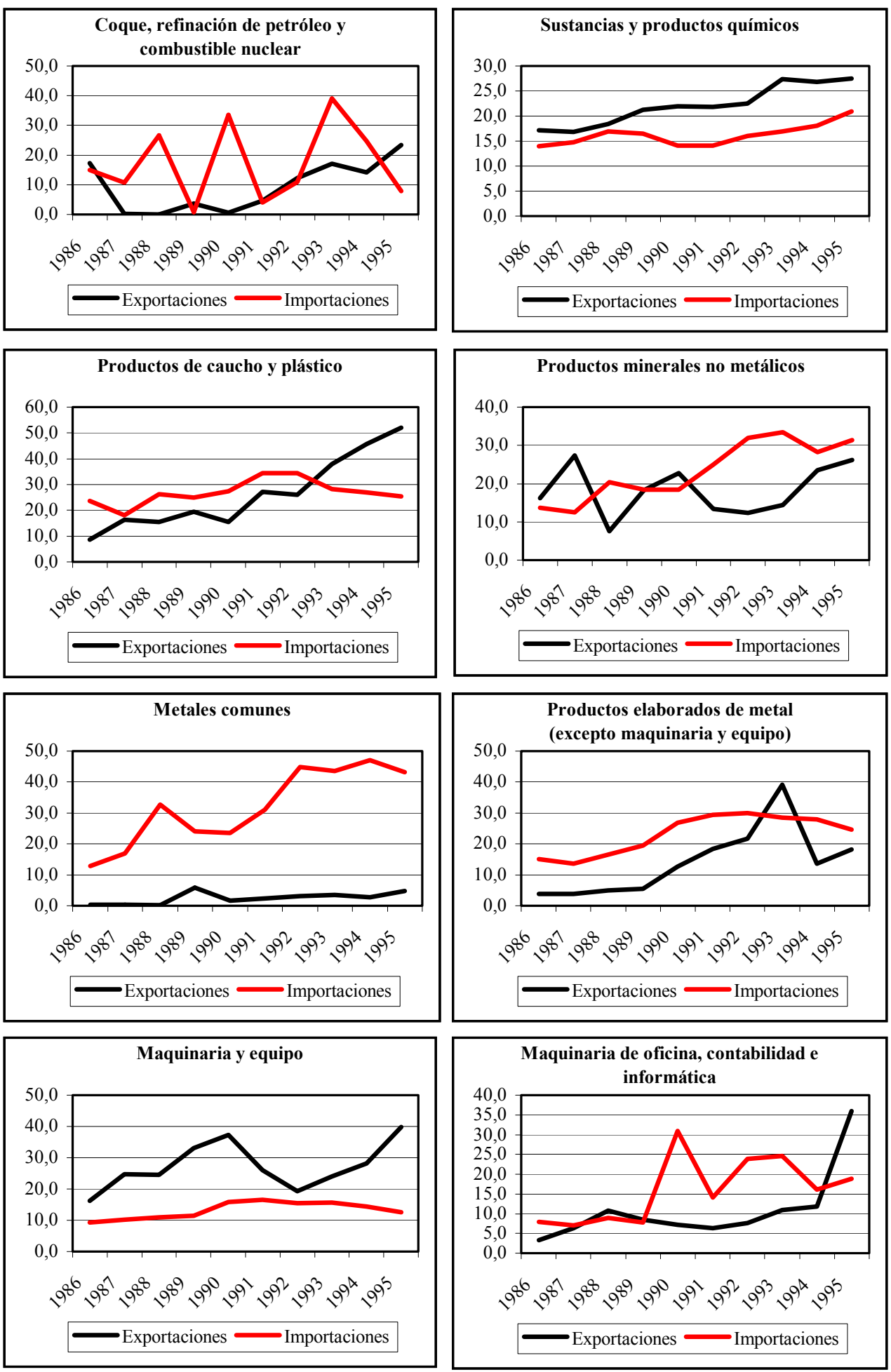

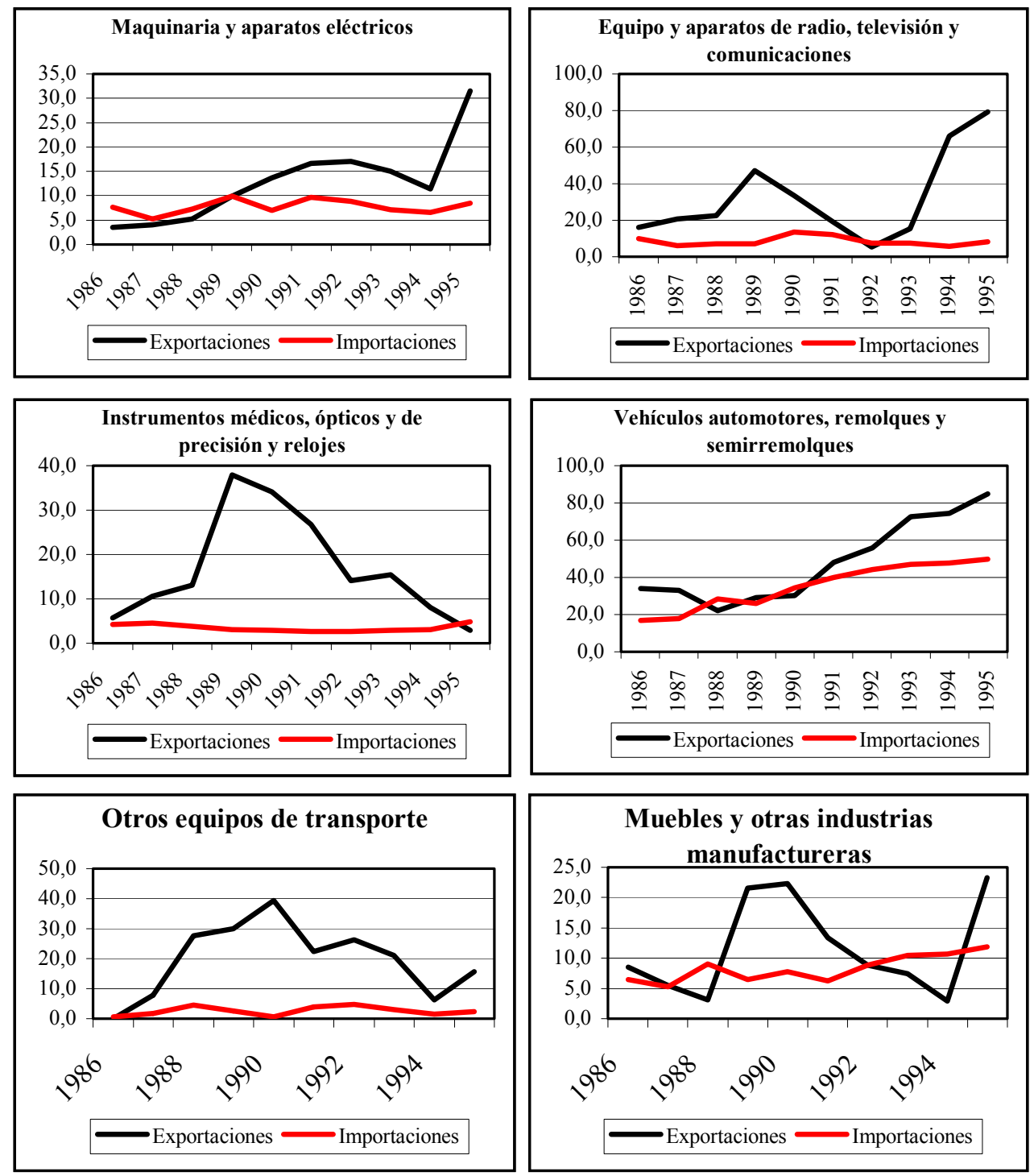

Fuente: Elaboración propia en base a BID/INTAL. 
El comportamiento del comercio intraindustrial entre Argentina y Brasil contrasta manifiestamente con los desarrollos del intercambio agregado (ver gráfico). La variación negativa registrada en diversas categorías es la consecuencia obvia de la apertura unilateral para una economía pequeña prevista por el tipo de modelo teórico aquí considerado.

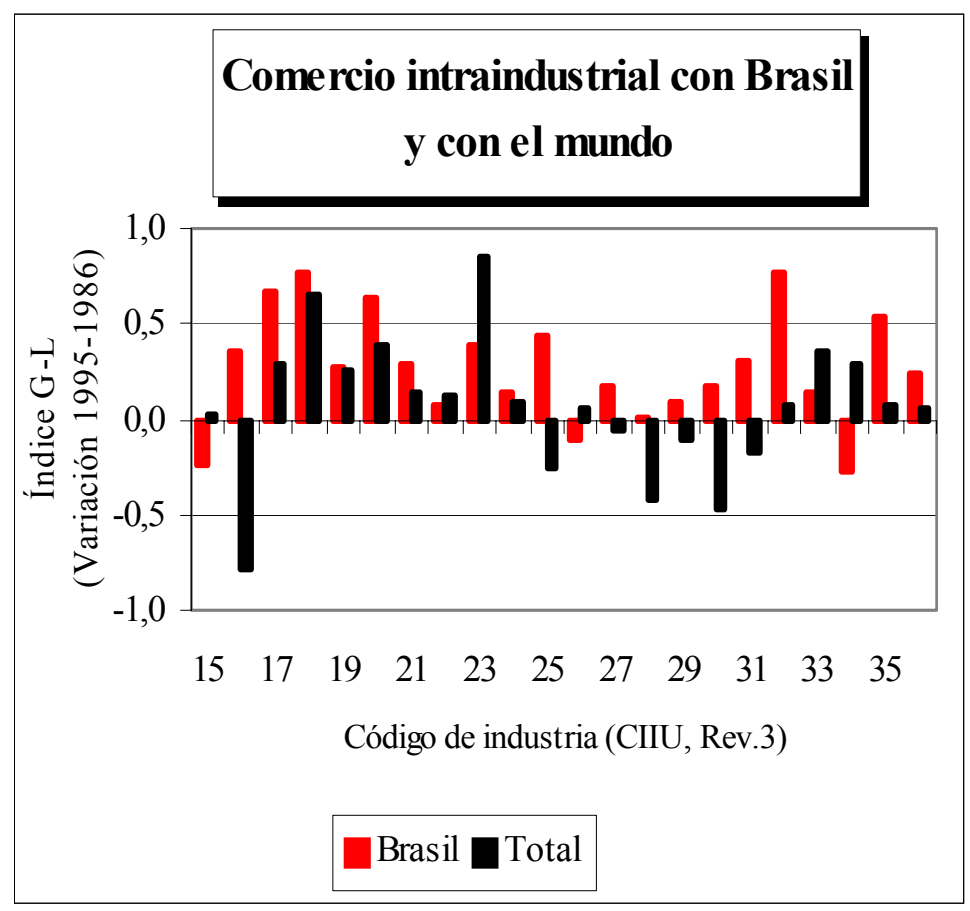

Fuente: Elaboración propia en base a BID/INTAL.

Finalmente, el fenómeno estudiado también reconoce una faceta regional. El siguiente cuadro muestra las exportaciones provinciales argentinas en el período 1993-1996 y la correspondiente participación de Brasil. 


\begin{tabular}{|c|c|c|c|c|c|c|c|c|}
\hline \multicolumn{9}{|c|}{ Exportaciones provinciales } \\
\hline \multirow[t]{2}{*}{ Provincia } & \multicolumn{4}{|c|}{$\begin{array}{c}\text { Exportaciones totales } \\
\text { (en millones de dólares) }\end{array}$} & \multicolumn{4}{|c|}{$\begin{array}{c}\text { Exportaciones al Mercosur } \\
\text { (en \%) }\end{array}$} \\
\hline & 1993 & 1994 & 1995 & 1996 & 1993 & 1994 & 1995 & 1996 \\
\hline Buenos Aires & $5.198,6$ & $6.223,2$ & $8.133,7$ & $8.908,8$ & 33,2 & 33,9 & 36,2 & 40,8 \\
\hline Capital Federal & 189,7 & 306,9 & 260,8 & 255,9 & 28,5 & 25,2 & 37,3 & 42,5 \\
\hline Catamarca & 11,5 & 25,0 & 18,4 & 21,6 & 30,5 & 23,3 & 35,8 & 34,0 \\
\hline Chaco & 152,6 & 246,2 & 389,4 & 427,2 & 22,6 & 37,3 & 19,7 & 34,1 \\
\hline Chubut & 396,1 & 540,4 & 745,4 & 841,9 & 12,9 & 16,5 & 16,3 & 20,9 \\
\hline Córdoba & $1.399,0$ & $1.599,3$ & $2.000,3$ & $2.332,4$ & 29,6 & 36,1 & 42,1 & 33,0 \\
\hline Corrientes & 65,9 & 97,3 & 145,0 & 121,4 & 41,6 & 39,0 & 54,5 & 33,0 \\
\hline Entre Ríos & 222,3 & 205,1 & 381,7 & 404,9 & 29,5 & 32,7 & 42,6 & 48,0 \\
\hline Formosa & 31,4 & 35,0 & 52,9 & 56,2 & 48,3 & 60,8 & 46,9 & 37,7 \\
\hline Jujuy & 70,3 & 70,7 & 107,1 & 148,6 & 11,5 & 11,3 & 10,9 & 9,9 \\
\hline La Pampa & 105,3 & 130,9 & 143,3 & 145,7 & 38,1 & 42,4 & 40,2 & 42,8 \\
\hline La Rioja & 46,6 & 69,9 & 136,0 & 114,3 & 39,8 & 39,3 & 35,9 & 45,9 \\
\hline Mendoza & 471,8 & 460,5 & 728,2 & 657,0 & 42,4 & 46,8 & 41,1 & 46,8 \\
\hline Misiones & 138,5 & 155,6 & 231,6 & 195,9 & 9,4 & 14,6 & 17,9 & 17,4 \\
\hline Neuquén & 319,2 & 538,7 & 6996,9 & 810,1 & 59,7 & 44,6 & 40,0 & 44,1 \\
\hline Río Negro & 212,8 & 232,6 & 404,0 & 418,9 & 34,4 & 38,9 & 31,5 & 35,6 \\
\hline Salta & 176,2 & 228,5 & 303,7 & 363,1 & 19,0 & 30,5 & 24,0 & 26,9 \\
\hline San Juan & 41,9 & 46,1 & 85,8 & 110,5 & 52,0 & 44,9 & 29,5 & 34,1 \\
\hline San Luis & 88,2 & 111,4 & 203,3 & 238,4 & 22,7 & 26,4 & 48,2 & 47,0 \\
\hline Santa Cruz & 328,4 & 567,2 & 768,6 & $1.297,9$ & 11,1 & 25,0 & 26,4 & 34,4 \\
\hline Santa Fe & $2.501,9$ & $2.838,1$ & $3.455,9$ & $4.218,0$ & 12,1 & 15,9 & 15,2 & 13,0 \\
\hline Santiago del Estero & 38,4 & 62,0 & 133,5 & 174,0 & 25,5 & 40,7 & 22,5 & 30,3 \\
\hline Tierra del Fuego & 195,6 & 237,0 & 232,8 & 262,4 & 43,1 & 34,0 & 35,1 & 38,2 \\
\hline Tucumán & 153,3 & 223,7 & 387,4 & 362,5 & 38,6 & 39,8 & 42,7 & 29,9 \\
\hline Extranjero & 91,6 & 141,5 & 224,1 & 322,3 & 32,4 & 24,6 & 44,1 & 26,7 \\
\hline Indeterminado & 470,7 & 446,6 & 593,1 & 600,8 & 32,1 & 32,6 & 42,2 & 43,9 \\
\hline Total del país & $13.117,8$ & $15.839,4$ & $20.962,9$ & $23.810,7$ & & & & \\
\hline
\end{tabular}


La mayor parte de las provincias incrementaron sus ventas externas. Adicionalmente, se observa que en la mayoría de las jurisdicciones creció la participación de las exportaciones dirigidas a Brasil en las exportaciones totales. Ahora bien, corresponde destacar que las provincias avanzadas (Buenos Aires, Capital Federal, Córdoba y Santa Fe) explicaron en promedio el $77,5 \%$ de las exportaciones totales al principal socio comercial del Mercosur en el trienio 1994-1996. En consecuencia, las ventas externas a Brasil exhiben una elevada concentración en su procedencia geográfica.

\section{5.d. La dimensión espacial de la industria en Argentina ${ }^{40}$}

\section{5.d.1. El centro de gravedad de las industrias}

Un método sencillo para evaluar la evolución general del patrón de localización de la industria consiste en calcular el denominado índice de gravedad económica. El mismo es un vector de dos elementos que se define del siguiente modo:

$\phi_{i}=\sum_{j}\left(L_{i j} / \sum_{j} L_{i j}\right) *\left(\right.$ Latitud $_{j}$, Longitud $\left._{j}\right)$

donde $\phi_{i}$ representa el índice de gravedad económica correspondiente a la industria $i, L_{i j}$ indica el nivel de empleo en la industria $i$ en la provincia $j$ y finalmente "latitud $d_{j}$ y “longitud ${ }_{j}$ " son las coordenadas cartográficas de la ciudad principal desde el punto de vista de su importancia económica de la provincia $j$. El índice de gravedad económica es entonces un índice "vectorial" que surge de sumar las latitudes y longitudes de las ciudades representativas de cada provincia ponderadas por la participación de la misma en la industria de referencia. De esta forma, cuanto mayor es la importancia relativa de una jurisdicción en una rama manufacturera, mayor es su peso en la determinación del patrón

\footnotetext{
${ }^{40}$ Cabe tener presente que los cambios en la configuración espacial de la industria se enmarca en un proceso de profunda reestruturación sectorial. Así, mientras la producción en volumen creció un 41\% entre 1990 y 1997, la cantidad de obreros empleados por la misma redujo un 16\% (Sarghini, Narodowski y Lódola, 1998).
} 
geográfico; en el límite, si la industria se concentra exclusivamente en una única provincia, su factor de ponderación es 1 , el factor de ponderación de las restantes provincias es cero y el índice de gravedad concide exactamente con las coordenadas cartográficas de la ciudad correspondiente a la provincia en cuestión.

Dicho índice fue calculado para los años 1985 y 1993 para las 22 ramas industriales de la clasificación CIIU (revisión 3) de dos dígitos. Los gráficos que se incluyen a continuación muestran los cambios operados en los respectivos índices de gravedad de cada una de tales actividades ${ }^{41}$.

\footnotetext{
${ }^{41}$ Los límites de los gráficos están dados, en el caso del eje vertical, por las latitudes mínima y máxima de las ciudades seleccionadas y, en el caso del eje horizontal, por las longitudes mímina y máxima de las mismas.
} 


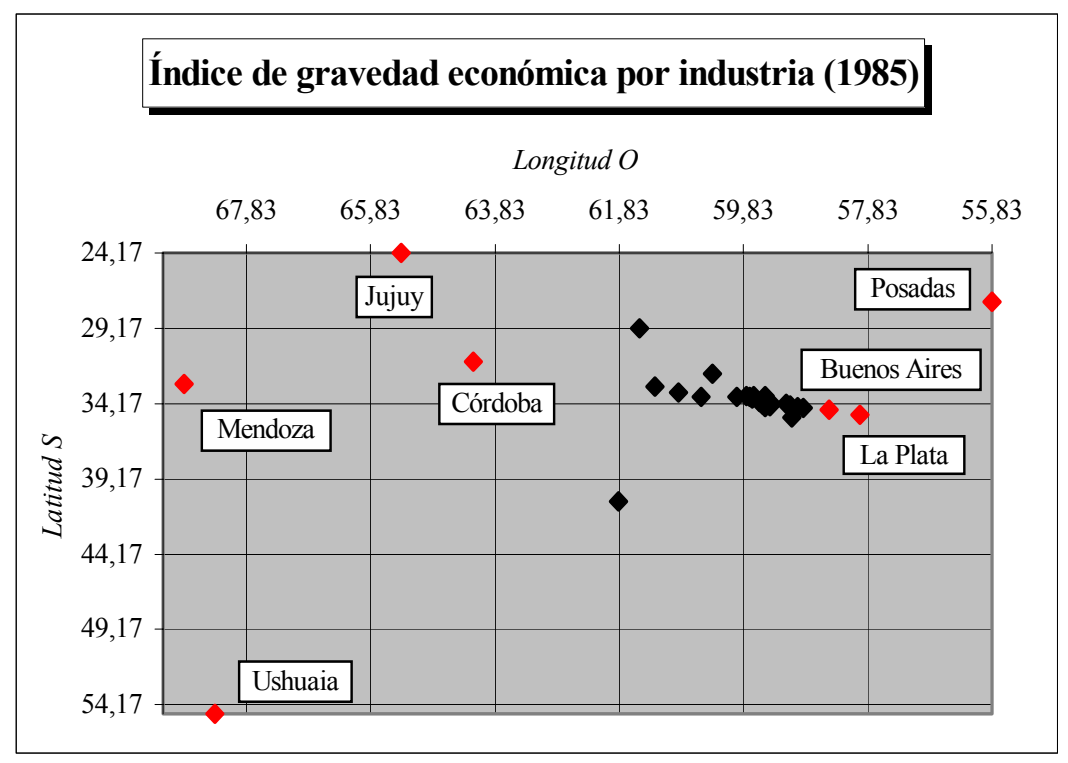

Fuente: Elaboración propia en base a Censo Nacional Económico 1985.

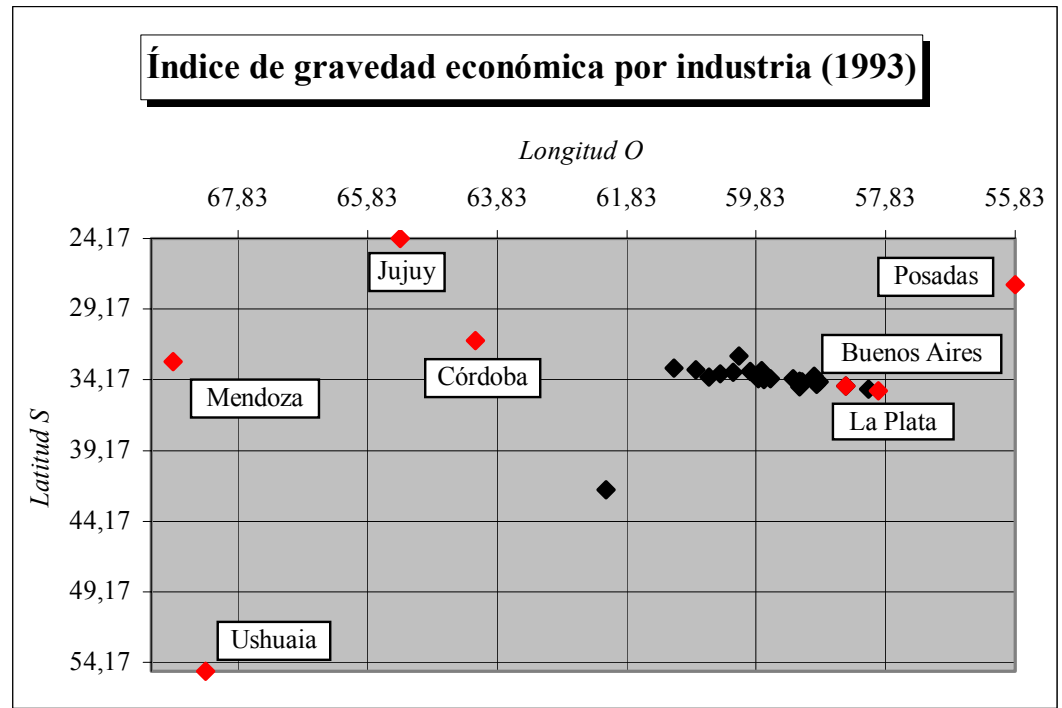

Fuente: Elaboración propia en base a Censo Nacional Económico 1994. 


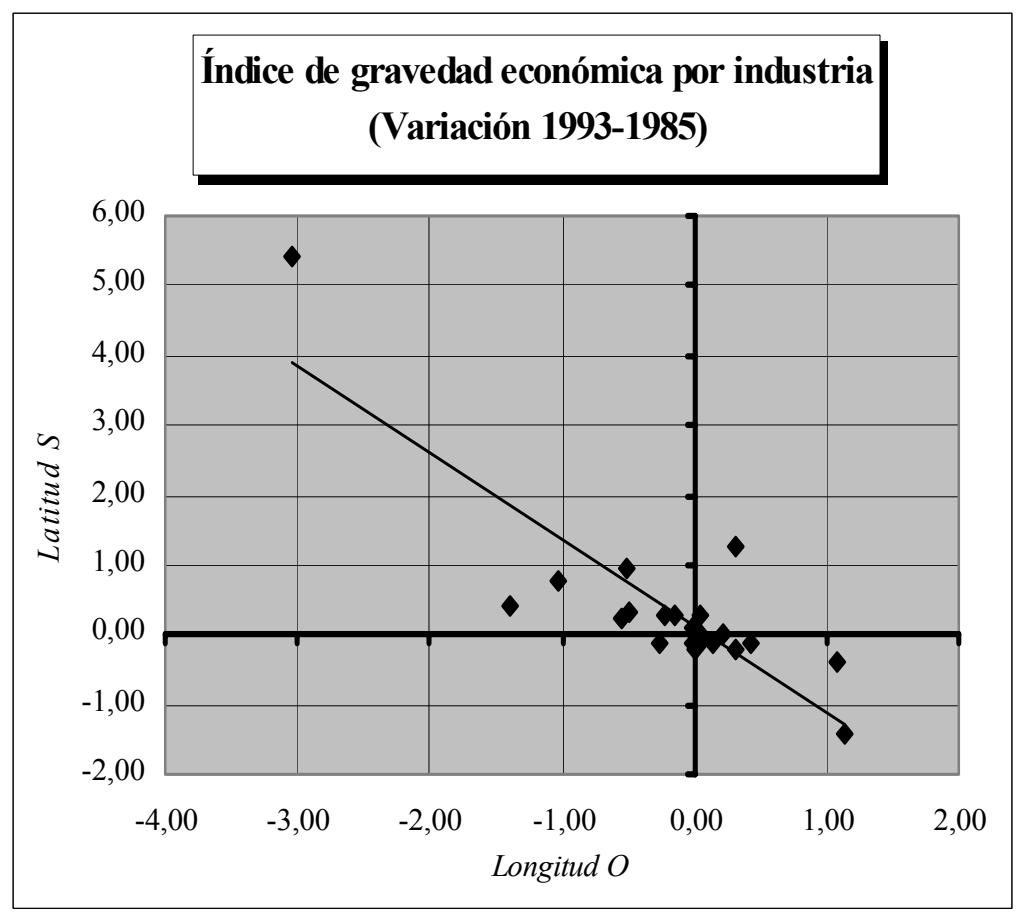

Fuente: Elaboración propia en base a Censos Nacionales Económicos 1985 y 1994.

Las figuras indican, en primer término, una elevada concentración espacial de las industrias, que parece persistir e incluso acentuarse en el tiempo. En segundo término, es posible determinar la prevalencia de un movimiento en dirección sur en el patrón de localización industrial $^{42}$. Específicamente, 12 de las 22 ramas industriales contempladas, con una participación conjunta del $57 \%$ en el empleo manufacturero total, experimentaron una traslación en sobredicha dirección en su centro de gravedad. Además, la significancia del corrimiento es mayor para las industrias que evidenciaron una orientación sur en el mismo; así, mientras que la variación en la latitud promedio por industria en el conjunto de los sectores cuyo epicentro se movió hacia el sur es de 0,86 , el cambio correspondiente a los sectores con un comportamiento opuesto sólo es de 0,27.

Ahora bien, es necesario reconocer que la modificación verificada en la pauta geográfica de la industria del tabaco, que en el gráfico correspondiente a 1985 estaba reflejado por el punto situado más al norte, está claramente afectada por problemas de secreto estadístico en

\footnotetext{
${ }^{42}$ Cabe resaltar que el punto que se ubica a una distancia considerable de la aglomeración corresponde a la rama 32, esto es, la industria de equipos y aparatos de comunicación, radio y televisión. Indudablemente, el
} 
la información proporcionada por el Censo Económico Nacional de 1994. Si se excluye tal sector se obtiene el siguiente cuadro de situación.

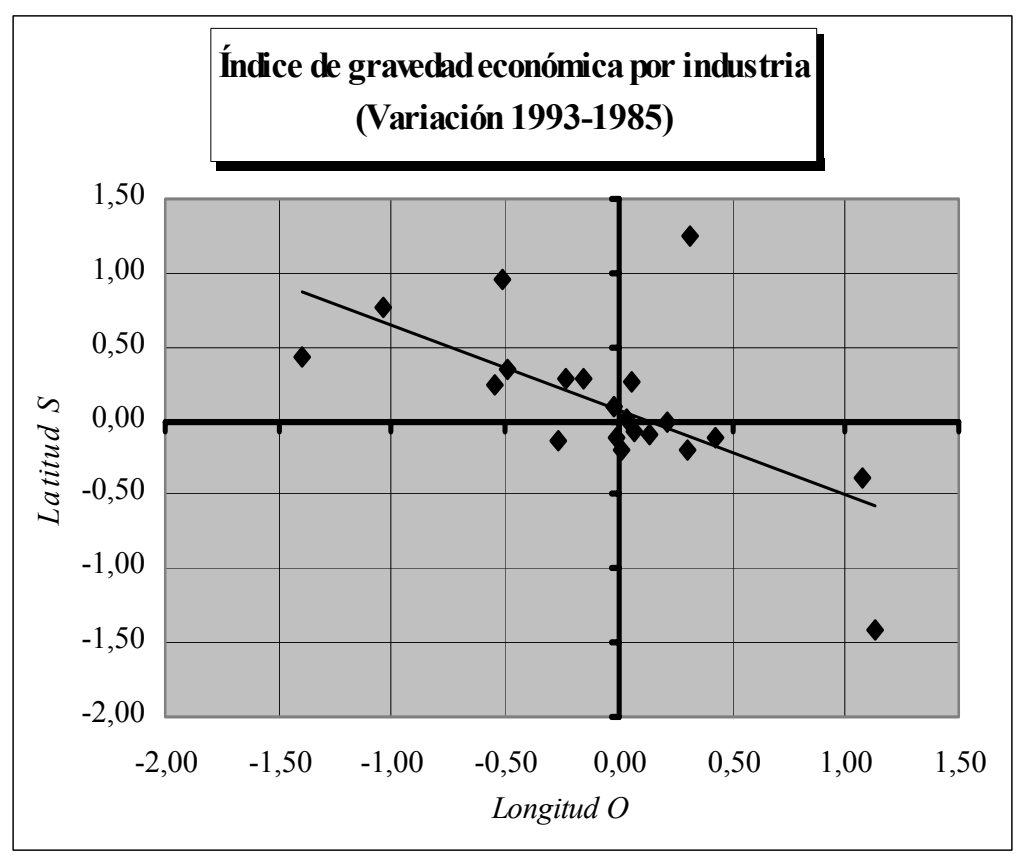

Fuente: Elaboración propia en base a Censos Nacionales Económicos 1985 y 1994.

El gráfico permite apreciar que aun cuando la intensidad es menor el sentido del desplazamiento espacial subsiste.

\section{5.d.2. La dimensión regional}

La desigualdad de tamaños económicos entre las regiones da lugar a la distinción teórica de un "centro" y una "periferia". Ello se puede capturar mediante el empleo del índice de centralidad ideado por Keeble (1986):

mismo puede explicarse por la importancia de Tierra del Fuego inducida por el régimen de promoción industrial instrumentado en la zona. 
$K_{i}=\sum_{j} \frac{Y_{j}}{D_{i j}}+\frac{Y_{i}}{D_{i i}} \quad ; i \neq j$

donde $i$ es la provincia focal, $j$ corresponde a las restantes provincias del país, $Y_{i}$ es el producto bruto geográfico de la provincia $i, D_{i j}$ mide la menor distancia de ruta entre las mayores ciudades en las provincias $i$ y $j$ y $D_{i i}$ es la distancia intrarregional, que se mesura como un tercio del radio de un círculo de la misma área que la región $i$. Una simple inspección de la fórmula que define el índice permite apreciar que el valor que adopta es más elevado cuanto mayor es el producto bruto geográfico de la región focal $\left(Y_{i}\right)$, entendido como una proxy del tamaño de su mercado, y cuanto menor es la distancia de la misma en relación a los principales mercados de las restantes regiones $\left(D_{i j}\right)$. En consecuencia, una región central es aquella que posee un mercado grande y cuenta con una ubicación favorable en términos del acceso a las restantes localizaciones. Indudablemente, la concurrencia de tales características determina que la región emerja como un emplazamiento conveniente para la actividad económica.

En el caso de nuestro país, los datos de PBG necesarios, que están expresados en pesos constantes de 1986, se han extraido de un trabajo reciente de la Facultad de Ciencias Económicas de la Universidad Nacional de La Plata publicado en la Serie de Estudios Fiscales (1999), en tanto los datos de distancia se han obtenido de un atlas publicado por el Automóvil Club Argentino ${ }^{43}$.

\footnotetext{
${ }^{43}$ La mayor parte de las ciudades representativas de las provincias corresponden a las respectivas capitales, con la excepción destacable de Rosario en el caso de Santa Fe originada obviamente en su peso económico relativo.
} 


\begin{tabular}{|c|c|c|c|c|c|}
\hline \multicolumn{6}{|c|}{ Índice de centralidad de Keeble } \\
\hline Provincia & \begin{tabular}{|l|}
$\begin{array}{l}\text { Valor del índice } \\
\text { de Keeble } 1985\end{array}$ \\
\end{tabular} & \begin{tabular}{|c|} 
Valor relativo del \\
índice de Keeble 1985 \\
\end{tabular} & $\begin{array}{l}\text { Valor del índice } \\
\text { de Keeble 1993 } \\
\end{array}$ & \begin{tabular}{|c|} 
Valor relativo del \\
índice de Keeble 1993 \\
\end{tabular} & $\begin{array}{c}\text { Var. Rel. } \\
1993-1985 \\
\end{array}$ \\
\hline Capital Federal & 825,8 & 0,684147 & 1107,8 & 0,692763 & 0,008616 \\
\hline Buenos Aires & 70,2 & 0,058150 & 97,5 & 0,060962 & 0,002812 \\
\hline Catamarca & 12,0 & 0,009936 & 15,3 & 0,009577 & $-0,000359$ \\
\hline Córdoba & 21,7 & 0,017977 & 27,4 & 0,017152 & $-0,000825$ \\
\hline Corrientes & 17,6 & 0,014556 & 22,1 & 0,013814 & $-0,000743$ \\
\hline Chaco & 19,3 & 0,015951 & 24,8 & 0,015529 & $-0,000421$ \\
\hline Chubut & 8,9 & 0,007356 & 10,9 & 0,006809 & $-0,000546$ \\
\hline Entre Ríos & 22,7 & 0,018833 & 29,5 & 0,018450 & $-0,000383$ \\
\hline Formosa & 10,4 & 0,008576 & 13,3 & 0,008306 & $-0,000270$ \\
\hline Jujuy & 10,8 & 0,008987 & 13,4 & 0,008369 & $-0,000618$ \\
\hline La Pampa & 14,5 & 0,012010 & 18,0 & 0,011283 & $-0,000727$ \\
\hline La Rioja & 11,5 & 0,009525 & 14,7 & 0,009174 & $-0,000351$ \\
\hline Mendoza & 14,1 & 0,011643 & 16,5 & 0,010315 & $-0,001328$ \\
\hline Misiones & 12,1 & 0,010004 & 16,0 & 0,010014 & 0,000010 \\
\hline Neuquén & 11,2 & 0,009253 & 15,3 & 0,009580 & 0,000327 \\
\hline Río Negro & 11,0 & 0,009134 & 13,8 & 0,008637 & $-0,000497$ \\
\hline Salta & 10,5 & 0,008688 & 13,0 & 0,008148 & $-0,000540$ \\
\hline San Juan & 12,3 & 0,010171 & 15,4 & 0,009604 & $-0,000567$ \\
\hline San Luis & 14,6 & 0,012054 & 19,9 & 0,012415 & 0,000361 \\
\hline Santa Cruz & 4,8 & 0,004003 & 6,1 & 0,003807 & $-0,000196$ \\
\hline Santa Fe & 33,3 & 0,027619 & 42,2 & 0,026416 & $-0,001202$ \\
\hline Santiago del Estero & 13,2 & 0,010921 & 16,6 & 0,010356 & $-0,000565$ \\
\hline Tierra del Fuego & 5,9 & 0,004877 & 6,2 & 0,003883 & $-0,000994$ \\
\hline Tucumán & 18,9 & 0,015631 & 23,4 & 0,014635 & $-0,000995$ \\
\hline Promedio & 50,3 & & 66,6 & & \\
\hline
\end{tabular}

Los guarismos derivados que se consignan en la tabla revelan, por un lado, una diferencia significativa entre la centralidad de las principales jurisdicciones avanzadas, Capital Federal, Buenos Aires, Córdoba y Santa Fe, y la correspondiente a las restantes provincias $\mathrm{y}$, por otro lado, un aumento en la centralidad relativa de las dos primeras jurisdicciones, lo cual es completamente consistente con el movimiento que se ha identificado en el patrón de localización industrial ${ }^{44}$.

Asimismo, el cuadro hace posible advertir otros hechos interesantes.

\footnotetext{
${ }^{44}$ La medida relativa, que apunta a aprehender las variaciones en la centralidad comparativa, surge de la suma de los índices de cada provincia y la estimación ulterior de la proporción que cada provincia significa en el total.
} 
Por una parte, la elevada centralidad relativa de la provincia de Entre Ríos, que puede explicarse fácilmente por su cercanía a los mercados más importantes del país.

Por otra parte, el aumento de la centralidad relativa de Misiones, Neuquén y San Luis. En tales casos, la variación del indicador obedece al comportamiento positivo del propio PBG que podría originarse en los efectos del Mercosur, el auge de la actividad petrolera en la primera parte de la década de 1990 y las implicancias del régimen de promoción industrial, respectivamente.

\section{5.d.3. El sesgo localizacional hacia el centro}

El sesgo localizacional de las industrias hacia la región central se puede determinar a través del cálculo de coeficiente de correlación de Pearson entre

$$
\left(L_{i} / \sum_{i} L i\right)_{j} \text { y } K_{j},
$$

donde $L_{i}$ indica el nivel de empleo en el sector manufacturero $i$ y $j$ señala la región y $K_{j}$ es el índice de centralidad correspondiente a la misma. 


\begin{tabular}{|c|c|c|}
\hline \multicolumn{3}{|c|}{ Sesgo localizacional hacia el centro } \\
\hline CIIU R3 & $\mathbf{1 9 8 5}$ & $\mathbf{1 9 9 3}$ \\
\hline $\mathbf{1 5}$ & $-0,289009$ & $-0,229872$ \\
$\mathbf{1 6}$ & $-0,066632$ & 0,996736 \\
$\mathbf{1 7}$ & 0,044267 & $-0,013447$ \\
$\mathbf{1 8}$ & 0,419025 & 0,346517 \\
$\mathbf{1 9}$ & 0,290829 & 0,084816 \\
$\mathbf{2 0}$ & $-0,210618$ & $-0,167864$ \\
$\mathbf{2 1}$ & 0,100299 & 0,048249 \\
$\mathbf{2 2}$ & 0,618105 & 0,633371 \\
$\mathbf{2 3}$ & $-0,063800$ & 0,422243 \\
$\mathbf{2 4}$ & 0,533159 & 0,407194 \\
$\mathbf{2 5}$ & 0,430875 & 0,233395 \\
$\mathbf{2 6}$ & $-0,268132$ & $-0,142104$ \\
$\mathbf{2 7}$ & $-0,035941$ & 0,024069 \\
$\mathbf{2 8}$ & 0,254136 & 0,070694 \\
$\mathbf{2 9}$ & 0,057509 & 0,030218 \\
$\mathbf{3 0}$ & 0,020799 & 0,764031 \\
$\mathbf{3 1}$ & 0,476403 & 0,513394 \\
$\mathbf{3 2}$ & $-0,034685$ & $-0,043865$ \\
$\mathbf{3 3}$ & 0,610566 & 0,841178 \\
$\mathbf{3 4}$ & 0,102477 & 0,012063 \\
$\mathbf{3 5}$ & 0,124037 & 0,247402 \\
$\mathbf{3 6}$ & 0,145554 & $-0,001445$ \\
\hline \hline
\end{tabular}

Fuente: Elaboración propia en base a Censos Nacionales Económicos 1985 y 1994.

El coeficiente de correlación de Pearson entre el índice de centralidad de una provincia y la participación de una industria dada en el empleo industrial total de la misma se visualiza como un indicador del sesgo localizacional hacia el centro, en virtud de que cuanto mayor es el valor que asume, mayor es la proporción del empleo en la industria de que se trate que corresponde a las provincias centrales respecto de la fracción que explican las regiones periféricas.

Una inspección de la tabla permite identificar una serie de resultados interesantes perfectamente compatibles con lo que cabría esperar a priori:

- Por un lado, las industrias Alimentos y bebidas (15), Fabricación de productos textiles (17) y Fabricación de muebles (20) exhiben sesgos negativos que reflejan los efectos de dispersión espacial ligados a la intensidad en mano de obra y la gravitación de la localización de las materias primas empleadas en los respectivos procesos productivos. 
- Por otro lado, la industria de Equipos de radio, televisión y aparatos de comunicaciones (32) presenta también una tendencia contraria a la concentración en el centro, que, a diferencia de los casos antes aludidos, puede explicarse básicamente por la importancia relativa de la provincia Tierra del Fuego fundada en el régimen de promoción industrial aplicado en la misma.

- Finalmente, las industrias Ediciones e imprenta (22), Fabricación de sustancias y productos químicos (24), Maquinarias de oficina, contabilidad e informática (30), Maquinaria y equipo eléctrico (31) y Fabricación de equipos médicos, ópticos, instrumentos de precisión y relojes (33) muestran un marcado sesgo localizacional hacia el centro en 1994. Claramente, se trata de sectores industriales donde los eslabonamientos productivos y de demanda, un mercado laboral conjunto y los derrames cognoscitivos, factores los cuales favorecen la aglomeración, desempeñan un rol trascendente ${ }^{45}$.

\section{5.d.4. Las perspectivas: las señales derivadas de los flujos de inversión}

Las educciones extraídas en las secciones anteriores se basan en datos históricos. Una pregunta trascendente es entonces en qué medida las mismas pueden considerarse un indicador de los desarrollos espaciales futuros de la industria manufacturera en nuestro país. Una forma conveniente de responder el interrogante antes planteado consiste en analizar la asignación geográfica de las corrientes de inversión que tuvieron lugar en los últimos años (Pacheco, 1999).

\footnotetext{
${ }^{45}$ El valor correspondiente a la rama 16 (Tabaco) en el año 1994 presenta los inconvenientes ya apuntados.
} 


\begin{tabular}{|c|c|c|c|c|c|c|c|c|c|c|c|c|c|c|c|c|c|c|c|}
\hline \multicolumn{20}{|c|}{ Inversiones en la industria manufacturera por provincia y por rubro (1990-1997) -en millones de dólares- } \\
\hline Provincia/Industria & 15 & 16 & 17-18 & 19 & 20 & 21 & 22 & 23 & 24 & 25 & 26 & 27 & 28 & 29-30 & 31-32 & 33 & 34-35 & 36 & Total \\
\hline Capital Federal & 667 & 219 & 3 & 11 & 0 & 53 & 69 & 2 & 57 & 103 & 10 & 0 & 87 & 0 & 7 & 1 & 50 & 0 & 1.339 \\
\hline Buenos Aires & 1.640 & 0 & 8 & 44 & 0 & 115 & 0 & 2.461 & 631 & 104 & 0 & 648 & 74 & 17 & 4 & 0 & 2.321 & 0 & 8.067 \\
\hline Catamarca & 26 & 0 & 9 & 11 & 0 & 0 & 1 & 0 & 4 & 6 & 0 & 0 & 3 & 0 & 6 & 0 & 0 & 7 & 73 \\
\hline Córdoba & 759 & 0 & 0 & 0 & 0 & 10 & 11 & 0 & 29 & 41 & 0 & 167 & 240 & 72 & 5 & 0 & 2.075 & 8 & 3.417 \\
\hline Corrientes & 39 & 0 & 0 & 0 & 102 & 100 & 0 & 0 & 0 & 0 & 0 & 0 & 0 & 0 & 0 & 0 & 0 & 0 & 241 \\
\hline Chaco & 53 & 0 & 3 & 0 & 0 & 0 & 0 & 0 & 0 & 0 & 0 & 0 & 0 & 1 & 0 & 0 & 0 & 0 & 57 \\
\hline Chubut & 7 & 0 & 18 & 0 & 1 & 0 & 0 & 229 & 8 & 0 & 0 & 208 & 23 & 0 & 1 & 0 & 0 & 2 & 497 \\
\hline Entre Ríos & 25 & 0 & 0 & 1 & 160 & 15 & 0 & 0 & 25 & 0 & 0 & 0 & 0 & 0 & 0 & 0 & 0 & 0 & 226 \\
\hline Formosa & 2 & 0 & 0 & 0 & 1 & 0 & 0 & 1 & 0 & 0 & 0 & 1 & 0 & 0 & 0 & 0 & 0 & 0 & 5 \\
\hline Jujuy & 6 & 0 & 0 & 0 & 0 & 0 & 0 & 0 & 0 & 0 & 0 & 64 & 0 & 0 & 0 & 0 & 0 & 0 & 70 \\
\hline La Pampa & 0 & 0 & 0 & 0 & 0 & 0 & 0 & 0 & 0 & 0 & 0 & 0 & 10 & 0 & 0 & 0 & 0 & 0 & 10 \\
\hline La Rioja & 20 & 0 & 89 & 34 & 0 & 11 & 0 & 0 & 20 & 7 & 0 & 0 & 1 & 1 & 0 & 0 & 2 & 0 & 185 \\
\hline Mendoza & 64 & 0 & 0 & 0 & 0 & 0 & 4 & 0 & 6 & 0 & 0 & 0 & 0 & 145 & 0 & 0 & 7 & 0 & 226 \\
\hline Misiones & 15 & 1 & 0 & 0 & 82 & 113 & 0 & 0 & 0 & 0 & 0 & 0 & 0 & 0 & 0 & 0 & 0 & 0 & 211 \\
\hline Neuquén & 6 & 0 & 3 & 0 & 1 & 1 & 1 & 21 & 28 & 7 & 0 & 0 & 18 & 0 & 0 & 0 & 0 & 2 & 88 \\
\hline Río Negro & 11 & 0 & 0 & 0 & 0 & 0 & 5 & 0 & 0 & 2 & 0 & 0 & 0 & 0 & 0 & 0 & 0 & 0 & 18 \\
\hline ta & 43 & 0 & 0 & 0 & 0 & 0 & 0 & 20 & 0 & 0 & 0 & 0 & 0 & 0 & 0 & 0 & 0 & 0 & 63 \\
\hline San Juan & 29 & 0 & 3 & 1 & 0 & 2 & 0 & 0 & 0 & 0 & 0 & 0 & 11 & 6 & 0 & 0 & 0 & 24 & 76 \\
\hline San Luis & & 0 & 5 & 0 & 0 & 0 & 0 & 0 & 0 & 9 & 0 & 15 & 1 & 0 & 6 & 0 & 0 & 0 & 41 \\
\hline Santa Cruz & $\mathrm{n} / \mathrm{d}$ & $\mathrm{n} / \mathrm{d}$ & $\mathrm{n} / \mathrm{d}$ & $\mathrm{n} / \mathrm{d}$ & $\mathrm{n} / \mathrm{d}$ & $\mathrm{n} / \mathrm{d}$ & $\mathrm{n} / \mathrm{d}$ & $\mathrm{n} / \mathrm{d}$ & $\mathrm{n} / \mathrm{d}$ & $\mathrm{n} / \mathrm{d}$ & $\mathrm{n} / \mathrm{d}$ & $\mathrm{n} / \mathrm{d}$ & $\mathrm{n} / \mathrm{d}$ & $\mathrm{n} / \mathrm{d}$ & $\mathrm{n} / \mathrm{d}$ & $\mathrm{n} / \mathrm{d}$ & $\mathrm{n} / \mathrm{d}$ & $\mathrm{n} / \mathrm{d}$ & $\mathbf{n} / \mathbf{d}$ \\
\hline Santa Fe & 1.268 & 0 & 36 & 18 & 2 & 25 & 11 & 98 & 103 & 0 & 0 & 143 & 37 & 56 & 0 & 0 & 557 & 0 & 2.354 \\
\hline Santiago de & 5 & 0 & 3 & 1 & 0 & 0 & 3 & 0 & 0 & 0 & 0 & 0 & 0 & 0 & 0 & 0 & 0 & 0 & 12 \\
\hline Tierra del Fuego & 0 & 0 & 0 & 0 & 150 & 0 & 0 & 0 & 0 & 0 & 0 & 0 & 0 & 0 & 0 & 0 & 0 & 0 & 150 \\
\hline Tucumán & 34 & 0 & 0 & 1 & 0 & 19 & 0 & 1 & 1 & 2 & 0 & 0 & 2 & 0 & 0 & 0 & 15 & 0 & 75 \\
\hline Total & 4.724 & 220 & 180 & 122 & 499 & 464 & 105 & 2.833 & 912 & 281 & 10 & 1.246 & 507 & 298 & 29 & 1 & \begin{tabular}{|l|}
5.027 \\
\end{tabular} & 43 & 17.501 \\
\hline
\end{tabular}

Los datos de inversión muestran una elevada concentración en las jurisdicciones más desarrolladas: Capital Federal, Buenos Aires, Córdoba y Santa Fe, que, en conjunto, representan el $86,7 \%$ del total registrado.

Desde el punto de vista sectorial, cabe resaltar las siguientes ramas ${ }^{46}$ :

- Alimentos y bebidas (50,0\%) y Tabaco (16,3\%) en Capital Federal;

- Derivados del petróleo, gas y productos farmaceúticos $(30,5 \%)$, Automóviles y autopartes $(28,8 \%)$ y Alimentos y bebidas (20,3\%) en Buenos Aires;

- Automóviles y autopartes $(60,7 \%)$ y Alimentos y bebidas $(22,2 \%)$ en Córdoba;

- Alimentos y bebidas (53,9\%) y Automóviles y autopartes $(23,7 \%)$ en Santa Fe.

La distribución geográfica de la inversión sectorial permite reparar en el hecho de que las provincias más avanzadas fueron particularmente receptivas a los flujos de inversiones correspondientes a los sectores con mayor participación en el total agregado: automotriz $(28,7 \%)$, alimentario $(27,0 \%)$ y petrolífero $(16,9 \%)$.

\footnotetext{
${ }^{46}$ Entre paréntesis se señala la participación porcentual en el total provincial.
} 
En síntesis, las inversiones parecen actuar en favor de la cristalización del patrón localizacional actual.

6. El impacto del Mercosur sobre el patrón de localización de la industria: la evidencia econométrica

6.a. Variables: definición y fuentes de los datos

Los costos de transacción y las economías de escala definen el núcleo conceptual del marco teórico. En consecuencia, el objetivo de la parte del trabajo destinada a la investigación econométrica del tema es indagar el influjo de tales factores sobre la localización de la actividad productiva en el Mercosur y, en especial, en Argentina.

A tal efecto, es necesario determinar la contraparte empírica de tales nociones.

Con respecto a los costos de transacción, los mismos se asimilarán exlusivamente a los aranceles, de modo que no se contempla la incidencia de otros tipos de impedimentos al comercio como las restricciones no arancelarias y los costos de transporte propiamente dichos. Los datos utlizados incluyen los aranceles con respecto al resto del mundo y con Brasil correspondientes a 1984, que constituyen una muy buena aproximación para los valores prevalecientes en 1985, y a 1994, que pueden considerarse representativos de los aranceles vigentes en 1993 debido a que, tal como se vio anteriormente, los cambios relevantes se operaron en $1992^{47}$.

\footnotetext{
${ }^{47}$ Cabe destacar que los aranceles impuestos por nuestro país en 1994 sobre las mercaderías provenientes de extrazona se han extraído de un trabajo de Lifschitz y Crespo Armengol (1995), mientras que los correspondientes a Brasil se calcularon mediante la aplicación del porcentaje de desgravación arancelaria promedio previsto en el Tratado constitutivo del Mercosur sobre antedichos aranceles; a tal efecto, se tuvo en cuenta la existencia de productos exceptuados en virtud de la lista presentada oportunamente por Argentina. Los datos de 1984 fueron elaborados siguiendo consejos de los autores en base a la Guía del Importador y Exportador del mismo año, en tanto que los aranceles relevantes para Brasil surgen de corregir estos últimos en función de los Acuerdos de Alcance Parcial de Naturaleza Comercial y los Acuerdos de Alcance Regional suscriptos en el marco de la ALADI.
} 
Con relación a las economías de escala, siguiendo a Kim (1995), se construyó una proxy en base a los tamaños de los establecimientos industriales. Concretamente, la misma se calculó como el número de empleados por unidad censal ${ }^{48}$. Los datos usados proceden de los Censos Nacionales Económicos de 1985 y 1994.

\section{6.b. Mercosur}

La presente subsección tiene por objeto analizar los efectos localizacionales de la conformación del Mercosur en Argentina y Brasil. Específicamente, se pretende determinar la forma en que el proceso de integración económica regional ha afectado el patrón de especialización productiva de los principales socios del bloque. Naturalmente, la forma óptima de hacerlo consistiría en un examen comparativo de las respectivas estadísticas de producción. No obstante, tal alternativa debió ser descartada, en virtud de que, al margen de los problemas de compatibilización que plantean las diferentes formas de divulgación de los datos en ambos país, Brasil no ha publicado censos industriales desde $1985^{49}$. Por consiguiente, se optó por una estrategia, que, aunque nítidamente es un segundo mejor, constituye un procedimiento común en los trabajos empíricos que estudian la localización a

\footnotetext{
48 Corresponde aclarar que los Censos Económicos de 1985 y 1994 emplean deficiones relativamente diferentes de unidad censal. En 1985 se usó como unidad censal el establecimiento, que es susceptible de conceptualizarse como cada actividad diferenciada (según el clasificador CIIU) realizada por una misma empresa en un mismo local, mientras que en 1994 se ha utilizado el local, entendido como todo espacio físico aislado o separado de otros, que la firma emplea para el desarrollo de actividades económicas durante el lapso muestral. El cambio en la unidad censal se justificó por la simplificación de las tareas censales que permitía la unidad "local" y la posibilidad de evitar las dificultades asociadas a la asignación de la información económica del local por establecimiento (Indec, 1994).

${ }^{49}$ Gonzaga, Terra y Cavalcante (1999) intentan determinar los efectos del Mercosur sobre el empleo y la producción sectorial en Argentina, Brasil y Uruguay por intermedio de un modelo de equilibrio general computado calibrado. Los autores realizan cuatro ejercicios de simulación. Por una parte, se supone que el trabajo tiene movilidad intersectorial perfecta; por otra parte, se asume que el mercado laboral se encuentra segmentado, esto es, existen imperfecciones en tres de los trece sectores considerados: productos químicos, metalurgia y automóviles. Los escenarios generales son, por un lado, la estructura arancelaria de 1996 y, por el otro, la estructura arancelaria prevista en el momento de la vigencia plena del Mercosur. En todos los casos, nuestro país experimenta retracciones en el empleo y la producción de la mayor parte de los sectores; las contracciones son especialmente severas en las ramas cueros y calzados, metalurgia, automóviles y autopiezas. Las excepciones a este comportamiento genérico son el sector químico, la construcción civil y los servicios. Por el contrario, Brasil exhibe tasas positivas en la mayoría de las categorías sectoriales contempladas.
} 
nivel internacional (Brülhart, 1998). En concreto, se utilizan datos de comercio intraindustrial entre Argentina y Brasil como medidas aproximadas de especialización productiva.

En este sentido, se sigue el argumento de Brülhart y Torstensson (1996). Cabe recordar que la idea postulada por los autores antes mencionados es que los conceptos de "concentración" o "localización" de la geografía económica se corresponden con la noción de "comercio interindustrial" del comercio internacional. La situación contraria es aquella en la cual predomina "dispersión localizacional" o "especialización intraindustrial". Si las empresas de industrias particulares exhiben propensiones a comerciar semejantes entre países, puede afirmarse que la especialización intraindustrial se vincula intrínsecamente con el comercio intraindustrial. Luego, a fin de cuantificar dicho fenómeno, se puede recurrir al índice de Grubel-Lloyd. Aquí se hace uso de la variante propuesta por Baumann (1998):

$$
C I I_{i, j, k}=1-\frac{\left|X_{i, j, k}-M_{i, j, k}\right|}{X_{i, j, k}+M_{i, j, k}}
$$

donde $i$ denota industria y $j$ y $k$ hacen alusión a los países de referencia.

El índice asume valores extremos de:

- 1, cuando las exportaciones de un país a su comercial en una determinada industria son iguales a las importaciones que recibe del mismo $\left(X_{i, j, k}=M_{i, j, k}\right), \mathrm{y}$

- 0 , cuando el saldo comercial bilateral coincide justamente con el intercambio comercial bilateral total $\left(\left|X_{i, j, k}-M_{i, j, k}\right|=X_{i, j, k}+M_{i, j, k}\right)$, ya que, en este caso, el flujo comercial es unidireccional $\left(X_{i, j, k}=0\right.$ ó $\left.M_{i, j, k}=0\right)$.

Antedicho índice fue calculado para cada una de las categorías industriales de la clasificación CIIU de 4 dígitos para los años 1986 y 1993 a partir de la información contenida en la base de datos de comercio exterior de América Latina del INTAL ${ }^{50}$.

\footnotetext{
${ }^{50}$ En la tabla los datos aparecen expresados en un nivel de agregación de dos dígitos de la clasificación CIIU.
} 


\begin{tabular}{|c|c|c|c|c|c|c|c|c|c|r|r|}
\hline \multicolumn{10}{|c|}{$\begin{array}{c}\text { Índice de Grubel-LLoyd (1986-1995) } \\
\text { Comercio intraindustrial Argentina-Brasil }\end{array}$} \\
\hline Código & $\mathbf{1 9 8 6}$ & $\mathbf{1 9 8 7}$ & $\mathbf{1 9 8 8}$ & $\mathbf{1 9 8 9}$ & $\mathbf{1 9 9 0}$ & $\mathbf{1 9 9 1}$ & $\mathbf{1 9 9 2}$ & $\mathbf{1 9 9 3}$ & $\mathbf{1 9 9 4}$ & $\mathbf{1 9 9 5}$ & Var. 1995-1986 \\
\hline $\mathbf{1 5}$ & 0,683 & 0,872 & 0,629 & 0,199 & 0,213 & 0,534 & 0,925 & 0,867 & 0,683 & 0,449 & $-0,234$ \\
$\mathbf{1 6}$ & 0,000 & & & 0,000 & 0,000 & & 0,716 & 0,000 & 0,000 & 0,353 & 0,353 \\
$\mathbf{1 7}$ & 0,301 & 0,624 & 0,883 & 0,291 & 0,339 & 0,541 & 0,166 & 0,266 & 0,514 & 0,972 & 0,671 \\
$\mathbf{1 8}$ & 0,139 & 0,015 & 0,174 & 0,175 & 0,152 & 0,525 & 0,059 & 0,311 & 0,219 & 0,913 & 0,774 \\
$\mathbf{1 9}$ & 0,000 & 0,002 & 0,009 & 0,003 & 0,014 & 0,067 & 0,323 & 0,219 & 0,332 & 0,270 & 0,270 \\
$\mathbf{2 0}$ & 0,025 & 0,034 & 0,295 & 0,990 & 0,359 & 0,471 & 0,066 & 0,206 & 0,211 & 0,666 & 0,640 \\
$\mathbf{2 1}$ & 0,221 & 0,538 & 0,981 & 0,512 & 0,619 & 0,350 & 0,113 & 0,115 & 0,201 & 0,514 & 0,293 \\
$\mathbf{2 2}$ & 0,312 & 0,877 & 0,461 & 0,012 & 0,014 & 0,182 & 0,679 & 0,759 & 0,728 & 0,382 & 0,069 \\
$\mathbf{2 3}$ & 0,052 & 0,006 & 0,000 & 0,099 & 0,846 & 0,334 & 0,442 & 0,862 & 0,876 & 0,437 & 0,385 \\
$\mathbf{2 4}$ & 0,522 & 0,561 & 0,725 & 0,870 & 0,983 & 0,743 & 0,644 & 0,669 & 0,635 & 0,662 & 0,140 \\
$\mathbf{2 5}$ & 0,359 & 0,824 & 0,822 & 0,854 & 0,769 & 0,451 & 0,219 & 0,407 & 0,545 & 0,795 & 0,436 \\
$\mathbf{2 6}$ & 0,714 & 0,808 & 0,457 & 0,831 & 0,634 & 0,604 & 0,261 & 0,309 & 0,417 & 0,608 & $-0,106$ \\
$\mathbf{2 7}$ & 0,062 & 0,036 & 0,013 & 0,788 & 0,419 & 0,214 & 0,086 & 0,143 & 0,101 & 0,242 & 0,181 \\
$\mathbf{2 8}$ & 0,312 & 0,256 & 0,346 & 0,524 & 0,803 & 0,563 & 0,309 & 0,646 & 0,169 & 0,327 & 0,015 \\
$\mathbf{2 9}$ & 0,616 & 0,610 & 0,761 & 0,909 & 0,873 & 0,537 & 0,267 & 0,363 & 0,325 & 0,712 & 0,096 \\
$\mathbf{3 0}$ & 0,514 & 0,668 & 0,998 & 0,986 & 0,525 & 0,894 & 0,224 & 0,191 & 0,296 & 0,695 & 0,182 \\
$\mathbf{3 1}$ & 0,162 & 0,196 & 0,210 & 0,430 & 0,653 & 0,381 & 0,174 & 0,324 & 0,419 & 0,463 & 0,301 \\
$\mathbf{3 2}$ & 0,112 & 0,134 & 0,150 & 0,340 & 0,280 & 0,083 & 0,025 & 0,061 & 0,598 & 0,873 & 0,761 \\
$\mathbf{3 3}$ & 0,207 & 0,267 & 0,568 & 0,601 & 0,848 & 0,619 & 0,343 & 0,408 & 0,289 & 0,342 & 0,136 \\
$\mathbf{3 4}$ & 0,872 & 0,762 & 0,718 & 0,917 & 0,991 & 0,903 & 0,761 & 0,899 & 0,876 & 0,599 & $-0,273$ \\
$\mathbf{3 5}$ & 0,352 & 0,625 & 0,482 & 0,513 & 0,068 & 0,708 & 0,709 & 0,828 & 0,587 & 0,896 & 0,544 \\
$\mathbf{3 6}$ & 0,505 & 0,501 & 0,364 & 0,528 & 0,806 & 0,376 & 0,162 & 0,248 & 0,257 & 0,746 & 0,241 \\
\hline Fuente: Elaboración propia en base a BID/INTAL.
\end{tabular}

Conforme se desprende del modelo teórico, el comercio intraindustrial crece en las primeras fases del proceso de integración. Luego, a fin de testear empíricamente dicho resultado se regresa el índice de Grubel-Lloyd $(G L)$ con respecto a los aranceles vigentes en el intercambio comercial con Brasil $(A B)$ y con los países no integrantes del Mercosur $(A E)^{51}$. Asimismo, se incluyen como variables explicativas: el indicador de economías de escala de la industria $(E C)$, la intensidad laboral $(C L)$ y en materia primas y materiales de la misma (CI), que, siguiendo la literatura existente sobre el tema, se suputan como la razón entre el costo de la mano de obra y el valor de producción y la relación entre el costo de tales consumos intermedios y el valor de producción, respectivamente. Estos últimos datos han sido calculados en base a las estadísticas sectoriales y provinciales incluidas en los Censos Económicos Nacionales de Argentina de 1985 y 1994. Teniendo en cuenta que el 
ejercicio econométrico involucra dos años y 125 ramas industriales se recurre al método de datos en panel en sus dos variantes, el modelo de efectos fijos y el modelo de efectos aleatorios.

Los resultados obtenidos indican en consonancia con lo que cabría esperar que el comercio intraindustrial bilateral entre Argentina y Brasil ha sido favorecido en esta primera etapa por la reducción de los aranceles relevantes para el mencionado intercambio. Ello obedece al mejoramiento en las condiciones de acceso al mercado del socio respecto del resto del mundo que supone la formación de la unión aduanera. Por otra parte, supradicho comercio ha sido afectado adversamente por la disminución de los aranceles extrazona, lo cual es decididamente lógico si se tiene en cuenta que comporta una dilución relativa de la preferencia arancelaria y una mayor exposición a la competencia de los mercados mundiales, que son sustancialmente grandes en relación a nuestra economía. Resulta menester destacar que ambas variables son significativas al $1 \%$.

\begin{tabular}{|c|r|r|r|r|}
\hline \multicolumn{6}{|c|}{ Comercio intraindustrial entre Argentina y Brasil } \\
\hline \multicolumn{6}{|c|}{ Modelo de efectos fijos } \\
\hline Variable & Coeficiente & D. Estándar & \multicolumn{1}{c|}{ t-ratio } & Prob. \\
\hline AE & 9,88020 & 2,06370 & 4,78800 & 0,00000 \\
\hline AB & $-9,15810$ & 2,03740 & $-4,49500$ & 0,00001 \\
\hline EC & 0,18001 & 0,12128 & 1,48400 & 0,13837 \\
\hline CI & $-0,21511$ & 0,15002 & $-1,43400$ & 0,15260 \\
\hline CL & 0,12544 & 0,26197 & 0,47900 & 0,63227 \\
\hline \multicolumn{5}{|c|}{ Modelo de efectos aleatorios } \\
\hline Variable & Coeficiente & D. Estándar & \multicolumn{1}{c|}{ t-ratio } & Prob. \\
\hline AE & 9,51780 & 1,96240 & 4,85000 & 0,00000 \\
\hline AB & $-8,81980$ & 1,94650 & $-4,53100$ & 0,00001 \\
\hline EC & 0,20701 & 0,10954 & 1,89000 & 0,05878 \\
\hline CI & $-0,12569$ & 0,13470 & $-0,91500$ & 0,36031 \\
\hline CL & 0,03789 & 0,23973 & 0,14100 & 0,88791 \\
\hline Constante & $-186,42000$ & 20,25100 & $-9,02500$ & 0,00000 \\
\hline
\end{tabular}

\footnotetext{
${ }^{51}$ En regresiones adicionales se prueba con definiciones alternativas de las barreras arancelarias: el cociente entre los aranceles extrazona y los aranceles para Brasil (BE) y la diferencia entre los primeros y los segundos (BEB1).
} 


\begin{tabular}{|c|r|r|r|r|}
\hline \multicolumn{6}{|c|}{ Comercio intraindustrial entre Argentina y Brasil } \\
\hline \multicolumn{5}{|c|}{ Modelo de efectos fijos } \\
\hline Variable & Coeficiente & D. Estándar & \multicolumn{1}{c|}{ t-ratio } & Prob. \\
\hline BE & 0,90647 & 0,26040 & 3,48100 & 0,00054 \\
\hline EC & 0,10681 & 0,12397 & 0,86200 & 0,38932 \\
\hline CI & $-0,19990$ & 0,15280 & $-1,30800$ & 0,19141 \\
\hline CL & 0,08399 & 0,26818 & 0,31300 & 0,75428 \\
\hline \multicolumn{5}{|c|}{ Modelo de efectos aleatorios } \\
\hline Variable & Coeficiente & D. Estándar & \multicolumn{1}{c|}{ t-ratio } & Prob. \\
\hline BE & 0,88170 & 0,23631 & 3,73100 & 0,00019 \\
\hline EC & 0,13390 & 0,11140 & 1,20200 & 0,22938 \\
\hline CI & $-0,11797$ & 0,13953 & $-0,84500$ & 0,39787 \\
\hline CL & $-0,00228$ & 0,24445 & $-0,00090$ & 0,99256 \\
\hline Constante & $-104,44000$ & 15,58400 & $-6,70200$ & 0,00000 \\
\hline
\end{tabular}

\begin{tabular}{|c|r|r|r|r|}
\hline \multicolumn{6}{|c|}{ Comercio intraindustrial entre Argentina y Brasil } \\
\hline \multicolumn{5}{|c|}{ Modelo de efectos fijos } \\
\hline Variable & Coeficiente & D. Estándar & \multicolumn{1}{c|}{ t-ratio } & \multicolumn{1}{c|}{ Prob. } \\
\hline BEB1 & 0,96845 & 0,25695 & 3,76900 & 0,00018 \\
\hline EC & 0,09483 & 0,12301 & 0,77100 & 0,44114 \\
\hline CI & $-0,20631$ & 0,15244 & $-1,35300$ & 0,17655 \\
\hline CL & 0,03788 & 0,26685 & 0,14200 & 0,88717 \\
\hline \multicolumn{7}{|c|}{ Modelo de efectos aleatorios } \\
\hline Variable & Coeficiente & D. Estándar & \multicolumn{1}{c|}{ t-ratio } & Prob. \\
\hline BEB1 & 0,93625 & 0,23308 & 4,10170 & 0,00006 \\
\hline EC & 0,12424 & 0,11053 & 1,12400 & 0,26099 \\
\hline CI & $-0,12361$ & 0,13923 & $-0,88800$ & 0,37462 \\
\hline CL & $-0,04407$ & 0,24339 & $-0,18100$ & 0,85632 \\
\hline Constante & $-107,17000$ & 15,27100 & $-7,01800$ & 0,00000 \\
\hline
\end{tabular}

En general, las restantes variables no son significativas. No obstante, la incidencia de las economías de escala de la industria y el nivel de consumo intermedio amerita un comentario particular.

El grado de economías de escala parece estar asociado positivamente con el nivel de comercio intraindustrial. Sobredicho resultado podría juzgarse contrario a las educciones derivadas del modelo teórico. Sin embargo, es necesario considerar, en primer lugar, que el ajuste en los patrones de especialización demanda tiempo y, en segundo lugar, que sin lugar a hesitación alguna el mismo ha sido y será modelado por las formas de comercio administrado que existen y existieron desde la formación del bloque regional, entre las 
cuales sobresalen los acuerdos en materia automotriz, un sector con un nivel importante de economías de escala ${ }^{52}$.

Por su parte, el consumo intermedio es concebido en los trabajos empíricos como una proxy para la noción de base industrial del país (Brülhart y Trionfetti, 1998). La relación negativa entre el nivel relativo del mismo y el comercio inttraindustrial podría reflejar entonces el mayor tamaño y la mayor diversidad de la base industrial con que cuenta Brasil, lo cual propende a favorecer un intercambio comercial unidireccional.

Por último, con referencia a los modelos en sí mismos, se aprecia que el test $\mathrm{F}$, que evalúa la ausencia de efectos fijos, no conduce a rechazar la existencia de sobredichos efectos ni al 1\% ni al 10\%. Por otra parte, el test de los multiplicadores de Lagrange rechaza la hipótesis nula de ausencia de efectos aleatorios. Finalmente, el test de Hausman, que compara los estimadores de efectos fijos, que son siempre consistentes, con los estimadores de efectos aleatorios, no contradice la exogeneidad de los regresores de este modelo, de manera que no correspondería desestimar su uso (ver anexo).

\section{6.c. Argentina}

La presente subsección indaga los efectos espaciales que el Mercosur ha causado en la industria de nuestro país. En particular, se procura determinar el modo en que el mismo ha repercutido en el grado de concentración geográfica del sector manufacturero. Por lo tanto, se adopta como variable dependiente el índice de Herfindahl $(H)$, que se define analíticamente del siguiente modo:

\footnotetext{
${ }^{52}$ Alternativamente, podría hipotizarse que el signo del coeficiente refleja el bajo grado de movilidad del factor trabajo entre los países de la unión aduanera y la presencia de costos de transacción. En los modelos de comercio internacional, bajo condiciones de competencia imperfecta e inmovilidad internacional del trabajo, las economías de escala son una fuente directa de comercio.
} 
$H_{i}=\sum_{j=1}^{N}\left(\frac{L_{i j}}{L_{i}}-\frac{L_{j}}{L}\right)^{2}$

donde $i$ denota rama industrial y $j$ indiza a las provincias, $L_{i j} / L_{i}$ representa la razón entre el nivel de empleo de la industria $i$ en la provincia $j$ y el nivel de empleo en la misma industria en el país en su conjunto y $L_{j} / L$ patentiza la relación entre el empleo manufacturero total en la provincia $j$ y el empleo manufacturero agregado del país.

El índice mide la magnitud del desvío que presenta el nivel de empleo de una industria en una provincia respecto del patrón general de empleo. Así, si $L_{i j} / L_{i}=L_{j} / L \forall j$, de modo que la industria particular observa el patrón de localización industrial agregado, $H=0 \mathrm{y}$, por ende, la industria no está concentrada geográficamente. Un incremento en el valor que adopta $H$ señala un aumento en el grado de concentración espacial de la industria de que se trate.

El índice de Herfindahl fue calculado para cada una de las industrias manufactureras identificadas en la clasificación de 4 dígitos para los años 1985 y 1993. A tal efecto, se emplearon los datos de empleo sectorial-provincial de los Censos Económicos Nacionales anteriormente referidos. 


\begin{tabular}{|c|c|c|c|c|c|c|c|}
\hline \multicolumn{8}{|c|}{ Índice de Herfindahl } \\
\hline CIIU & 1985 & 1993 & $1993 / 1985$ & CIIU & 1985 & 1993 & $1993 / 1985$ \\
\hline 1511 & 0,024 & 0,030 & 0,007 & 2692 & 0,108 & 0,120 & 0,012 \\
\hline 1512 & 0,141 & 0,301 & 0,160 & 2693 & 0,050 & 0,049 & $-0,001$ \\
\hline 1513 & 0,478 & 0,403 & $-0,076$ & 2694 & 0,093 & 0,240 & 0,146 \\
\hline 1514 & 0,107 & 0,119 & 0,012 & 2695 & 0,035 & 0,026 & $-0,009$ \\
\hline 1520 & 0,075 & 0,089 & 0,013 & 2696 & 0,010 & 0,021 & 0,012 \\
\hline 1531 & 0,056 & 0,049 & $-0,007$ & 2699 & 0,016 & 0,034 & 0,018 \\
\hline 1532 & 0,033 & 0,104 & 0,071 & 2710 & 0,090 & 0,118 & 0,027 \\
\hline 1533 & 0,063 & \begin{tabular}{l|l}
0,079 \\
\end{tabular} & 0,016 & 2720 & 0,046 & 0,080 & 0,035 \\
\hline 1541 & 0,008 & 0,003 & $-0,005$ & 2731 & 0,090 & 0,071 & $-0,019$ \\
\hline 1542 & 0,486 & 0,552 & 0,066 & 2732 & 0,046 & 0,095 & 0,049 \\
\hline 1543 & 0,201 & 0,100 & $-0,101$ & 2811 & 0,011 & 0,015 & 0,004 \\
\hline 1544 & 0,001 & 0,002 & 0,000 & 2812 & 0,059 & 0,048 & $-0,011$ \\
\hline 1549 & 0,173 & 0,056 & $-0,117$ & 2813 & 0,086 & 0,222 & 0,137 \\
\hline 1551 & 0,026 & 0,058 & 0,033 & 2891 & 0,051 & 0,010 & $-0,042$ \\
\hline 1552 & 0,598 & 0,422 & $-0,175$ & 2892 & 0,021 & 0,014 & $-0,006$ \\
\hline 1553 & 0,089 & 0,229 & 0,140 & 2893 & 0,041 & 0,025 & $-0,016$ \\
\hline 1554 & 0,013 & 0,007 & $-0,005$ & 2899 & 0,021 & 0,009 & $-0,012$ \\
\hline 1600 & 0,208 & 0,235 & 0,027 & 2911 & 0,114 & 0,491 & 0,377 \\
\hline 1711 & 0,025 & 0,033 & 0,008 & 2912 & 0,114 & 0,013 & $-0,100$ \\
\hline 1712 & 0,052 & 0,065 & 0,013 & 2913 & 0,021 & 0,029 & 0,008 \\
\hline 1721 & 0,023 & 0,029 & 0,006 & 2914 & 0,051 & 0,015 & $-0,036$ \\
\hline 1722 & 0,187 & \begin{tabular}{l|l}
0,137 \\
\end{tabular} & $-0,050$ & 2915 & 0,059 & 0,038 & $-0,021$ \\
\hline 1723 & 0,089 & 0,066 & $-0,023$ & 2919 & 0,040 & 0,011 & $-0,029$ \\
\hline 1729 & 0,090 & 0,075 & $-0,014$ & 2921 & 0,204 & 0,187 & $-0,017$ \\
\hline 1730 & 0,075 & 0,056 & $-0,019$ & 2922 & 0,021 & 0,037 & 0,016 \\
\hline 1810 & 0,099 & 0,069 & $-0,030$ & 2923 & 0,021 & 0,106 & 0,085 \\
\hline 1820 & 0,130 & 0,112 & $-0,018$ & 2924 & 0,012 & 0,036 & 0,024 \\
\hline 1911 & 0,060 & 0,055 & $-0,004$ & 2925 & 0,021 & 0,098 & 0,077 \\
\hline 1912 & 0,201 & 0,120 & $-0,082$ & 2926 & 0,391 & 0,149 & $-0,243$ \\
\hline 1920 & 0,020 & 0,014 & $-0,005$ & 2927 & 0,266 & 0,434 & 0,168 \\
\hline 2010 & 0,167 & 0,177 & 0,010 & 2929 & 0,011 & 0,028 & 0,017 \\
\hline 2021 & 0,207 & 0,106 & $-0,101$ & 2930 & 0,013 & 0,021 & 0,009 \\
\hline 2022 & 0,019 & 0,040 & 0,021 & 3000 & 0,091 & 0,206 & 0,115 \\
\hline 2023 & 0,152 & 0,118 & $-0,034$ & 3110 & 0,008 & 0,011 & 0,003 \\
\hline 2029 & 0,003 & 0,004 & 0,001 & 3120 & 0,006 & 0,077 & 0,071 \\
\hline 2101 & 0,260 & 0,100 & $-0,160$ & 3130 & 0,073 & 0,049 & $-0,024$ \\
\hline 2102 & 0,063 & \begin{tabular}{l|}
0,011 \\
\end{tabular} & $-0,052$ & 3140 & 0,006 & 0,044 & 0,038 \\
\hline 2109 & 0,029 & 0,028 & $-0,001$ & 3150 & 0,232 & 0,056 & $-0,176$ \\
\hline 2211 & 0,158 & 0,666 & 0,508 & 3190 & 0,060 & 0,052 & $-0,008$ \\
\hline 2212 & 0,125 & 0,264 & 0,138 & 3210 & 0,232 & 0,073 & $-0,159$ \\
\hline 2213 & 0,247 & 0,562 & 0,316 & 3220 & 0,054 & 0,067 & 0,013 \\
\hline 2219 & 0,247 & 0,233 & $-0,014$ & 3230 & 0,301 & 0,680 & 0,380 \\
\hline 2221 & 0,146 & 0,058 & $-0,088$ & 3311 & 0,053 & 0,066 & 0,013 \\
\hline 2222 & 0,247 & 0,214 & $-0,033$ & 3312 & 0,033 & 0,039 & 0,006 \\
\hline 2230 & 0,247 & 0,403 & 0,156 & 3313 & 0,053 & 0,140 & 0,087 \\
\hline 2310 & 0,169 & 0,223 & 0,054 & 3320 & 0,063 & 0,239 & 0,176 \\
\hline 2320 & 0,148 & 0,135 & $-0,013$ & 3330 & 0,058 & 0,312 & 0,254 \\
\hline 2330 & 0,169 & 0,236 & 0,067 & 3410 & 0,075 & 0,337 & 0,263 \\
\hline 2411 & 0,029 & 0,045 & 0,016 & 3420 & 0,051 & 0,211 & 0,160 \\
\hline 2412 & 0,130 & 0,080 & $-0,050$ & 3430 & 0,033 & 0,029 & $-0,004$ \\
\hline 2413 & 0,031 & 0,039 & 0,008 & 3511 & 0,066 & 0,085 & 0,018 \\
\hline 2421 & 0,130 & 0,140 & 0,011 & 3512 & 0,066 & 0,213 & 0,147 \\
\hline 2422 & 0,067 & 0,151 & 0,084 & 3520 & 0,033 & 0,123 & 0,090 \\
\hline 2423 & 0,168 & 0,170 & 0,003 & 3530 & 0,749 & 0,209 & $-0,540$ \\
\hline 2424 & 0,034 & 0,051 & 0,017 & 3591 & 0,042 & 0,063 & 0,021 \\
\hline 2429 & 0,087 & 0,050 & $-0,037$ & 3592 & 0,042 & 0,085 & 0,043 \\
\hline 2430 & 0,234 & 0,292 & 0,058 & 3599 & 0,032 & 0,209 & 0,178 \\
\hline 2511 & 0,167 & 0,264 & 0,097 & 3610 & 0,006 & 0,011 & 0,005 \\
\hline 2519 & 0,052 & 0,041 & $-0,011$ & 3691 & 0,581 & 0,341 & $-0,240$ \\
\hline 2520 & 0,031 & 0,022 & $-0,008$ & 3692 & 0,063 & 0,056 & $-0,007$ \\
\hline 2610 & 0,085 & 0,082 & $-0,004$ & 3693 & 0,014 & 0,061 & 0,047 \\
\hline 2691 & 0,064 & 0,046 & $-0,017$ & 3694 & 0,072 & 0,038 & $-0,034$ \\
\hline 2692 & 0,108 & 0,120 & 0,012 & 3699 & 0,031 & 0,021 & $-0,010$ \\
\hline
\end{tabular}

Fuente: Elaboración propia en base a Censos Nacionales Económicos 1985 y 1994. 
Las variables explicativas y el método son análogos a los empleados en las regresiones de comercio intraindustrial entre Argentina y Brasil. En este caso, se consignan los resultados que surgen de especificaciones alternativas, como aquellas que expresan dichas variables en términos logarítmicos.

Las estimaciones revelan que, tal como cabría esperar a priori, el grado de concentración espacial de las industrias se relaciona positivamente con el nivel de economías de escala de las mismas y negativamente con los aranceles aplicados en el intercambio comercial con Brasil y la intensidad laboral de la industria.

En el primer caso, la explicación del vínculo es simplemente definicional. Cuando existen economías de escala significativas, resulta proficuo para las firmas atender al mercado desde un número reducido de emplazamientos, ya que de esa forma se minimizan los costos fijos que importa la radicación de establecimientos.

En el segundo caso, se puede hirmar que la reducción de las barreras arancelarias con el principal socio comercial parece haber impelido una acentuación de la concentración espacial de las industrias con el designio de beneficiarse de las economías de aglomeración y alcanzar un nivel de eficiencia operativa suficiente para poder operar en el mercado regional ampliado ${ }^{53}$.

En el tercer caso, es posible aseverar que en aquellas industrias con elevada participación de los costos laborales en el valor de producción, la concentración espacial es decididamente inconveniente, habida cuenta de la presión sobre el mercado laboral que la misma conllevaría.

Vale la pena destacar que aun cuando las variables poseen siempre los signos correctos, la significatividad de las mismas depende de la especificación que se utilice.

Finalmente, en cuanto a los modelos propiamente dichos, se observa que el test $\mathrm{F}$ permite rechazar la hipótesis nula de ausencia de efectos fijos. Por su parte, el test de los multiplicadores de Lagrange rechaza la hipótesis nula de inexistencia de efectos aleatorios,

\footnotetext{
${ }^{53}$ Según los guarismos resultantes de las estimaciones, la apertura general de la economía se relacionaría negativamente pero en forma no significativa con la concentración industrial. Una explicación plausible podría ser el cierre de múltiples establecimientos en las zonas tradicionalmente industriales.
} 
mientras que el test de Hausman no conduce a desechar la utilización del modelo correspondiente al 5\%, ya que los regresores parecerían ser exógenos (ver anexo) ${ }^{54}$.

\begin{tabular}{|c|r|r|r|r|}
\hline \multicolumn{6}{|c|}{ Índice de Herfindahl localizacional (Argentina) } \\
\hline \multicolumn{6}{|c|}{ Modelo de efectos fijos } \\
\hline Variable & Coeficiente & D. Estándar & \multicolumn{1}{c|}{ t-ratio } & Prob. \\
\hline AE & 0,00091 & 0,00195 & 0,46900 & 0,63973 \\
\hline AB & $-0,00131$ & 0,00125 & $-1,04800$ & 0,29569 \\
\hline EC & 0,00011 & 0,00006 & 1,66800 & 0,09659 \\
\hline CI & 0,00003 & 0,00008 & 0,43300 & 0,66505 \\
\hline CL & $-0,00026$ & 0,00013 & $-1,92000$ & 0,05596 \\
\hline \multicolumn{5}{|c|}{ Modelo de efectos aleatorios } \\
\hline Variable & Coeficiente & D. Estándar & t-ratio & Prob. \\
\hline AE & 0,00156 & 0,00167 & 0,93000 & 0,35220 \\
\hline AB & $-0,00184$ & 0,00109 & $-1,69400$ & 0,09035 \\
\hline EC & 0,00016 & 0,00006 & 2,93900 & 0,00329 \\
\hline CI & 0,00001 & 0,00007 & 0,17100 & 0,86389 \\
\hline CL & $-0,00035$ & 0,00012 & $-2,95400$ & 0,00313 \\
\hline Constante & 0,11740 & 0,02705 & 4,34000 & 0,00001 \\
\hline
\end{tabular}

\begin{tabular}{|c|r|r|r|r|}
\hline \multicolumn{7}{|c|}{ Índice de Herfindahl localizacional (Argentina) } \\
\hline \multicolumn{7}{|c|}{ Modelo de efectos fijos } \\
\hline Variable & Coeficiente & D. Estándar & \multicolumn{1}{c|}{ t-ratio } & \multicolumn{1}{c|}{ Prob. } \\
\hline LnAE & 0,00431 & 0,02667 & 0,16100 & 0,87190 \\
\hline LnAB & $-0,01555$ & 0,01003 & $-1,55100$ & 0,12221 \\
\hline LnEC & 0,03490 & 0,01125 & 3,10300 & 0,00214 \\
\hline LnCI & 0,00008 & 0,00008 & 1,06800 & 0,26840 \\
\hline LnCL & $-0,00035$ & 0,00014 & $-2,60800$ & 0,00968 \\
\hline \multicolumn{7}{|c|}{ Modelo de efectos aleatorios } & \\
\hline Variable & Coeficiente & D. Estándar & \multicolumn{1}{c|}{ t-ratio } & Prob. \\
\hline LnAE & 0,02352 & 0,02302 & 1,02200 & 0,30693 \\
\hline LnAB & $--0,02299$ & $-0,00906$ & $-2,53600$ & 0,01122 \\
\hline LnEC & 0,03318 & 0,00731 & 4,53800 & 0,00001 \\
\hline LnCI & 0,00008 & 0,00007 & 1,10100 & 0,27081 \\
\hline LnCL & $-0,00046$ & 0,00012 & $-3,81800$ & 0,00013 \\
\hline Constante & 0,00973 & 0,05783 & 0,16800 & 0,86645 \\
\hline
\end{tabular}

\footnotetext{
${ }^{54}$ El test de Hausman sugiere rechazar la hipótesis nula al $10 \%$ en el tercer modelo.
} 


\begin{tabular}{|c|r|r|r|r|}
\hline \multicolumn{6}{|c|}{ Índice de Herfindahl localizacional (Argentina) } \\
\hline \multicolumn{5}{|c|}{ Modelo de efectos fijos } \\
\hline Variable & Coeficiente & D. Estándar & \multicolumn{1}{c|}{ t-ratio } & Prob. \\
\hline BE & $-0,03340$ & 0,01531 & $-2,18100$ & 0,03010 \\
\hline EC & 0,00012 & 0,00006 & 1,79100 & 0,74470 \\
\hline CI & 0,00004 & 0,00008 & 0,47600 & 0,63430 \\
\hline CL & $-0,26480$ & 0,00013 & $-1,99800$ & 0,46830 \\
\hline \multicolumn{5}{|c|}{ Modelo de efectos aleatorios } \\
\hline Variable & Coeficiente & D. Estándar & \multicolumn{1}{c|}{ t-ratio } & Prob. \\
\hline BE & 0,04148 & 0,01483 & $-2,79800$ & 0,00515 \\
\hline EC & 0,00017 & 0,00005 & 3,06300 & 0,00219 \\
\hline CI & 0,00002 & 0,00007 & 0,23700 & 0,81257 \\
\hline CL & $-0,00035$ & 0,00012 & $-3,05200$ & 0,00227 \\
\hline Constante & 0,14876 & 0,01338 & 11,11900 & 0,00000 \\
\hline
\end{tabular}

\begin{tabular}{|c|r|r|r|r|}
\hline \multicolumn{6}{|c|}{ Índice de Herfindahl localizacional (Argentina) } \\
\hline \multicolumn{7}{|c|}{ Modelo de efectos fijos } \\
\hline Variable & Coeficiente & D. Estándar & \multicolumn{1}{c|}{ t-ratio } & Prob. \\
\hline LnBE & $-0,03168$ & 0,01516 & $-2,08900$ & 0,07700 \\
\hline LnEC & 0,03180 & 0,01117 & 2,84700 & 0,00479 \\
\hline LnCI & 0,00008 & 0,00008 & 1,02500 & 0,30618 \\
\hline LnCL & $-0,00034$ & 0,00014 & $-2,44900$ & 0,01501 \\
\hline \multicolumn{5}{|c|}{ Modelo de efectos aleatorios } \\
\hline Variable & Coeficiente & D. Estándar & \multicolumn{1}{c|}{ t-ratio } & Prob. \\
\hline LnBE & $-0,03461$ & 0,01383 & $-2,50300$ & 0,01233 \\
\hline LnEC & $-0,03167$ & 0,00735 & 4,30700 & 0,00002 \\
\hline LnCI & 0,00008 & 0,00007 & 1,06700 & 0,28581 \\
\hline LnCL & $-0,00044$ & 0,00012 & $-3,64600$ & 0,00027 \\
\hline Constante & 0,05846 & 0,02437 & 2,39900 & 0,01646 \\
\hline
\end{tabular}

\section{Recomendaciones de política}

El análisis llevado a cabo en las secciones precedentes permite la derivación de una serie de prescripciones de política económica. No obstante, resulta menester aclarar que ello supone una tarea sumamente delicada, en virtud de que las implicancias en términos de medidas deben considerarse en el contexto de los supuestos que delimitan el estudio del tema y, en consecuencia, del foco central del mismo. En otras palabras, si se consideran las restricciones analíticas y metodológicas existentes en el trabajo es factible proceder a 
delinear un conjunto de pautas que deberían seguirse en la instancia de la formulación de la política relevante para la geografía económica regional.

Una forma de evaluar las políticas económicas universalmente aceptada en la literatura consiste en indagar los efectos que las mismas engendran sobre el nivel de bienestar de la sociedad. En el caso de los modelos de la nueva geografía económica, antedicho examen parte de la obtención de las funciones de utilidad indirectas. Conforme a los supuestos adoptados en el presente estudio, uno de los elementos centrales que tornan relevantes las decisiones localizaciones de las firmas son los costos asociados al intercambio interregional de bienes. Ahora bien, los costos de transacción se combinan con el número de empresas en cada localización en los respectivos índices de precios. Por lo tanto, el comportamiento de sobredichos índices representa la guía más apropiada para estudiar los impactos originados en los procesos de integración económica regional.

En particular, si la liberalización preferencial del comercio en el ámbito regional refluye en un descenso de los índices de precios de los países miembros del acuerdo entonces la misma incrementa ceteris paribus el bienestar. El efecto primario se concatena con la posibilidad de adquirir bienes elaborados en el país socio a un precio más reducido debido a la disminución de los óbices artificiales al comercio sobreimpuestos a los precios en origen de tales bienes, dada la distribución espacial de las firmas. Sin embargo, existe asimismo un efecto secundario que se vincula con la reasignación geográfica de la producción a que da lugar la integración regional. Según se desprende del marco analítico, el número total de empresas es constante, razón por la cual supradicho proceso afecta positivamente el nivel de bienestar en la medida en que induce la radicación de firmas en el país de referencia o en el país con el cual el mismo mantiene barreras comerciales bajas siempre que la localización de procedencia de las firmas sea el resto del mundo (Torstensson, 1995).

Sin lugar a hesitación alguna, la constitución de una unión aduanera conduce a una reducción en el nivel de bienestar del resto del mundo, ya que, aun cuando los costos ligados al intercambio comercial se mantienen constantes, experimenta una contracción en su participación en la producción manufacturera agregada, debido a la emigración de firmas hacia la unión que se registra. Por el contrario, el nivel de bienestar crece sin ningún tipo de anfibología en los países que deciden integrarse en su conjunto. El motivo es dual. Por una 
parte, el acuerdo preferencial de comercio permite acceder en mejores condiciones a los productos elaborados en el socio. Por otra parte, dicho acuerdo suscita la aferencia de empresas pertenecientes a industrias que operan bajo condiciones de rendimientos crecientes a escala hacia el nuevo espacio económico ampliado creado.

Ahora bien, los efectos de bienestar pueden ser disímiles para los países que componen la unión aduanera. Efectivamente, tal como se desprende del modelo teórico, el país pequeño de la misma puede sufrir una retracción en su participación en la producción manufacturera total, lo cual importa indudablemente un efecto adverso sobre el nivel de bienestar de la población asentada en su territorio que contrabalancea al menos parcialmente los efectos positivos antes individualizados.

Resulta evidente que el análisis realizado en el presente trabajo no aprehende la totalidad de las repercusiones de la liberalización comercial preferencial. En efecto, con asiduidad se sostiene que la producción de bienes sofisticados bajo condiciones de rendimientos crecientes a escala involucra economías externas que benefician tanto a la industria de que se trate como a otras industrias. Tales externalidades podrían ser de naturaleza puramente tecnológica. Sin embargo, la productividad también puede crecer debido a que la mayor producción de bienes finales factibiliza la elaboración de insumos no transables altamente especializados, que constituyen elementos importantes en el proceso productivo de aquellos.

Luego, si se tienen en cuenta sobredichas externalidades, es probable que los países que enfrentan una contracción en su industria de rendimientos crecientes padezcan una reducción en su nivel de bienestar. Este sería precisamente el caso del país pequeño de la unión aduanera.

Los efectos antes identificados podrían ser natural y artificialmente potenciados. En el primer caso, la razón podría ser la existencia de un sesgo en las preferencias de los consumidores del país central de la unión hacia los productos que se elaboran domésticamente y en detrimento de los bienes procedentes del exterior (Venables, 1987; Reed y Torstensson, 1996) o la presencia de eslabonamientos de insumo-producto entre las industrias, que podrían llegar a posibilitar la desindustrilización de un país como producto de la relocalización de una parte de la cadena productiva (Venables, 1993). En el segundo 
caso, el motivo podría ser la vigencia de regímenes de compras gubernamentales (Brülhart y Trionfetti, 1998) o la presencia de sistemas de incentivos diferenciales a la radicación de firmas (Fernández de Brito y Bonelli, 1997).

La contracara de dicho fenómeno está dada por la acentuación de las disparidades interregionales en las estructuras económicas. Como resultado, se podría asistir a un aumento en la sensibilidad de los países integrantes a shocks específicos a una industria en particular y, en consecuencia, a una intensificación del carácter idiosincrático de los ciclos económicos. Según se desprende de la teoría de las áreas monetarias óptimas, tales desarrollos actúan en contra de la convergencia macroeconómica indispensable para garantizar la estabilidad regional en un escenario de creciente integración. Otrosí, la ausencia de la misma, que se asocia a una alta variabilidad del tipo de cambio, puede erigirse en un canal superádito de aglomeración de la actividad económica en la economía más grande (Ricci, 1998).

Las consideraciones precedentes permiten establecer una serie de recomendaciones de política para el Mercosur. A tal fin, es imprescindible definir en primer término qué tipo de objetivos pueden perseguirse. En este sentido, es claro que el responsable de la conducción de la política económica puede preocuparse tanto por el bienestar regional absoluto como por el bienestar regional relativo (Porto, 1995). Maguer ambos criterios resultan válidos, es innegable que la viabilidad de un proceso de integración depende en gran medida de la no ruptura de la unidad entitiva del espacio relevante; en otros términos, si se pretenden evitar reversiones unilateralmente decididas en procesos de tal índole es indispensable impedir que las disparidades interregionales alcancen niveles políticamente inaceptables (Martin y Rogers, 1994). Justamente, este parece ser el principio rector de la política regional europea (Begg, Judgin y Morris, 1996). Por consiguiente, en lo sucesivo se asumirá que quienes tienen a su cargo la labor de diseñar la política económica tienen una función objetivo cuyo nivel se relaciona negativamente con el nivel de un argumento que representa la magnitud de las asimetrías regionales.

En este contexto, una recomendación de política natural consiste en suprimir las medidas económicas que artificialmente favorecen la concentración en un cierto espacio geográfico. Dos ejemplos manifiestos en el ámbito del Mercosur son los esquemas de asistencia pública 
y los regímenes de compras gubernamentales. A este respecto, las legislaciones en vigor en los principales socios del bloque regional indican que mientras que nuestro país ha liberalizado completamente las adquisiciones estatales en lo atinente a la nacionalidad de los proveedores y ha desarticulado en gran medida el sistema de ayudas públicas, el Estado brasileño mantiene un sesgo inequívoco hacia los productores locales en las compras que realiza y posee una inextricable trama de subsidios que se funda en la distribución jurisdiccional de potestades. Antedichas discrepancias elevan ficticiamente el atractivo localizacional de Brasil. Por ende, un avance serio y perentorio en el establecimiento de un régimen común de compras gubernamentales, el relevamiento de los sistemas de ayudas estatales y la determinación consecuente de un mecanismo objetivo de disciplinamiento de los mismos son tareas imprescindibles. Europa ha progresado significativamente en dicha dirección a través del Programa Mercado Único.

Asimismo, sería apropiado principiar una tarea dual en cuanto a los plazos en el ámbito macroeconómico. En primer lugar, desde el punto de vista del corto plazo, se debería implementar un esquema que posibilite una compensación al menos parcial de los efectos generados por cambios sustantivos en las condiciones macroeconómicas prevalecientes en los países miembros, en general, y por modificaciones súbitas en la política cambiaria, en particular, tal como lo hizo Europa en su momento. En segundo lugar, desde la perspectiva de largo plazo, es menester prefinir perentoriamente pautas concretas de coordinación macroeconómica en la región. El designio relevante para el análisis aquí efectuado que se persigue en ambos casos es restringir el potencial de aglomeración asociado a la volatilidad cambiaria.

Por otro lado, de acuerdo a las inferencias surgidas del modelo, las industrias con rendimientos crecientes propenden a concentrarse en el centro de la unión. Sin dudas, dicha aglomeración no será completa, en virtud de que los beneficios de la misma serán contrarrestados por los costos correspondientes, ya sean costos de congestión o costos derivados del comportamiento de los mercados de factores. No obstante, la necesidad de obstar una profundización excesiva de las disparidades interregionales en las estructuras productivas y en los niveles de bienestar por las motivaciones expuestas oportunamente 
podría justificar bajo ciertas condiciones la puesta en práctica de una política sectorialregional a nivel del bloque ${ }^{55}$.

Desde la óptica sectorial, en la medida en que la dinámica espacial siga la trayectoria que se desprende del modelo de Brülhart y Torstensson (1996), la introducción de algún sistema definido en base a parámetros objetivos que, en el marco de una transición programada, asegure cierto nivel mínimo de equilibrio geográfico posterior en las ramas industriales con economías de escala elevadas, es una alternativa de política al menos digna de evaluación. La idea es posibilitar el aprovechamiento de las economías de escala dinámicas propias de este tipo de industrias y generar subsecuentemente un efecto de lock-in para el país. El régimen automotriz es un ejemplo trascendente en este sentido ${ }^{56}$.

De esta forma, se aseguraría consectariamente la subsistencia del comercio intraindustrial. Cabe tener presente que el mismo factibiliza la obtención de ganancias del comercio internacional adicionales a los beneficios concatenados con las ventajas comparativas, en virtud de que permite a los países tomar ventaja del acceso a mercados de mayores dimensiones. En efecto, bajo las condiciones que supradicho comercio supone, el país puede simultáneamente reducir el número de productos que elabora $\mathrm{y}$, en consecuencia, producir a una escala mayor con un nivel de productividad superior y un nivel de costos inferior e incrementar la variedad de bienes disponibles para los consumidores (Krugman y Obstfeld, 1991).

La política regional debería articularse en torno a dos ejes centrales: por una parte, un criterio directriz, y, por otra parte, un esquema operativo.

\footnotetext{
${ }^{55}$ En este caso, la presencia de economías de aglomeración torna más eficiente la concentración espacial de la producción. La misma asegura menores costos de producción, lo cual favorece a los consumidores de todas las regiones. Por tanto, la aplicación de políticas no es propugnable por consideraciones de eficiencia. Además, dicha situación no representaría ningún inconveniente si el objeto principal de atención es el bienestar absoluto. La concentración beneficia al conjunto de las regiones, pero perpetúa las disparidades entre ellas (Porto, 1995).

Por ende, la implementación de políticas se fundaría estrictamente en cuestiones de equidad. La conveniencia de las mismas debería justipreciarse en términos del trade off entre los beneficios derivados del mejoramiento del nivel de equidad y los costos de eficiencia originados en las medidas que aquel requiere.

${ }^{56}$ En cambio, si el perfil temporal de las desigualdades se ajusta a las predicciones del modelo de Puga y Venables (1995), podría pensarse en la canalización de fondos originados en las ganancias agregadas de la unión hacia las regiones periféricas para financiar la transición hasta que sobrevenga la reindustrialización de las mismas.
} 
Con respecto al criterio estratégico, la política regional debería entronizar la movilización del potencial de desarrollo endógeno de las regiones. En tal acervo de recursos, sobresalen las innovaciones tecnológicas y su difusión territorial, el capital humano, el papel de las pymes y los servicios completivos de la producción. La Unión Europea parece haberse inclinado en los últimos años a una abordaje de este tipo en detrimento de las políticas de subsidios directos (Fernandes de Brito y Bonelli, 1997).

Las pymes ameritan un comentario aparte ${ }^{57}$. De acuerdo a Brülhart y Torstensson (1996), es probable que conforme se profundiza el proceso de integración regional, se verifique una concentración de las industrias con economías de escala reducidas y las industrias con rendimientos constantes a escala en las regiones periféricas habida cuenta de las ventajas que contarían en ambos casos. La tendencia a la dispersión en las industrias trabajo intensivas detectada en las regresiones cohonestaría empíricamente la observación anterior. Las pymes predominan precisamente en la estructura según tamaño de empresas de ambas industrias, a diferencia de lo que acaece en las industrias con fuertes rendimientos crecientes a escala. Dada la importancia de dicho tipo de firmas para el equilibrio espacial, asegurar condiciones propicias para su establecimiento $\mathrm{y}$ desarrollo es decididamente aconsejable. La política pública debería apuntar asimismo a promover la coordinación de los esfuerzos empresarios para medrar el entorno competitivo local (Vanhaverbeke, 1998; Nicolini, 1998). La política regional europea atribuye una importancia central a sobredicho segmento de empresas; la misma se orienta a: el auxilio a las nuevas firmas, el desarrollo de la terciarización, la promoción de las exportaciones, el desenvolvimiento de actividades financieras, el estímulo del empleo y el progreso de la educación y la formación profesional (Fernandes de Brito y Bonelli, 1997).

Con relación al esquema operativo, el mismo debería delinearse como contraparte del criterio rector. Así, si el objetivo es actualizar potenciales regionales de desarrollo intrínsecos se tendrían que individualizar las especificidades locales, lo cual supone llevar a cabo una regionalización, de manera de delimitar espacios geográficos con idiosincracias productivas comunes que admitan tratamientos de política semejantes. Las regiones objetivo europeas constituyen un ejemplo relevante en este sentido (Begg, Gudgin y

\footnotetext{
${ }^{57}$ Las pymes exhiben en Argentina un alto grado de concentración espacial. El 85\% de los establecimientos industriales se concentra en Capital Federal, Buenos Aires, Santa Fe, Córdoba y Mendoza (CEPAL, 1997).
} 
Morris, 1996; Dignan, 1996) ${ }^{58}$. Cada una de las mismas podría asignarse a una Agencia Regional de Desarrollo en un marco que contenga un sistema de coordinación de las decisiones $^{59}$.

\section{Consideraciones conclusivas}

La década de 1990 fue un período de intensa actividad en materia de acuerdos comerciales preferenciales regionales y del surgimiento de una corriente en la literatura académica, la nueva geografía económica, que procuró determinar las implicancias espaciales de tales desarrollos comerciales.

La teoría indica que, en presencia de costos ligados al intercambio y economías de escala, las decisiones localizacionales devienen relevantes. En particular, un proceso de integración económica reduce los costos de transacción entre los países participantes y puede alterar las condiciones que definen el equilibrio geográfico predominante hasta entonces. Precisamente, el modelo planteado como marco teórico del análisis ilustra tal situación.

En efecto, el mismo muestra que la conformación de una unión aduanera entre países de diferentes dimensiones induce una dinámica espacial que es susceptible de describirse a través de una trayectoria no monotónica; en términos específicos, las industrias sujetas a rendimientos crecientes tienden a dispersarse en las primeras fases del proceso de integración y propenden a concentrarse en la economía de mayor tamaño del bloque en las etapas ulteriores, una vez que los costos asociados al intercambio comercial se ubican por debajo de cierto nivel crítico. Vale la pena resaltar que la proclividad centrípeta es una función creciente de la relevancia de las economías de escala de la industria de referencia. Bajo la hipótesis de que las firmas radicadas en los distintos países tienen propensiones a

${ }^{58}$ El objetivo 1 es promover el desarrollo y el ajuste estructural de las regiones menos desarrolladas, entendidas como aquellas que cuyo PNB per cápita es inferior al 75\% del PNB medio de la Unión Europea. El objetivo 2 es auxiliar a las regiones que padecen una declinación industrial (el indicador es una tasa de desempleo relativamente alta). El objetivo $5 \mathrm{~b}$ se refiere a las áreas rurales que se hallan en dificultades. Los objetivos 3, 4 y 5b, que no son de naturaleza regional, aluden al combate del desempleo de larga duración y el desempleo de los jóvenes y la promoción de la readaptación de la fuerza laboral a las transformaciones industriales y la modernización agrícola (Fernandes de Brito y Bonelli, 1997). 
comerciar similares, el comportamiento localizacional de la producción puede concebirse como una imagen de espejo de la evolución del comercio intraindustrial intrazona. Por consiguiente, antedicho comercio se expande cuando principia la integración y se contrae ulteriormente, de modo que su sendero temporal asume gráficamente una forma de $\mathrm{U}$ invertida. Las consideraciones anteriores permite colegir naturalmente que la importancia relativa del comercio intraindustrial se relaciona negativamente con el grado de economías de escala de la industria de que se trate.

La disminución de los óbices aplicados a los flujos comerciales intrabloque también pueden engendrar repercusiones significativas sobre la distribución geográfica de la actividad económica entre las regiones de cada uno de los países miembros. En concreto, la integración regional puede inducir la aglomeración de las industrias con rendimientos crecientes en aquellas áreas que cuenta con el mercado más grande.

La evidencia empírica internacional es enteramente consistente con las predicciones derivadas de la teoría. En primer término, en la Unión Europea se observa con nitidez que las industrias con rendimientos crecientes exhiben un patrón localizacional altamente concentrado, una tendencia a asentarse en los países centrales del espacio económico integrado y un nivel de comercio intraindustrial relativa y sistemáticamente reducido. En segundo término, en América del Norte, es posible individualizar una correlación positiva entre el crecimiento del empleo industrial regional y el nivel salarial y la facilidad de acceso a los principales mercados de exportación; asimismo, la integración ha propulsado la formación de un núcleo dinámico de actividad manufacturera binacional en la frontera mexicana-estadounidense. En tercer término, la puesta en marcha del Mercosur parece haber favorecido a las regiones tradicionalmente industriales de Brasil.

La evidencia econométrica para nuestro país también es compatible con las educciones del modelo teórico delineado en los parágrafos anteriores. Especfícamente, la disminución de las barreras arancelarias bilaterales entre Argentina y Brasil ha redundado en una expansión del comercio intraindustrial correspondiente, tal como cabría esperar en las etapas iniciales del proceso de integración; en consecuencia, el patrón de especialización entre países en el seno del Mercosur estaría ubicado en el tramo descendente de la curva U a que se hizo

\footnotetext{
${ }^{59}$ Para más detalles ver Fernandes de Brito y Bonelli (1997).
} 
alusión precedentemente. Además, parece haber contribuido a perpetuar la concentración espacial del empleo manufacturero en Argentina. Adicionalmente, resulta menester destacar que se comprueba econométricamente que la significancia relativa de los consumos intermedios afecta adversamente el nivel de comercio intraindustrial y que el grado de aglomeración geográfica de las industrias se relaciona positivamente con la trascendencia de las economías de escala y negativamente con la intensidad laboral.

La tendencia centrípeta ínsita en la integración regional conduciría a una creciente divergencia en las estructuras económicas y, bajo los supuestos del modelo, en los niveles de bienestar. Por ende, la misma exige suprimir todos los factores que actúan en favor de su acentuación artificial como el sistema de subsidios y el régimen de compras gubernamentales vigentes en Brasil y, en la medida en que el responsable de la formulación de la política económica tenga una función objetivo entre cuyos argumentos figure el bienestar relativo, podría justificar la instrumentación de una política sectorial-regional. Por último, cabe subrayar que la atención de la dimensión espacial del proceso bajo estudio podría fundar asimismo la implementación de políticas de naturaleza macroeconómica, habida cuenta de que la variabilidad del tipo de cambio puede instituirse en un factor directo de aglomeración. 


\section{Referencias bibliográficas}

AMITI, Mary (1997). "Specialization patterns in Europe". CEP Discussion Paper 363. London School of Economics.

AMITI, Mary (1998). "New trade theories and industrial location in the European Union: A survey of evidence". Oxford Review of Economic Policy.

AZZONI, Carlos Roberto y FERREIRA, Dirceu Alves (1997). "Competitividade regional e reconcentraçao: o futuro das desigualdades regionais no Brasil". NEMESIS - Núcleo de Estudos e Modelos Espaciais Sistêmicos.

BAGWELL, Kyle y STAIGER, Robert (1997).”Regionalism and multilateral tariff cooperation". NBER Working Paper 5921.

BALASSA, Bela y BAUWENS, Luc (1987). "Intra-industry specialization in a multicountry and multi-industry framework". Economic Journal. Vol. 97.

BALDWIN (1993). “A domino theory of regionalism”. NBER Working Paper 4465.

BAUMANN, Renato (1998). "Nota sobre as relacoes intra-setorais no comércio externo brasileiro - 1980-1996”. CEPAL, Oficina de Brasil.

BEGG, Ian; GUDGIN, Grahan; y MORRIS, Derek (1996). "The assessment: Regional policy in the European Union”. Oxford Review of Economic Policy. Vol. 11. № 2.

BERLINSKI, Julio (1994). "Post-trade liberalization institutional issues in Argentina". Reunión Anual de la Asociación Argentina de Economía Política. La Plata.

BERLINSKI, Julio (1998). "El sistema de incentivos en Argentina". Estudios de la Economía Real №6.

BID/INTAL. Base de datos de comercio exterior de América Latina (1986-1996).

BRAMBILLA, Irene; PORTO, Guido; y POSADAS, Josefina (1998). "Desarrollo, crecimiento regional y política económica. Causas y efectos de la concentración de la actividad económica". Cuadernos de Economía № 35. Ministerio de Economía de la Provincia de Buenos Aires. 
BRÜLHART, Marius y TORSTENSSON, Johan (1996). "Regional integration, sacle economy and industry location in the European Union". CEPR Discussion Paper No 1435. BRÜLHART, Marius (1998). "Economic geography, industry location and trade: The evidence". The World Economy.

BRÜLHART, Marius y TRIONFETTI, Federico (1998). "Industrial specialization and public procurement: Theory and empirical evidence". Trinity Economic Paper Series. Technical Paper98/3.

CEP (1998). "Esquemas de integración. Evolución del comercio intra y extra-bloque: El caso del Mercosur". Notas de la Economía Real.

CEP (1998). "Evolución de la política arancelaria en la última década". Notas de la Economía Real.

CEP (1999). "La industria en el interior del país: Producción, empleo e inversiones". Informe especial.

CEPAL (1997). "Consecuencias iniciales de los comportamientos pymes en el nuevo escenario de negocios en la Argentina".

http://www.cepal.cl/espanol/investigacion/buenosaires/dt79

CEPAL. Base de datos del Mercosur.

CHRISTALLER, W. (1933). Die zentralen Orte in Süddeutschland. Gustav Fischer Verlag. Jena.

DEVLIN y FFRENCH-DAVIS (1998). "Towards an evaluation of regional integration in Latin America in the 1990s". Working Paper 2. INTAL.

DIGNAN, Tony (1996). "Regional disparities and regional policy in the European Union". Oxford Review of Economic Policy. Vol. 11. № 2.

DIXIT, Avinash y STIGLITZ, Joseph (1977). "Monopolistic competition and optimum product diversity". American Economic Review. Vol. 67.

FCE-UNLP (1999). PBG 1960-1995. Serie de Estudios Fiscales. 
FERNANDES DE BRITO, Adriana y BONELLI, Regis (1997). "Políticas industriais decentralizadas: As exprièncias euuropéias e as iniciativas subnacionales no Brasil". Planeamiento e políticas públicas. Número 15.

FERNÁNDEZ, Raquel (1998). "Returns to regionalism: An evaluation of non-traditional gains from RTAs". The World Bank Economic Review. Vol. 12. № 2.

FRANKEL, Jeffrey; STEIN, Ernesto; y WEI, Shang-Jin (1996). "Regional trading arrangements: Natural o super-natural?”. NBER Working Paper 5431.

GONZAGA, Gustavo; TERRA, Cristina; y CAVALCANTE, Jorge (1999). "O impacto do Mercosul sobre o emprego setorial no Brasil". Texto para Discussao No 382. Pontificia Universidad Católica de Río de Janeiro.

GREENAWAY, David y MILNER, Chris (1984). "A cross-section analysis of intraindustry trade in the UK". European Economic Review. Vol. 25.

GRUNWALD, Joseph y FLAMM, Kenneth (1985). The global factory: Foreign assembly in international trade. Washington D.C. Brookings Institution.

GRUBEL, Herbert y LLOYD, P.J. (1975). Intra-industry trade. Macmillan. Londres.

GUÍA DEL IMPORTADOR y EXPORTADOR (1984).

HADDAD, Eduardo y AZZONI, Carlos (1999). "Trade liberalization and location: Geographical shifts in the brazilian economic structure". NEMESIS - Núcleo de Estudos e Modelos Espaciais Sistêmicos.

HANSON, Gordon (1994). "Localizations economies, vertical organization, and trade". NBER Working Paper 4744.

HANSON, Gordon (1996). "Economic integration, intraindustry trade, and frontier regions". European Economic Review. Vol. 40. Elsevier.

HANSON, Gordon (1997). "Increasing returns, trade and the regional structure of wages". Economic Journal. Vol. 107.

HANSON, Gordon (1998). "Market potential, increasing returns, and geographic concentration". NBER Working Paper 6429. 
HANSON, Gordon (1998). "North american economic integration and industrial location". NBER Working Paper 6587.

HANSON, Gordon (1998). "Regional adjustment to trade liberalization". Regional Science and Urban Economics. Vol. 28.

HARRIS, C. (1954). "The market as a factor on the localization of industry in the United States". Annals of the Association of American Geographers. 64.

HIRSCHMAN, Albert (1982). "Rival interpretations of market society: Civilizing, destructive o feeble?. The World Bank Economic Review. Vol. 12. № 2.

IBGE (1999). http://www.ibge.gov.br

INDEC (1985). Censo Nacional Económico. Industria Manufacturera.

INDEC (1991). Censo Nacional de Población y Vivienda.

INDEC (1994). Censo Nacional Económico.

INDEC (1999). Anuario Estadístico 1998.

KEEBLE, David; OFFORD, John; WALKER, Sheila (1986). Peripherial regions in a Community of twelve member states. Commission of the European Communities. Luxemburgo.

KIM, Sukkoo (1995). "Expansion of markets and the geographic distribution of economic activities: The trends in U.S. regional manufacturing structure, 1860-1987'. Quarterly Journal of Economics”. Vol. 110.

KRUGMAN, Paul y OBSTFELD, Maurice (1991). International Economics: Theory and Policy. HarperCollins Publishers.

KRUGMAN, Paul (1991). "Increasing return and economic geography". Journal of Political Economy. Vol. 99. № 3.

KRUGMAN, Paul (1992). Geografía y Comercio. Antoni Bosch editor. Barcelona.

KRUGMAN, Paul (1993). "First nature, second nature, and metropolitan location". Journal of Regional Science. Vol. 33. 
KRUGMAN, Paul y VENABLES, Anthony (1995). "The seamless world: A spatial model of international specialization". NBER Working Paper $\mathrm{N}^{\mathrm{0}} 5220$.

KRUGMAN, Paul y VENABLES, Anthony (1995). "Globalization and the inequality of nations". Quarterly Journal of Economics. Vol. 110.

KRUGMAN, Paul (1998). "The role of geography in development". Annual Bank Conference on Development Economics. Banco Mundial. Washington D.C..

KUME, Honorio y PIANI, Guida (1998). "Efeitos regionais do Mercosul: uma análise diferencial-estrutural para o período 1990-1995”. NEMESIS - Núcleo de Estudos e Modelos Espaciais Sistêmicos.

LAIRD, Sam (1995). "Fostering regional integration". OMC. http://www.wto.org.

LAVINAS, Lena; GARCÍA, Eduardo; y DO AMARAL, Marcelo (1997). "Desigualdades regionais e retomada do crescimento num quadro de integraçao econômica". Texto para discussao $\mathrm{N}^{\circ}$ 466. IPEA.

LIFSCHITZ, Edgardo y CRESPO ARMENGOL, Eugenia (1995). "Evolución de la protección arancelaria, 1990-2001”. Boletín Informativo Techint $\mathrm{N}^{\circ} 283$.

LOERTSCHER, Rudolf y WOLTER, Frank (1980). "Determinants of intra-industry trade among countries and across industries". Weltwirschaftliches Archiv. Vol. 116.

LÖSCH, Augustus (1940). The economics of location. Fischer Verlag. Jena.

LUDEMA, Rodney y WOOTON, Ian (1997). "Regional integration, trade, and migration: Are demand linkages relevant in Europe?". Conferencia CEPR sobre "Comercio y movilidad factorial". Venecia.

MARTIN, Philippe y ROGERS, Carol Ann (1994). "Trade effects of regional aid". CEPR Discussion Paper № 910.

MENDES, Constantino Cronemberger (1997). "Efeitos do Mercosul no Brasil: uma visao setorial e locacional do comércio". Texto para discussao No 510 . IPEA.

NICOLINI, Rosella (1998). "Learning and agglomeration in industrial networks". Université Catholique de Louvain. 
OMC (1995). Regionalism and the World Trading System. Ginebra.

OTTAVIANO, Gianmarco y PUGA, Diego (1997). "Agglomeration in the Global Economy: A Survey of the New Economic Geography". CEPR Discussion Paper No 1.699. Londres.

PACHECO, Carlos Américo (1999). "Novos padroes de localizaçao industrial? Tendências recentes dos indicadores da produçao e do investimento industrial". Texto para discussao $\mathrm{N}^{\circ}$ 633. IPEA.

PENN WORLD TABLES 5.6. Universidad de Pennsylvania.

PERRONI, Carlo. y WHALLEY, John. (1994). "The new regionalism: Trade liberalization or insurance?". NBER Working Paper 4626.

PORTO, Guido (1995). Las economías regionales en la Argentina. Fundación Arcor. Nuevohacer Grupo Editor Latinoamericano.

PRED, A. R. (1956). The spatial dynamics of U.S. urban-industrial growth 1800-1914.

PRATTEN, Cliff (1988). "A survey of the economies of scale", en The Cost of Non

Europa. Volumen 2: Studies on the economics of integration. Commission of the European Communities. Luxemburgo.

PUGA, Diego y VENABLES, Anthony (1995). "Preferential Trading Arrangements and Industrial Location". CEPR Discussion Paper No 1.309.

RAY, Edward (1991). "U.S. Protection and intra-industry trade: The message to developing countries". Economic Development and Cultural Change. Vol. 40.

REED, Geoffrey y TORSTENSSON, Johan (1996). "National product preferences and international trade". FIEF Working Paper $\mathrm{N}^{\circ} 145$.

RICCI, Luca (1998). "Uncertainty, Flexible Exchange Rates, and Agglomeration". IMF Working Paper 98/9. Fondo Monetario Internacional, Washington.

SAMUELSON, Paul (1954). "The transfer problem and transport costs". Economic Journal. Vol. 64. 
SANGUINETTI, Pablo y GARRIGA, Marcelo (1997). "La política comercial y las economías regionales en Argentina: la apertura unilateral y el Mercosur". Congreso de Economia: "Las tendencias económicas para el fin de siglo". Consejo Profesional de Ciencias Económicas. Buenos Aires.

SANGUINETTI, Pablo; POSADAS, Josefina; y KUMAR, Mukul (1998). "Trade liberalization, transport cost and regional adjustment in manufacturing employment: Theory and applications for Argentina". Reunión Anual de la Asociación Argentina de Economía Política.

SARGHINI, Jorge; NARODOWSKI, Patricio; y LÓDOLA, Agustín (1998). "La industria en los '90". Cuadernos de Economía No 42. Ministerio de Economía de la Provincia de Buenos Aires.

SCHIFF, Maurice y WINTERS, Alan (1998). "Regional integration as diplomacy". The World Bank Economic Review. Vol. 12. № 2.

SERRA, Jaime; GROSSMAN, Gene; y otros (1997). Reflections on regionalism. Carnegie endowment for international peace.

SOMMA, Ernesto (1994). "Intra-industry trade in the European computers industry". Weltwirtschaftliches Archiv. Vol. 130.

TRATADO DE ASUNCIÓN (1991). Documentación oficial del Mercosur.

TORSTENSSON, Johan (1995). "Economic integration, market size and the location of industries". CREDIT Research Paper 95/2.

VANHAVERBEKE, Wim (1998). "Realizing new regional core competence: Establishing a customer-oriented SME-network”. NIBOR. University of Maastricht.

VENABLES, Anthony (1987). "Trade and trade policy with differentiated products: A chamberlinian-ricardian model”. Economic Journal. Vol. 97.

VENABLES, Anthony (1993). "Equilibrium locations of vertically linked industries". CEPR Discussion Paper $\mathrm{N}^{\circ} 802$.

von THÜNEN, J. (1826). The isolated state. Pergamon. Londres. 
WHALLEY, John (1996). "Why do countries seek regional trade agreements?". NBER Working Paper 5552.

WEBER, M. (1909). Über den Standort der Industrien. J.C.B. Mohr. Tübingen. 
10. Anexo 


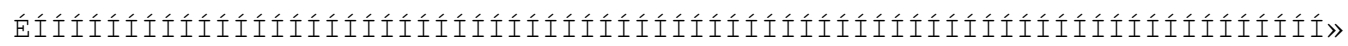

- Least Squares with Group Dummy Variables

- Ordinary least squares regression Weighting variable $=$ ONE 0

- Dependent variable is GL Mean $=-542.95932$, S.D. $=498.2194{ }^{\circ}$

- Model size: Observations $=493$, Parameters $=130$, Deg.Fr. $=363 \circ$

- Residuals: Sum of squares $=0.136630 \mathrm{E}+08$ Std.Dev. $=\quad 194.00788^{\circ}$

- Fit: R-squared $=0.88812$, Adjusted R-squared $=\quad 0.84837 \circ$

- Model test: $\mathrm{F}[129,363]=22.34$, Prob value $=0.00000^{\circ}$

- Diagnostic: $\log -\mathrm{L}=-3221.1556$, Restricted $(a ́=0)$ Log-L $=-3761.0792 \circ$

Amemiya Pr. Crt. $=47564.163$, Akaike Info. Crt. $=\quad 13.595$ 。
$\circ$ Estd. Autocorrelation of e $(i, t) \quad 0.000000$

- Estd. Autocorrelation of e(i,t) 0.000000

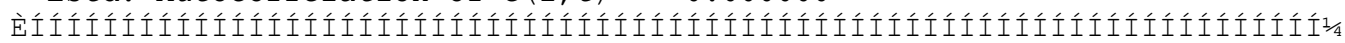

Variable Coefficient Standard Error t-ratio P[ ${ }^{3} \mathrm{~T}^{3}$ ot $]$ Mean of $\mathrm{X}$

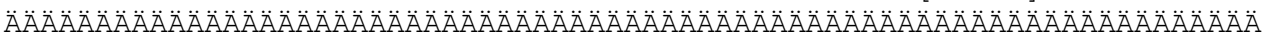

$\begin{array}{lrrrrr}\mathrm{AE} & 9.8802 & 2.0637 & 4.788 & 0.00000 & -479.5 \\ \mathrm{AB} & -9.1581 & 2.0374 & -4.495 & 0.00001 & -483.2 \\ \mathrm{EC} & 0.18001 & 0.12128 & 1.484 & 0.13837 & -470.4 \\ \mathrm{CI} & -0.21511 & 0.15002 & -1.434 & 0.15226 & -477.0 \\ \mathrm{CL} & 0.12544 & 0.26197 & 0.479 & 0.63227 & -485.7\end{array}$

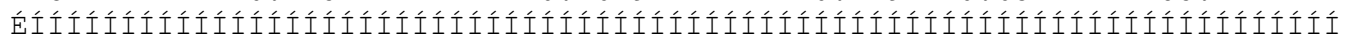

Test Statistics for the Classical Model Model Log-Likelihood Sum of Squares

R-squared

- (2) Group effects only $-3743.00853-0.113493 \mathrm{E}+09$

- (3) X - variables only $-3335.16985 \quad 0.216980 \mathrm{E}+08$

(4) $X$ and group effects $-3221.15558 \quad 0.136630 \mathrm{E}+08$

0.0000000

0.0706864

0.8223299

0.8881235

Hypothesis Tests

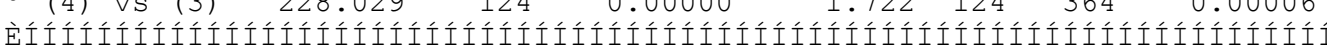

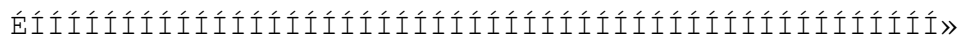

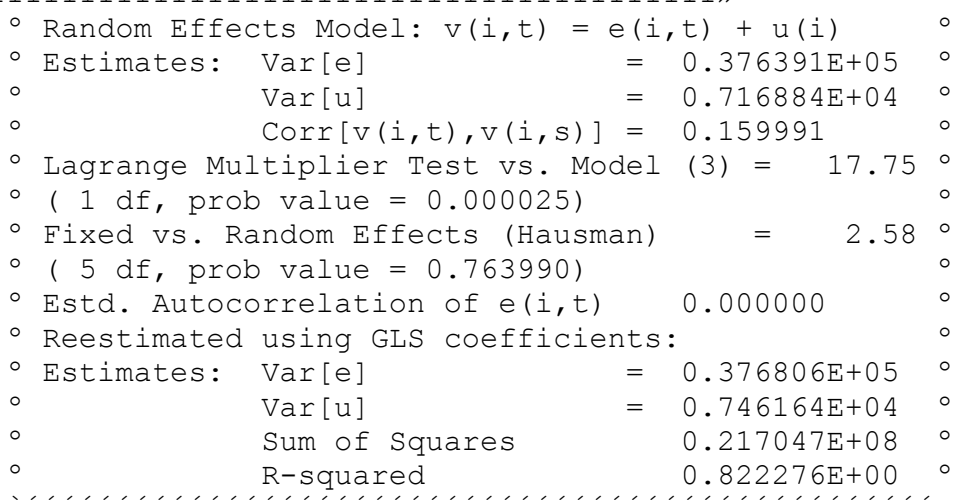

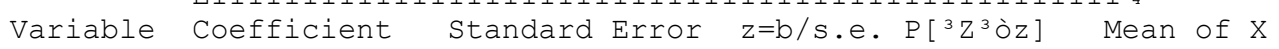
Ӓ $\ddot{A} \ddot{A} \ddot{A} \ddot{A} \ddot{A} \ddot{A} \ddot{A} \ddot{A} \ddot{A} \ddot{A} \ddot{A} \ddot{A} \ddot{A} \ddot{A} \ddot{A} \ddot{A} \ddot{A} \ddot{A} \ddot{A} \ddot{A} \ddot{A} \ddot{A} \ddot{A} \ddot{A} \ddot{A} \ddot{A} \ddot{A} \ddot{A} \ddot{A} \ddot{A} \ddot{A} \ddot{A} \ddot{A} \ddot{A} \ddot{A} \ddot{A} \ddot{A} \ddot{A} \ddot{A} \ddot{A} \ddot{A} \ddot{A} \ddot{A} \ddot{A} \ddot{A} \ddot{A} \ddot{A} \ddot{A} \ddot{A} \ddot{A} \ddot{A} \ddot{A} \ddot{A} \ddot{A} \ddot{A}$

$\begin{array}{lcrrrr}\mathrm{AE} & 9.5178 & 1.9624 & 4.850 & 0.00000 & -479.5 \\ \mathrm{AB} & -8.8198 & 1.9465 & -4.531 & 0.00001 & -483.2 \\ \mathrm{EC} & 0.20701 & 0.10954 & 1.890 & 0.05878 & -470.4 \\ \mathrm{CI} & -0.12569 & 0.13740 & -0.915 & 0.36031 & -477.0 \\ \mathrm{CL} & 0.33790 \mathrm{E}-01 & 0.23973 & 0.141 & 0.88791 & -485.7 \\ \text { Constant } & -186.42 & 20.251 & -9.205 & 0.00000 & \end{array}$




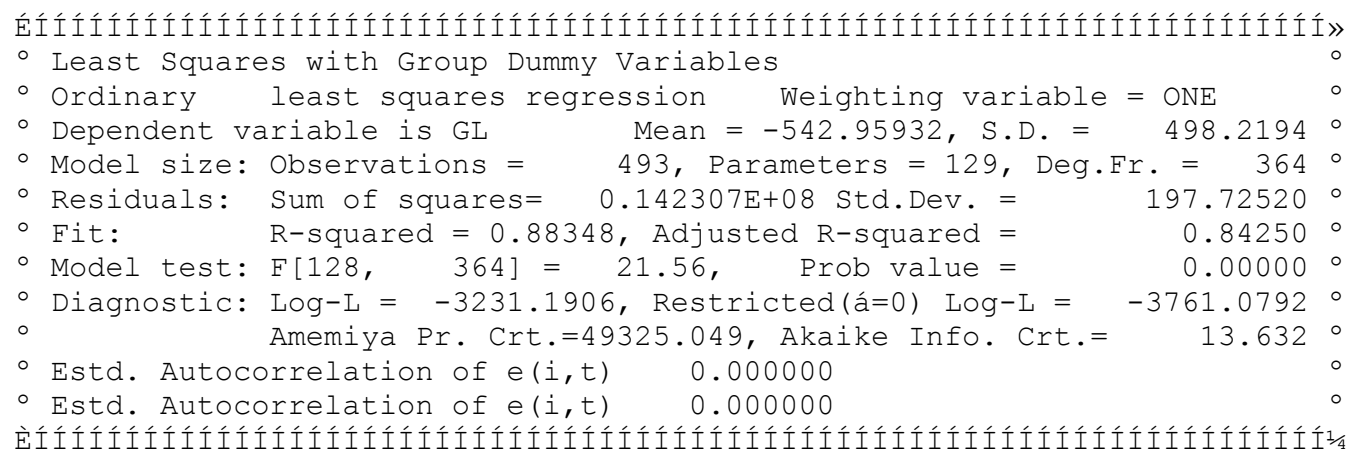

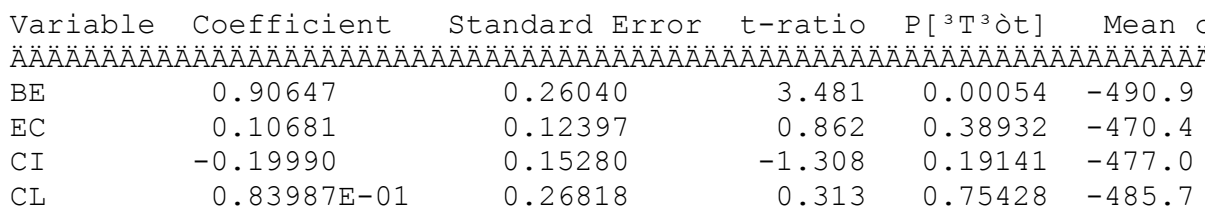

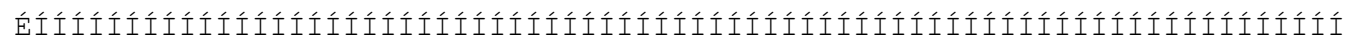
- Test Statistics for the Classical Model

\begin{tabular}{|c|c|c|c|c|}
\hline & Model & Log-Likelihood & Sum of Squares & R-squared \\
\hline (1) & Constant term only & -3761.07921 & $0.122126 \mathrm{E}+09$ & 0.0000000 \\
\hline (2) & Group effects only & -3743.00853 & $0.113493 E+09$ & 0.0706864 \\
\hline (3) & $x$ - variables only & -3341.84684 & $0.222938 \mathrm{E}+08$ & 0.8174516 \\
\hline (4) & $\mathrm{X}$ and group effects & -3231.19057 & $0.142307 \mathrm{E}+08$ & 0.8834750 \\
\hline
\end{tabular}

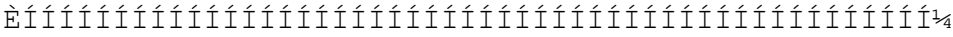

\begin{tabular}{|c|c|c|c|c|c|}
\hline $\begin{array}{l}\text { Variable } \\
\ddot{A} \ddot{A} \ddot{A} \ddot{A} \ddot{A} \ddot{A} \ddot{A} \ddot{A} \ddot{A}\end{array}$ & $\begin{array}{l}\text { Coefficient } \\
\dot{A} \ddot{A} \ddot{A} \ddot{A} \ddot{A} \ddot{A} \ddot{A} \ddot{A} \ddot{A} \ddot{A} \ddot{A} \ddot{A} \ddot{A}\end{array}$ & $\begin{array}{l}\text { andard EI } \\
\dot{A} \ddot{A} \ddot{A} \ddot{A} \ddot{A} \ddot{A} \ddot{A} \ddot{A} \dot{I}\end{array}$ & $\begin{array}{l}z=\mathrm{b} / \mathrm{s} . \mathrm{e} . \\
\ddot{A} \ddot{A} \ddot{A} \ddot{A} \ddot{A} \ddot{A} \ddot{A} \ddot{A}\end{array}$ & $\begin{array}{l}P\left[{ }^{3} z^{3} \mathrm{òz}\right] \\
\dot{A} \ddot{A} \ddot{A} \ddot{A} \ddot{A} \ddot{A} \ddot{A} \ddot{A} \dot{z}\end{array}$ & $\begin{aligned} & \text { Mean } \\
& \dot{A} \ddot{A} \ddot{A} \ddot{A} \ddot{A} \ddot{A} \ddot{A} \dot{~}\end{aligned}$ \\
\hline $\mathrm{BE}$ & 0.88170 & 0.23631 & 3.731 & 0.00019 & -490.9 \\
\hline $\mathrm{EC}$ & 0.13390 & 0.11140 & 1.202 & 0.22938 & -470.4 \\
\hline CI & -0.11797 & 0.13953 & -0.845 & 0.39787 & -477.0 \\
\hline $\mathrm{CL}$ & $-0.22784 E-02$ & 0.24445 & -0.009 & 0.99256 & -485.7 \\
\hline Constant & -104.44 & 15.584 & -6.702 & 0.00000 & \\
\hline
\end{tabular}




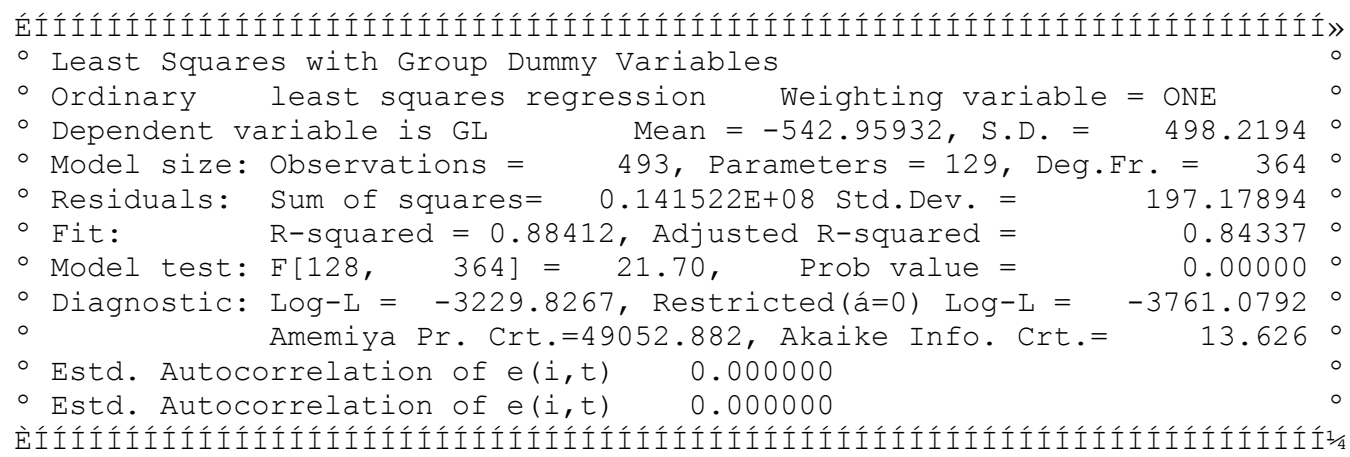

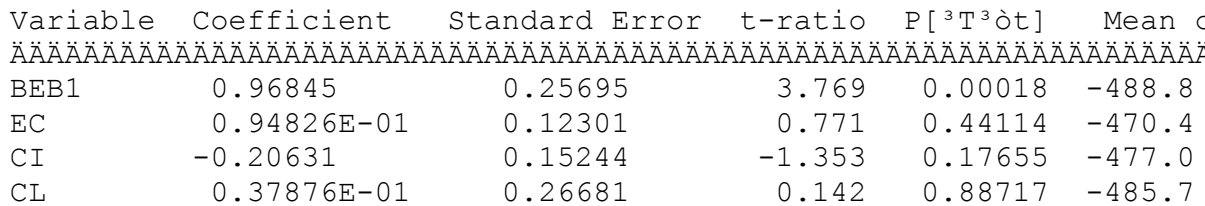

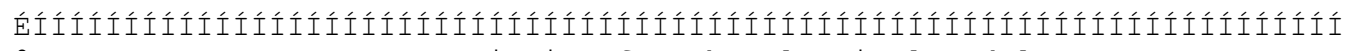
- Test Statistics for the Classical Model

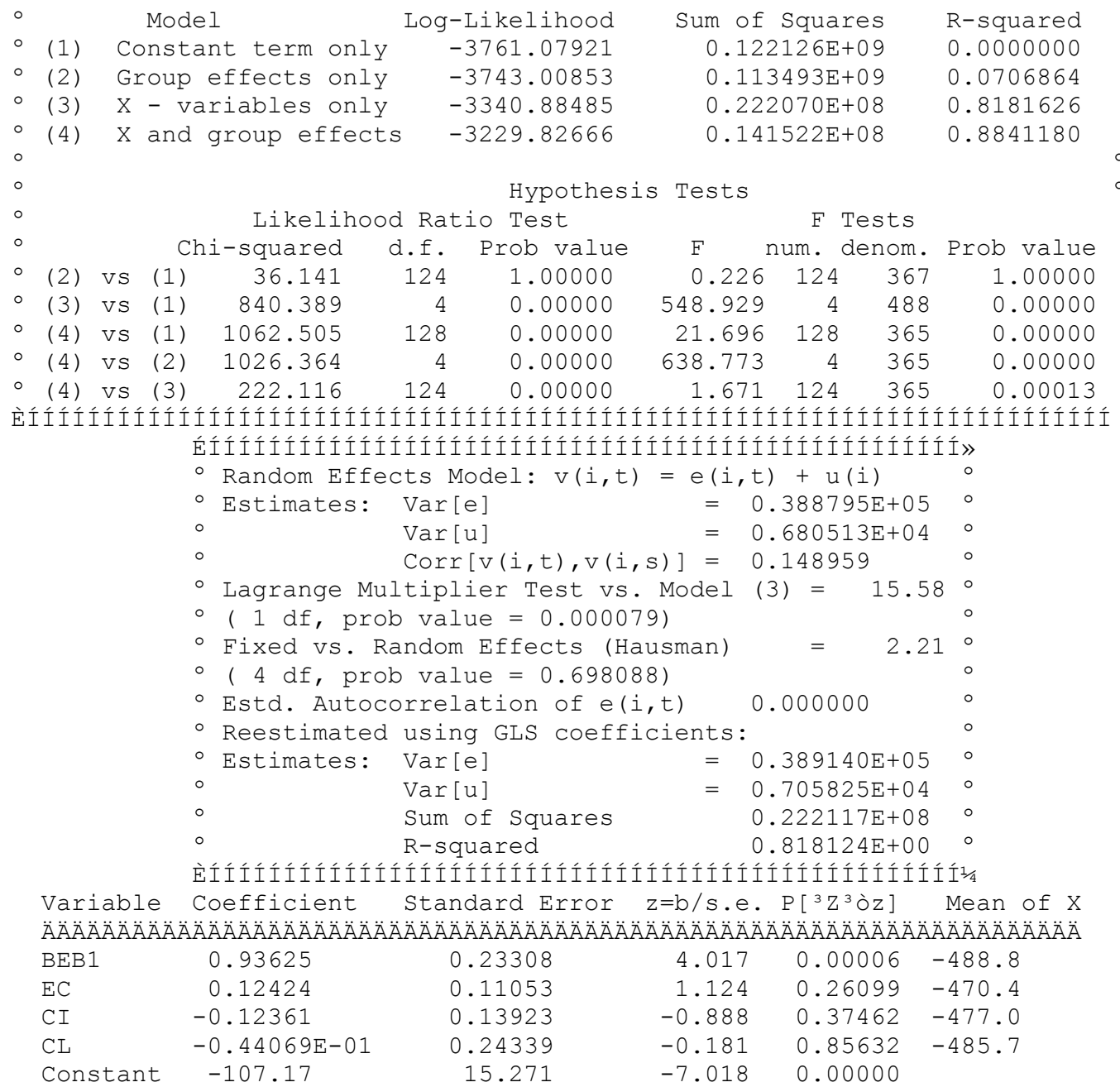




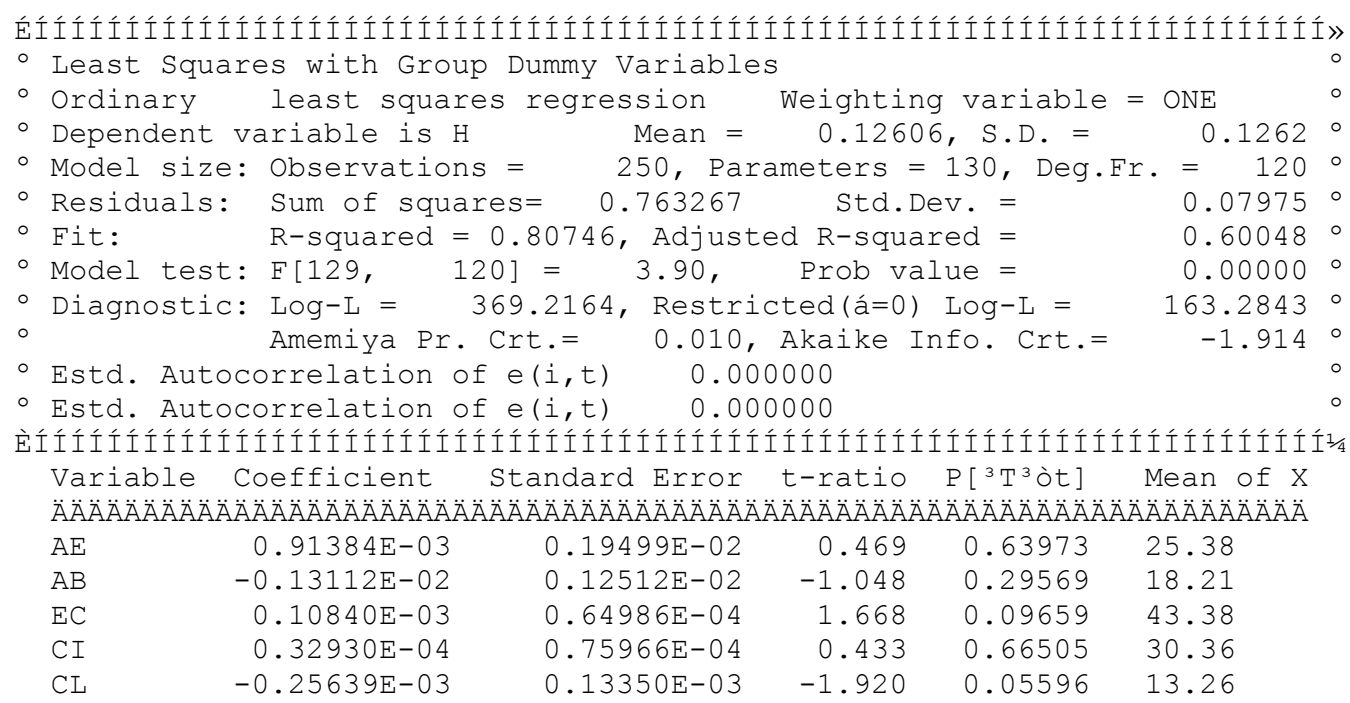

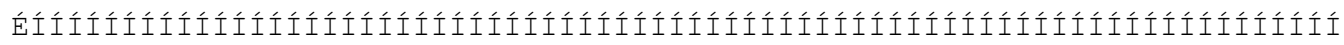
- Test Statistics for the Classical Model

- Model $\quad$ Mest statistics for the cl

- (2) Group effects only $359.19833 \quad 0.826957 \mathrm{E}+00 \quad 0.7913948$

- (3) X - variables only $\quad 178.36979 \quad 0.351355 \mathrm{E}+01 \quad 0.1136856$

-(4) X and group effects $369.21636 \quad 0.763267 \mathrm{E}+00 \quad 0.8074609$

\begin{tabular}{|c|c|c|c|c|c|c|c|c|c|}
\hline \multirow{2}{*}{\multicolumn{2}{|c|}{$\begin{array}{l}\circ \\
\circ\end{array}$}} & \multicolumn{8}{|c|}{ Hypothesis Tests } \\
\hline & & & - squared & d.f. & Prob value & $\mathrm{F}$ & num. & denom. & Prob value \\
\hline$\circ(2)$ & vs & (1) & 391.828 & 124 & 0.00000 & 3.824 & 124 & 124 & 0.00000 \\
\hline$\circ \quad(3)$ & vS & (1) & 30.171 & 5 & 0.00001 & 6.259 & 5 & 244 & 0.00002 \\
\hline$\circ \quad(4)$ & vS & (1) & 411.864 & 129 & 0.00000 & 3.901 & 129 & 121 & 0.00000 \\
\hline$\circ(4)$ & vs & (2) & 20.036 & 5 & 0.00123 & 2.003 & 5 & 121 & 0.08300 \\
\hline$\circ \quad(4)$ & vs & (3) & 381.693 & 124 & 0.00000 & 3.487 & 124 & 121 & 0.00000 \\
\hline
\end{tabular}

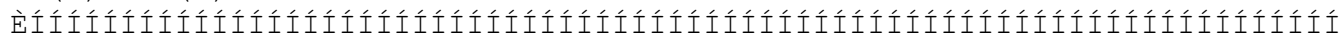

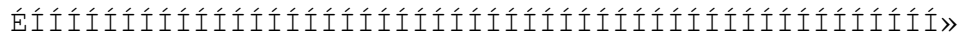

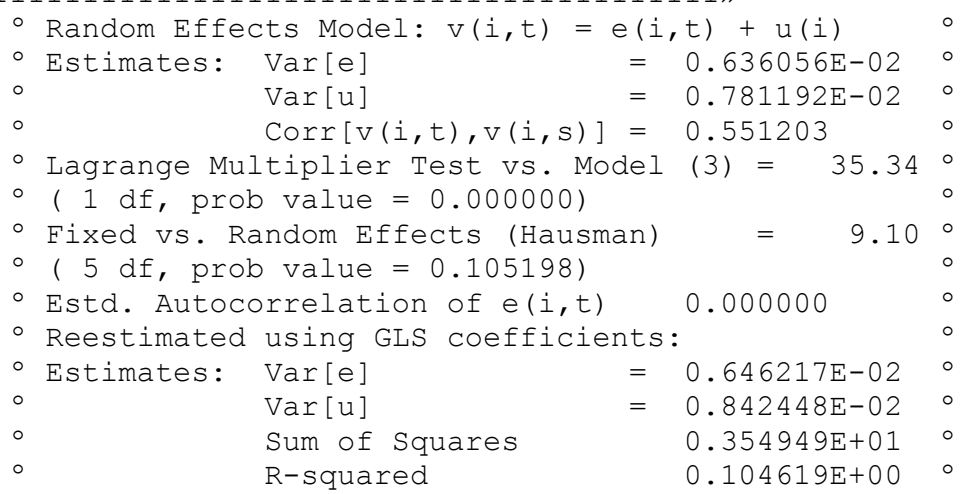

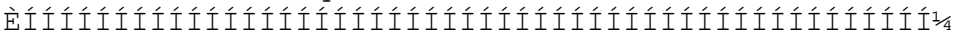

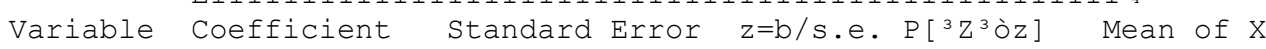

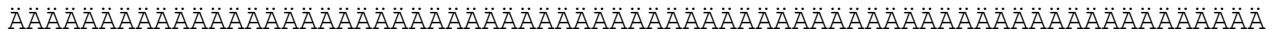

$\begin{array}{lrrrrr}\mathrm{AE} & 0.15569 \mathrm{E}-02 & 0.16735 \mathrm{E}-02 & 0.930 & 0.35220 & 25.38 \\ \mathrm{AB} & -0.18493 \mathrm{E}-02 & 0.10919 \mathrm{E}-02 & -1.694 & 0.09035 & 18.21 \\ \mathrm{EC} & 0.16252 \mathrm{E}-03 & 0.55293 \mathrm{E}-04 & 2.939 & 0.00329 & 43.38 \\ \mathrm{CI} & 0.11422 \mathrm{E}-04 & 0.66625 \mathrm{E}-04 & 0.171 & 0.86389 & 30.36 \\ \mathrm{CL} & -0.34531 \mathrm{E}-03 & 0.11688 \mathrm{E}-03 & -2.954 & 0.00313 & 13.26 \\ \text { Constant } & 0.11740 & 0.27049 \mathrm{E}-01 & 4.340 & 0.00001 & \end{array}$




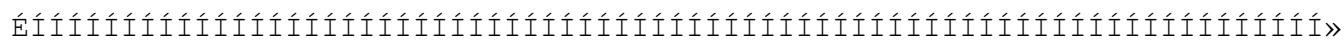

- Least Squares with Group Dummy Variables

- Ordinary least squares regression Weighting variable $=$ ONE O

- Dependent variable is H Mean $=0.12606$, S.D. $=0.1262 \circ$

- Model size: Observations $=\quad 250$, Parameters $=130$, Deg.Fr. $=120 \circ$

- Residuals: Sum of squares= $0.711620 \quad$ Std.Dev. = 0.077010

- Fit: R-squared $=0.82049$, Adjusted R-squared $=0.62752 \circ$

- Model test: $\mathrm{F}[129,120]=4.25, \quad$ Prob value $\quad 0.00000 \circ$

- Diagnostic: $\log -\mathrm{L}=377.9744$, Restricted(á=0) Log-L = $163.2843 \circ$

Amemiya Pr. Crt.= 0.009, Akaike Info. Crt.= $-1.984 \circ$

- Estd. Autocorrelation of e(i,t) 0.000000

- Estd. Autocorrelation of e(i,t) 0.000000

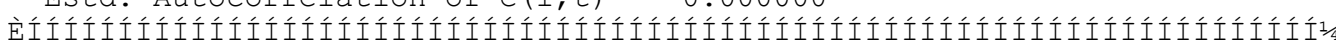

Variable Coefficient Standard Error t-ratio P[3T'òt] Mean of X $\ddot{A} \ddot{A} \ddot{A} \ddot{A} \ddot{A} \ddot{A} \ddot{A} \ddot{A} \ddot{A} \ddot{A} \ddot{A} \ddot{A} \ddot{A} \ddot{A} \ddot{A} \ddot{A} \ddot{A} \ddot{A} \ddot{A} \ddot{A} \ddot{A} \ddot{A} \ddot{A} \ddot{A} \ddot{A} \ddot{A} \ddot{A} \ddot{A} \ddot{A} \ddot{A} \ddot{A} \ddot{A} \ddot{A} \ddot{A} \ddot{A} \ddot{A} \ddot{A} \ddot{A} \ddot{A} \ddot{A} \ddot{A} \ddot{A} \ddot{A} \ddot{A} \ddot{A} \ddot{A} \ddot{A} \ddot{A} \ddot{A} \ddot{A} \ddot{A} \ddot{A} \ddot{A} \ddot{A} \ddot{A} \ddot{A} \ddot{A} \ddot{A} \ddot{A}$

$\begin{array}{lrrrrr}\text { LNAE } & 0.43057 \mathrm{E}-02 & 0.26674 \mathrm{E}-01 & 0.161 & 0.87190 & 3.142\end{array}$

$\begin{array}{llllll}\text { LNAB } & -0.15554 \mathrm{E}-01 & 0.10029 \mathrm{E}-01 & -1.551 & 0.12221 & 2.388\end{array}$

$\begin{array}{llllll}\text { LNEC } & 0.34897 \mathrm{E}-01 & 0.11245 \mathrm{E}-01 & 3.103 & 0.00214 & 2.936\end{array}$

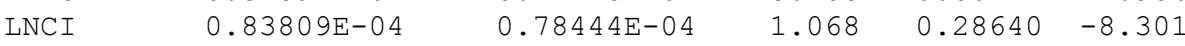

LNCL $\quad-0.35367 \mathrm{E}-03 \quad 0.13563 \mathrm{E}-03 \quad-2.608 \quad 0.00968 \quad-1.241$

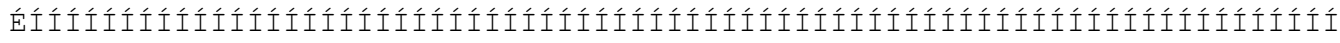

- Test Statistics for the Classical Model

Model Log-Likelihood Sum of Squares R-squared

- (1) Constant term only $\quad 163.28434 \quad 0.396422 \mathrm{E}+01$

- (2) Group effects only $\quad 359.19833 \quad 0.826957 \mathrm{E}+00 \quad 0.7913948$

- (3) X - variables only $\quad 184.81142 \quad 0.333707 \mathrm{E}+01 \quad 0.1582032$

$\begin{array}{lllll} & (4) X \text { and group effects } \quad 377.97444 & 0.711620 E+00 & 0.8204894\end{array}$

Likelihood Ratio Test

Chi-squared d.f. Prob value F num. denom. Prob value

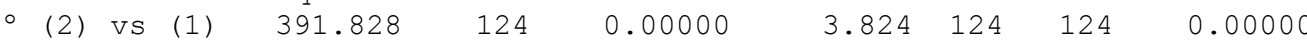

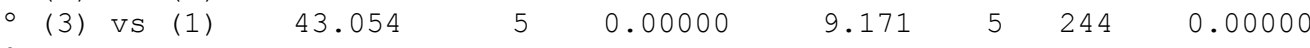

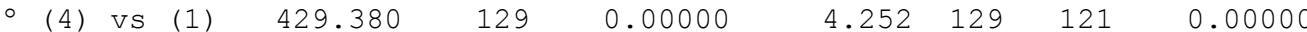

$\begin{array}{lllllllll}\circ & (4) \\ V S & (2) & 37.552 & 5 & 0.00000 & 3.890 & 5 & 121 & 0.00264\end{array}$

- (4) VS (3) $\quad 386.326 \quad 124 \quad 0.00000 \quad 3.570 \quad 124 \quad 121 \quad 0.00000$

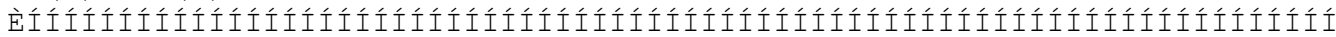

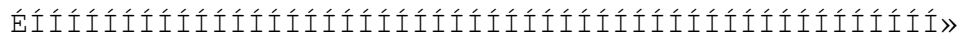

- Estimates: Var[e] $\quad=0.593016 \mathrm{E}-02$

- Var[u] $\quad=0.769641 \mathrm{E}-02$

- $\operatorname{Corr}[\mathrm{v}(i, t), \mathrm{v}(i, s)]=0.564809$

- Lagrange Multiplier Test vs. Model (3) $=37.48^{\circ}$

- ( 1 df, prob value $=0.000000)$

- Fixed vis. Random Effects (Hausman) $=6.47^{\circ}$

- ( 5 df, prob value $=0.262798)$

- Estd. Autocorrelation of e(i,t) 0.000000 .

- Reestimated using GLS coefficients:

- Estimates: $\operatorname{Var}[\mathrm{e}] \quad=0.600239 \mathrm{E}-02 \circ$

Var[u] $\quad=0.810935 \mathrm{E}-02 \circ$

- Sum of Squares $0.336460 \mathrm{E}+01$ \%

R-squared $0.151258 \mathrm{E}+00$

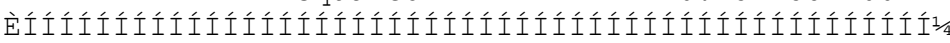

Variable Coefficient Standard Error $z=b / s . e . ~ P\left[{ }^{3} z^{3}\right.$ òz] Mean of X

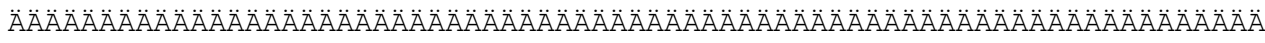

$\begin{array}{lrrrrr}\text { LNAE } & 0.23518 \mathrm{E}-01 & 0.23019 \mathrm{E}-01 & 1.022 & 0.30693 & 3.142 \\ \text { LNAB } & -0.22986 \mathrm{E}-01 & 0.90646 \mathrm{E}-02 & -2.536 & 0.01122 & 2.388 \\ \text { LNEC } & 0.33182 \mathrm{E}-01 & 0.73128 \mathrm{E}-02 & 4.538 & 0.00001 & 2.936 \\ \text { LNCI } & 0.76524 \mathrm{E}-04 & 0.69492 \mathrm{E}-04 & 1.101 & 0.27081 & -8.301 \\ \text { LNCL } & -0.45633 \mathrm{E}-03 & 0.11951 \mathrm{E}-03 & -3.818 & 0.00013 & -1.241 \\ \text { Constant } & 0.97260 \mathrm{E}-02 & 0.57833 \mathrm{E}-01 & 0.168 & 0.86645 & \end{array}$




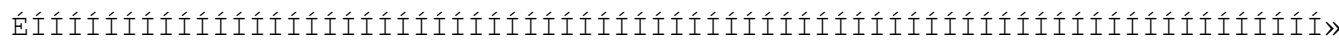

- Least Squares with Group Dummy Variables

- Ordinary least squares regression Weighting variable $=$ ONE 0

- Dependent variable is H Mean $=0.12606, \mathrm{~S} . \mathrm{D}$. $=0.1262 \circ$

- Model size: Observations $=$ 250, Parameters = 129, Deg.Fr. = $121 \circ$

- Residuals: Sum of squares $=0.756916 \quad$ Std.Dev. = $0.07909 \circ$

- Fit: R-squared $=0.80906$, Adjusted R-squared $=\quad 0.60708 \circ$

- Model test: $\mathrm{F}[128,121]=4.01, \quad$ Prob value $=00000$

- Diagnostic: Log-L = 370.2608, Restricted(á=0) Log-L = $163.2843 \circ$

- Amemiya Pr. Crt.= 0.009, Akaike Info. Crt.= $-1.930 \circ$

- Estd. Autocorrelation of e(i,t) 0.000000

- Estd. Autocorrelation of e(i,t) 0.000000

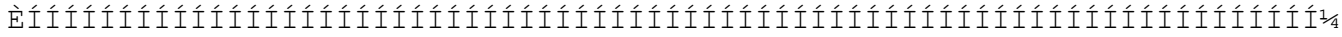

Variable Coefficient Standard Error t-ratio P[ ${ }^{3} \mathrm{~T}^{3}$ òt] Mean of X

$\ddot{A} \ddot{A} \ddot{A} \ddot{A} \ddot{A} \ddot{A} \ddot{A} \ddot{A} \ddot{A} \ddot{A} \ddot{A} \ddot{A} \ddot{A} \ddot{A} \ddot{A} \ddot{A} \ddot{A} \ddot{A} \ddot{A} \ddot{A} \ddot{A} \ddot{A} \ddot{A} \ddot{A} \ddot{A} \ddot{A} \ddot{A} \ddot{A} \ddot{A} \ddot{A} \ddot{A} \ddot{A} \ddot{A} \ddot{A} \ddot{A} \ddot{A} \ddot{A} \ddot{A} \ddot{A} \ddot{A} \ddot{A} \ddot{A} \ddot{A} \ddot{A} \ddot{A} \ddot{A} \ddot{A} \ddot{A} \ddot{A} \ddot{A} \ddot{A} \ddot{A} \ddot{A} \ddot{A} \ddot{A} \ddot{A}$

$\begin{array}{lrrrrr}\mathrm{BE} & -0.33403 \mathrm{E}-01 & 0.15313 \mathrm{E}-01 & -2.181 & 0.03010 & 0.6207 \\ \mathrm{EC} & 0.11549 \mathrm{E}-03 & 0.64474 \mathrm{E}-04 & 1.791 & 0.07447 & 43.38 \\ \mathrm{CI} & 0.35802 \mathrm{E}-04 & 0.75171 \mathrm{E}-04 & 0.476 & 0.63430 & 30.36 \\ \mathrm{CL} & -0.26480 \mathrm{E}-03 & 0.13254 \mathrm{E}-03 & -1.998 & 0.04683 & 13.26\end{array}$

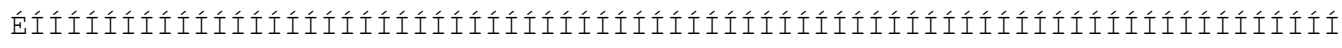

- Test Statistics for the Classical Model

- Model Log-Likelihood

- (1) Constant term only 163.28434

- (2) Group effects only 359.19833

(3) X - variables only 179.05861

(4) $X$ and group effects

\begin{abstract}
Sum of Squares
$0.396422 \mathrm{E}+01$

$0.826957 \mathrm{E}+00$

$0.349424 \mathrm{E}+01$

$0.756916 \mathrm{E}+00$
\end{abstract}

R-squared

0.0000000

0.7913948

0.1185562

0.8090630

Hypothesis Tests

\begin{tabular}{|c|c|c|c|c|c|c|c|c|c|}
\hline ○ & & & Likelir & od Rat & io Test & 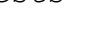 & & Tests & \\
\hline$\circ$ & & & -squared & d.f. & Prob value & $F$ & num. & denom. & Prob value \\
\hline$\circ \quad(2)$ & VS & $(1)$ & 391.828 & 124 & 0.00000 & 3.824 & 124 & 124 & 0.00000 \\
\hline$\circ \quad(3)$ & VS & (1) & 31.549 & 4 & 0.00000 & 8.238 & 4 & 245 & 0.00000 \\
\hline$\circ \quad(4)$ & VS & $(1)$ & 413.953 & 128 & 0.00000 & 4.006 & 128 & 122 & 0.00000 \\
\hline$\circ \quad(4)$ & VS & (2) & 22.125 & 4 & 0.00019 & 2.799 & 4 & 122 & 0.02892 \\
\hline$\circ \quad(4)$ & VS & (3) & 382.404 & 124 & 0.00000 & 3.529 & 124 & 122 & 0.00000 \\
\hline
\end{tabular}

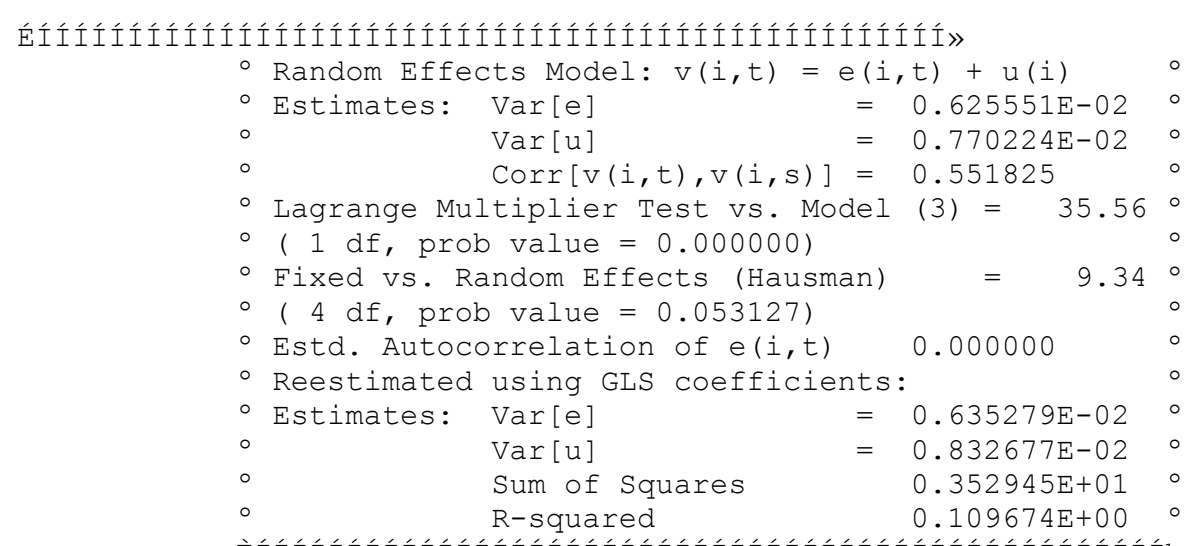

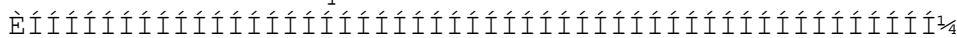




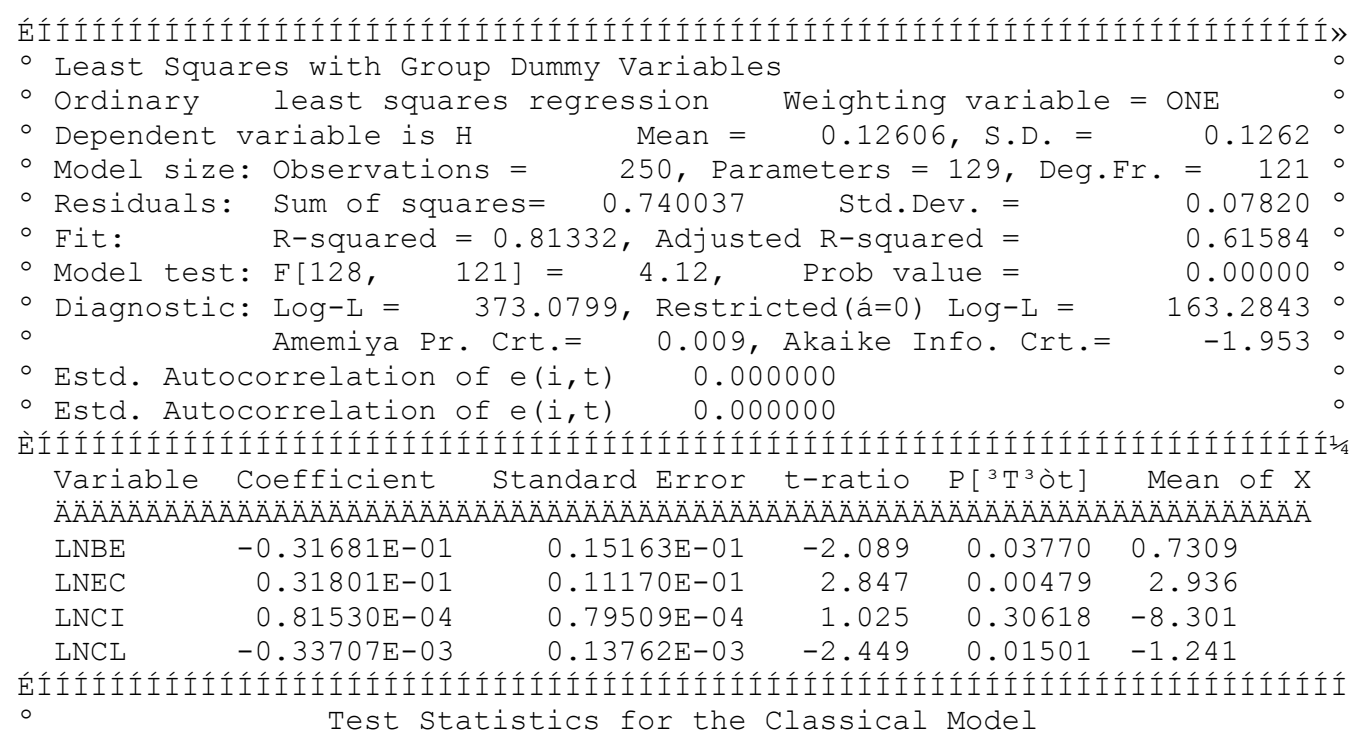

\begin{tabular}{|c|c|c|c|c|c|c|c|c|c|}
\hline \multicolumn{4}{|c|}{ Model } & \multicolumn{2}{|c|}{ Log-Likelihood } & \multicolumn{3}{|c|}{ Sum of Squares } & \multirow{2}{*}{$\begin{array}{l}\text { R-squared } \\
0.0000000\end{array}$} \\
\hline (1) & \multicolumn{4}{|c|}{ Constant term only } & 163.28434 & \multicolumn{3}{|c|}{$0.396422 \mathrm{E}+01$} & \\
\hline$\circ \quad(2)$ & \multicolumn{4}{|c|}{ Group effects only } & 359.19833 & \multicolumn{3}{|c|}{$0.826957 \mathrm{E}+00$} & .7913948 \\
\hline (3) & & \multirow{2}{*}{\multicolumn{3}{|c|}{$\begin{array}{l}X \text { - variables only } \\
X \text { and group effects }\end{array}$}} & 182.16 & \multicolumn{3}{|c|}{$0.340859 \mathrm{E}+01$} & 22 \\
\hline (4) & $\mathrm{x}$ & & & & 373.07987 & \multirow{2}{*}{\multicolumn{3}{|c|}{$0.740037 \mathrm{E}+00$}} & 3209 \\
\hline & & & & & Hypot & & & & \\
\hline & & \multicolumn{4}{|c|}{ Likelihood Ratio Test } & \multicolumn{3}{|c|}{ F Tests } & \\
\hline$p$ & & & -squared & d.f. & Prob value & F & num. & denom. & Prob va \\
\hline (2) & vs & (1) & 391.828 & 124 & 0.00000 & 3.824 & 124 & 124 & 0.00000 \\
\hline (3) & vs & (1) & 37.753 & 4 & 0 . & 9.984 & 4 & 245 & 0 . \\
\hline (4) & vs & (1) & 419.591 & 128 & 0 . & 4.119 & 128 & 122 & 0 . \\
\hline (4) & vs & (2) & 27.763 & 4 & 0.000 & 3.553 & 4 & 122 & 0 . \\
\hline (4) & vs & & 38 & 124 & 0.00000 & 3.519 & 124 & 122 & 0.000 \\
\hline
\end{tabular}

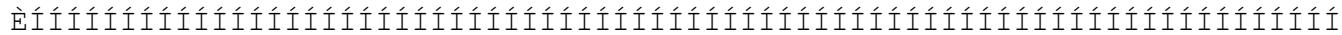

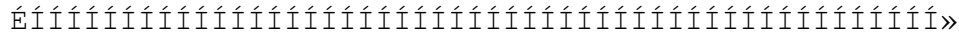

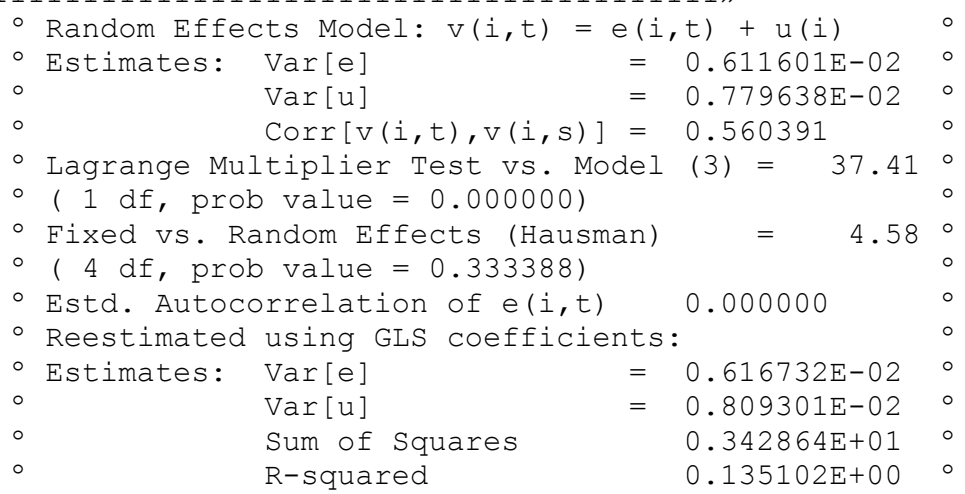

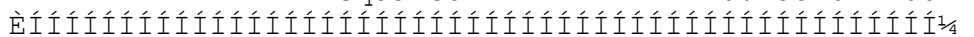

Variable Coefficient Standard Error $z=b / s . e . ~ P\left[{ }^{3} Z^{3}\right.$ òz] Mean of X $\ddot{A} \ddot{A} \ddot{A} \ddot{A} \ddot{A} \ddot{A} \ddot{A} \ddot{A} \ddot{A} \ddot{A} \ddot{A} \ddot{A} \ddot{A} \ddot{A} \ddot{A} \ddot{A} \ddot{A} \ddot{A} \ddot{A} \ddot{A} \ddot{A} \ddot{A} \ddot{A} \ddot{A} \ddot{A} \ddot{A} \ddot{A} \ddot{A} \ddot{A} \ddot{A} \ddot{A} \ddot{A} \ddot{A} \ddot{A} \ddot{A} \ddot{A} \ddot{A} \ddot{A} \ddot{A} \ddot{A} \ddot{A} \ddot{A} \ddot{A} \ddot{A} \ddot{A} \ddot{A} \ddot{A} \ddot{A} \ddot{A} \ddot{A} \ddot{A} \ddot{A} \ddot{A} \ddot{A} \ddot{A} \ddot{A} \ddot{A} \ddot{A} \ddot{A} \ddot{A}$

$\begin{array}{lrrrrr}\text { LNBE } & -0.34606 \mathrm{E}-01 & 0.13828 \mathrm{E}-01 & -2.503 & 0.01233 & 0.7309 \\ \text { LNEC } & 0.31669 \mathrm{E}-01 & 0.73525 \mathrm{E}-02 & 4.307 & 0.00002 & 2.936 \\ \text { LNCI } & 0.75187 \mathrm{E}-04 & 0.70443 \mathrm{E}-04 & 1.067 & 0.28581 & -8.301 \\ \text { LNCL } & -0.44124 \mathrm{E}-03 & 0.12103 \mathrm{E}-03 & -3.646 & 0.00027 & -1.241 \\ \text { Constant } & 0.58463 \mathrm{E}-01 & 0.24374 \mathrm{E}-01 & 2.399 & 0.01646 & \end{array}$

